NO $\mathbf{x}$ DESTRUCTION IN DIFFUSION FLAME ENVIRONMENTS FInal Report

By J. O. L. Wendt W. C. Lin

P. Mwabe

July 31,1991

Work Performed Under Contract No. FG22-88PC88944

\author{
For \\ U.S. Department of Energy \\ Pittsburgh Energy Technology Center \\ Pittsburgh, Pennsyivania \\ By \\ University of Arizona \\ Tucson, Arizona
}




\section{DISCLAIMER}

This repert was prepared as an account of work sponsored by an agency of the Lnited States Government. Neither the United States Government nor any agency thereof. nor any of their employees. makes an! warranty, express or implied, or assumes any legal liability or responsibility for the accuracy, completeness, or usefulness of any information, apparatus, product, or process disclosed. or represents that its use would not infringe privately ow'ned rights. Reference herein to any specific commercial product, process, or service by trade name, trademark. manufacturer. or otheruise does not necessarily constitute or imply its endorsement. recommendation. or favoring b) the United States Government or any agency thereof. The views and opinions of authors expressed herein do not necessarily state or reflect those of the United States Government or any agency thereof

This report has been reproduced directly from the best available copy.

Available to DOE and DOE contractors from the Office of Scientific and Tecnnical Information. P.O. Box 62, Oak Ridge, TN 37831; prices available from $6151576 \cdot 8401$, FTS 626-8401.

A vailable to the public from the National Technical Information Service, U.S. Department of Commerce, 5285 Port Royal Rd., Springfield, VA 22161. 


\title{
NO DESTRUCTION IN DIFFUSION FLAME ENVIRONMENTS
}

\author{
Final Report
}

for

DOE Grant No. DE-FG22-88PC88944

Prepared by

J.O.L. Wendt, W.C. Lin and P. Mwabe Department of Chemical Engineering, University of Arizona, Tucson, AZ 85721.

\author{
Submitted to: \\ Douglas Gyorke, \\ Advanced Research and Technology Development, \\ Pittsburgh Energy Research Center, \\ U.S Department of Energy.
}

July 31, 1991 


\begin{abstract}
This research is concerned with reburning, which is an $\mathrm{NO}_{\mathrm{x}}$ abatement technique involving the injection of secondary fuel into the post flame of a furnace. The specific objectives of this research are to determine whether heterogeneities inherent in diffusion flame environments can be exploited to achieve greater reductions in NO than can be achieved in premixed systems. The research project described here is but a first step to explore this question, and should be viewed more as a screening study rather than as completed research, the results of which are completely understood.
\end{abstract}

The problem was attacked through both experimentation and theoretical modeling. Experiments employed a bench scale, laminar, counter-flow, diffusion flame, which was designed to simulate the stretched diffusion flamelets that arise at the interface between turbulent fuel and oxidant jets. Data gathered were of two types. First, NO destruction from the integral system was investigated through parametric studies in which only inlet and outlet species and flows were measured. Three different experimental configurations were examined, under a wide range of operating conditions, with emphasis on reburning under overall fuel lean conditions. Second, in order to gain insight into the observed phenomena, detailed axial profiles of major and minor species were measured for one configuration.

Theoretical modeling consisted of computer simulations which attempt to describe the experimental configuration as an infinitely wide flat flame. This yielded predictions of axial profiles but was not readily adaptable for (integral) predictions of total NO destroyed in our flame. The model employed detailed chemical reactions, and was also used to determine regimes in which ignition occurs under diffusion flame conditions.

Experimental results are new, and suggest that, under diffusion flame conditions, significant NO destruction occurs, even when the overall conditions are fuel lean. Furthermore, destruction is extremely efficient for NO molecules that contact the (diffusion) flame zone, and, in our system, the exhaust NO concentrations are roughly independent of the primary NO level, when that is above $450 \mathrm{ppm}$. Mathematical modeling results were consistent with the (differential) experimental observations of species profiles, but more work is required to connect it to the integral experimental measurements, and to practical systems.

Overall, results from this research support the idea that reburning through large scale eddies in full scale furnaces, may be able to: 1) allow retrofit reburning under overall fuel lean conditions, and 2) achieve greater reburning efficiencies than are possible under more premixed conditions. The work reported here provides a basis for additional research which is required to understand how the concept of reburning through large reducing eddies can be optimized and subsequently applied to practical systems. 


\section{TABLE OF CONTENTS}

ABSTRACT $\quad \ldots \ldots \ldots \ldots \ldots \ldots \ldots \ldots \ldots \ldots \ldots \ldots \ldots \ldots$

RESEARCH OBJECTTVES $\ldots \ldots \ldots \ldots \ldots \ldots \ldots \ldots \ldots \ldots \ldots \ldots$

SIGNIFICANCE $\quad \ldots \ldots \ldots \ldots \ldots \ldots \ldots \ldots \ldots \ldots \ldots \ldots \ldots$

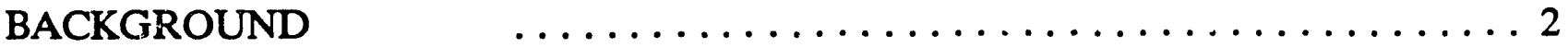

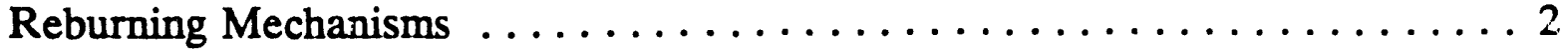

Laminar Flamelets $\quad \ldots \ldots \ldots \ldots \ldots \ldots \ldots \ldots \ldots \ldots \ldots$

Counterflow Diffusion Flames $\ldots \ldots \ldots \ldots \ldots \ldots \ldots \ldots \ldots$

EXPERIMENTAL EQUIPMENT $\ldots \ldots \ldots \ldots \ldots \ldots \ldots \ldots \ldots \ldots \ldots \ldots$

Laminar Counterflow Burner $\ldots \ldots \ldots \ldots \ldots \ldots \ldots \ldots \ldots \ldots \ldots$

Sampling and Analysis $\ldots \ldots \ldots \ldots \ldots \ldots \ldots \ldots \ldots \ldots \ldots \ldots \ldots$

EXPERIMENTAL RESULTS $\ldots \ldots \ldots \ldots \ldots \ldots \ldots \ldots \ldots \ldots \ldots \ldots \ldots$

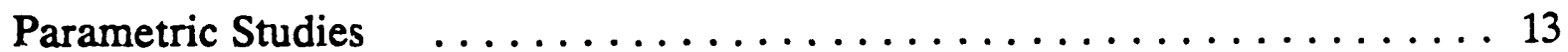

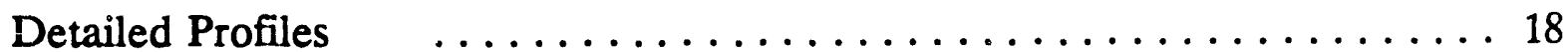

THEORETICAI MODEL . . . . . . . . . . . . . . . . . . . . . 19

Kinetic Mechanism .......................... 19

Thermochemical Data . . . . . . . . . . . . . . . . . . . . 19

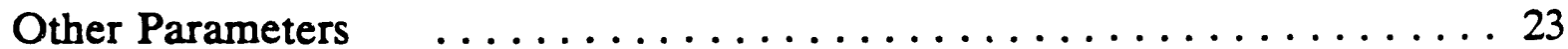

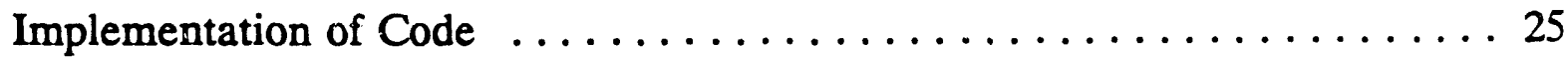

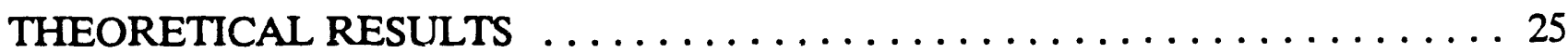

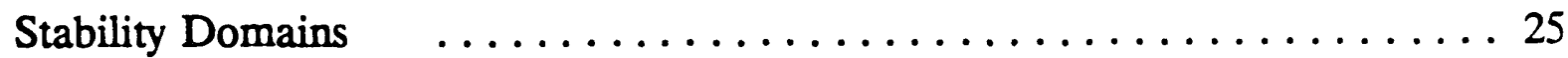

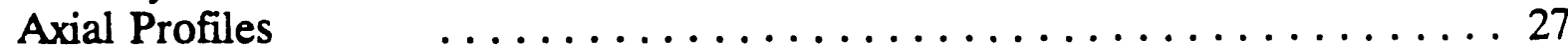

CONCLUSIONS AND FUTURE WORK $\ldots \ldots \ldots \ldots \ldots \ldots \ldots \ldots \ldots$

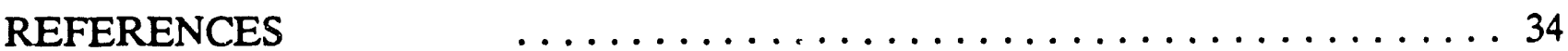

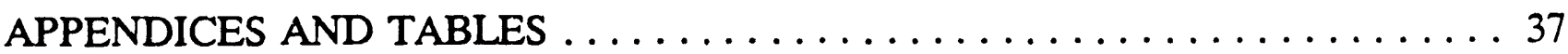

Experimental Data, Tables 1 through 16

Detailed Reaction Kinetic Mechanism, Table 17

Thermochemical Data, Taule 18

Equilibrium Constants, Table 19

Transport Parameters, Table 20 


\section{RESEARCH OBJECTIVES}

This report presents research results of a project that was designed to address two questions: First, can large reductions in NO be achieved by exploiting non-equilibrium aspects and heterogeneities present in diffusion flames? Second, what are the mechanisms governing the destruction of NO during reburning in diffusion flame environments? Emphasis was on overall fuel lean environments, since these constitute more benign environments for the retrofit application of reburning in the field.

\section{SIGNIFICANCE}

Available understanding of the parameters which limit and control reduction of NO by reburning in full scale boilers is limited. Much of previous research on reburning has been directed at premixed or almost premixed systems (Chen et al.1986, Mereb and Wendt, 1990, Wendt and Mereb, 1990). That research has provided useful insight into kinetic mechanisms in downflow laboratory combustors, where mixing is rapid, but has overlooked potentially important phenomena which can occur in large turbulent diffusion flames or in transient reducing eddies, which may occur in large scale units. It is hypothesized that heterogeneities or unmixedness, as exemplified by a diffusion flame front sweeping through a NO containing mixture, can produce free radicals that allow NO destruction kinetics to destroy NO to values approaching equilibrium. Of course, the flue gas temperatures and oxygen contents that support a diffusion flame (front) before micro-mixing occurs are not known, and so a secondary issue that must be addressed is the determination of diffusion flame stability limits as a function of these two parameters.

A recently developed reburning concept is a process denoted as "Reducing Eddy After-Burn (REAB)" (Breen, Gabrielson, and Lange, 1988), in which puffs of natural gas sweep through the primary flue gas of a boiler. The hypothesis is that the diffusion flame attributes at the boundaries of each puff are sufficient to destroy $\mathrm{NO}$ efficiently, without ever having to operate the upper half of the furnace under overall fuel rich conditions, i.e., without having to add additional burnout air, as is required for conventional reburning processes. The screening study conducted here was designed to determine whether this idea had merit, and whether, in fact, NO could be destroyed in diffusion flames more efficiently than is possible in premixed systems, and under more benign overall environments. Therefore, emphasis in this work is on reburning in diffusion flames under overall fuel lean conditions, although it should be noted that as far as a diffusion flame front (which as always located at a point where the local stoichiometry is close to unity) is concerned, the overall stoichiometry is irrelevant. 


\section{BACKGROUND}

\section{Reburning Mechanisms}

NO is not favored by equilibrium at low temperatures. Therefore, its destruction is kinetically limited. Free radicals can form a path to allow NO destruction, but they have very short lifetimes at significant concentrations in the cooler portions of the flue gas. Most of the available literature on reburning mechanisms has focussed on homogeneous, premixed systems. Detailed kinetic mechanisms have been developed by Glarborg, Miller and Kee (1986) and later modified by Miller and Bowman (1989). The major paths to production of $\mathrm{N}_{2}$ from NO are shown on Figure 1. A reaction subset, derived frorn these references and employing 151 reactions was used in the theoretical portion of this work and is shown on Table 17 in the Appendix.

More recently, Mereb and Wendt (1990) developed global approximations to reburning mechanisms as they occurred under premixed conditions in the reburning zone. This approach provides insight into rate controlling mechanisms under premixed conditions, and therefore is presented here. Following Bose and Wendt (1988), they used the detailed kinetic mechanism of Glarborg, Miller and Kee (1986) as a basis for determining both, which reactions were likely to be most important, and values of kinetic rate coefficients to be employed. No adjustunent of any rate constant was made and the analysis was done only in terms of known detailed kinetic mechanisms taken from the literature.

According to their data, the rate of destruction of NO can be given by:

$$
\begin{array}{ll}
\mathrm{NO}+\mathrm{NH}_{i} \rightarrow \text { products } & i=0,1,2 \\
\mathrm{NO}+\mathrm{CH}_{i} \rightarrow \text { products } & i=0,1,2
\end{array}
$$

where $\mathrm{NH}_{\mathrm{i}}$ and $\mathrm{CH}_{\mathrm{i}}$ concentrations were calculated from partial equilibria:

$$
\begin{array}{rr}
\mathrm{NH}_{i}+\mathrm{OH}-\mathrm{NH}_{i-1}+\mathrm{H}_{2} \mathrm{O} & i=1,2,3 \\
\mathrm{CH}_{i}+\mathrm{OH}-\mathrm{CH}_{i-1}+\mathrm{H}_{2} \mathrm{O} & i=1,2,3,4
\end{array}
$$

This yields the following expression for the rate of change of NO: 


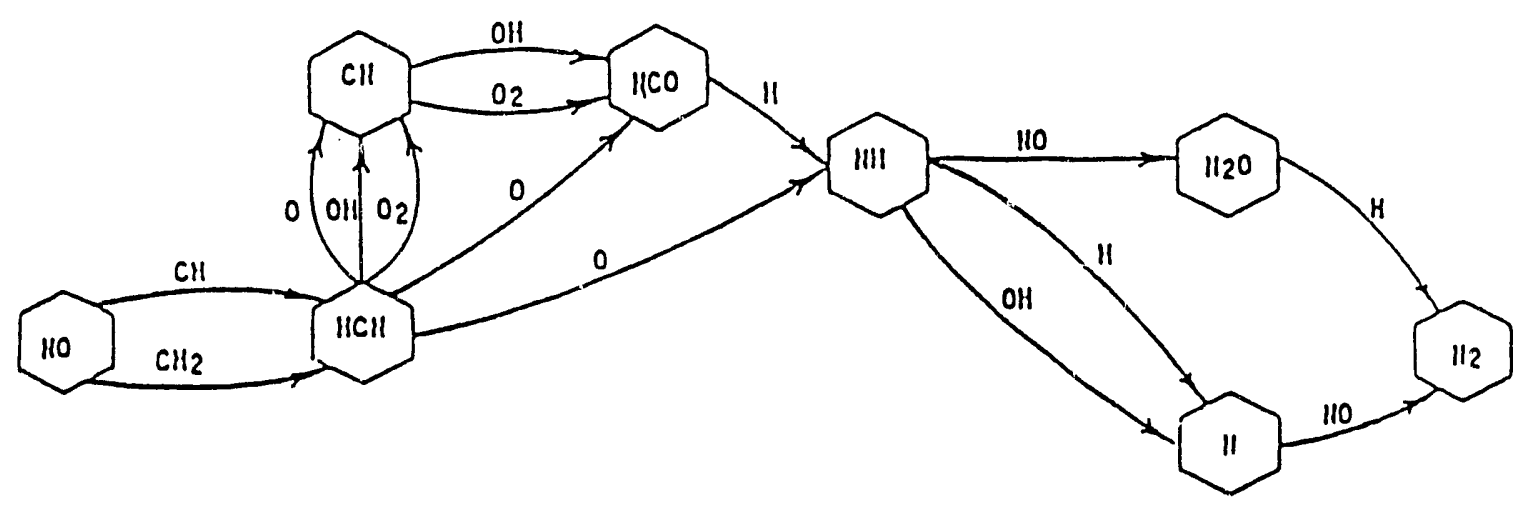

Figure 1: Major Paths for the Production of $\mathrm{N}_{2}$ from NO

$$
\frac{d(N O)}{d t}=-(N O)\left(N H_{3}\right) f_{1}-(N O)\left(C H_{4}\right) f_{2}
$$

which depends on the local $\mathrm{NO}, \mathrm{OH}, \mathrm{CH}_{4}$, and $\mathrm{NH}_{3}$ concentrations. Functions $\mathrm{f}_{\mathrm{i}}$, which depend on temperature, $\mathrm{OH}$ and $\mathrm{H}_{2} \mathrm{O}$ concentrations, represent groupings of known elementary reaction rate constants and equilibrium constants and are shown on Table 17.

$\mathrm{HCN}$ destruction rate was based on $\mathrm{HCN}+\mathrm{O}$ reactions, $\mathrm{HCN}+\mathrm{OH}$ reactions and the reversible reaction:

$$
\mathrm{HCN}+\mathrm{H} \rightleftharpoons \mathrm{CN}+\mathrm{H}_{2}
$$

where CN was at a pseudo stationary state derived from Reaction (6), together with reactions $\mathrm{CN}+\mathrm{OH} \rightarrow \mathrm{NCO}+\mathrm{H}$ and $\mathrm{C}+\mathrm{NO}->\mathrm{CN}+\mathrm{O}$. Assumption of partial equilibrium was made for $\mathrm{HCN}+\mathrm{OH}=\mathrm{CN}+\mathrm{H}_{2} \mathrm{O}$ and $\mathrm{O}$ was assumed to be in partial equilibrium with $\mathrm{H}_{2} \mathrm{O}$ and $\mathrm{H}_{2}$.

HCN formation rate was based on Reaction (2) in addition to the reactions: 


$$
\begin{gathered}
\mathrm{CH}+\mathrm{N}_{2} \rightarrow \mathrm{HCN}+\mathrm{N} \\
\mathrm{CH}_{3}+\mathrm{N} \rightarrow \mathrm{HCN}+\mathrm{H}+\mathrm{H}
\end{gathered}
$$

This yields the following expressions for the rates of change of $\mathrm{HCN}$ :

$$
\begin{gathered}
\frac{d(H C N)}{d t} \underbrace{}_{\text {destruction }}=-(H C N)\left[f_{3}+f_{4}\right] \\
\frac{d(H C N)}{d t}=\left(C H_{4}\right)\left[(N O) f_{2}+\left(N_{2}\right) f_{5}+\left(N H_{3}\right) f_{6}\right]
\end{gathered}
$$

$\mathrm{N}_{2}$ was formed by Reaction (1) and destroyed by Reaction (7), yielding:

$$
\frac{d\left(\mathrm{~N}_{2}\right)}{d t}=(\mathrm{NO})\left(\mathrm{NH}_{3}\right) f_{7}-\left(\mathrm{CH}_{4}\right)\left(\mathrm{N}_{2}\right) f_{5}
$$

The rate of change of $\mathrm{NH}_{3}$ was determined from a nitrogen balance:

$$
\frac{d\left(N H_{3}\right)}{d t}=-\frac{d(N O)}{d t}-\frac{d(H C N)}{d t}-2 \frac{d\left(N_{2}\right)}{d t}
$$

The $f_{i}$ in Equations (5 and 9-11) have the form:

$$
f_{i}=\sum_{j=1}^{1,2, \text { or } 3} A_{i j} T^{N_{y}} \exp \left(\frac{B_{i j}}{T}\right) \times \frac{(\mathrm{OH})^{m_{i j}}}{\left(\mathrm{H}_{2} \mathrm{O}\right)^{l_{y}}}
$$

where values for parameters in $f_{i}$ are derived from fundamental equilibrium and rate constants taken from the literature, and are given by Mereb and Wendt (1990). Equations (5 and 9-12) can predict $\mathrm{XN}$ species profiles, $a b$ initio, provided initial conditions and estimates for $\mathrm{OH}$ are available.

The relevance of the above discussion to the current research, which is concerned with non premixed systems, lies in the importance of hydrocarbon radicals both to destroy NO directly and to form $\mathrm{HCN}$, which is then the source for additional $\mathrm{N}$ radicals that can further destroy NO to make $\mathrm{N}_{2}$. Unfortunately, that research also showed that hydrocarbon radicals can also fix nitrogen by making $\mathrm{HCN}$ from $\mathrm{N}_{2}$, and this can limit reburning 
effectiveness. Under premixed conditions, $\mathrm{CH}$ radicals have a very short lifetime, and this also limits reburning effectiveness.

\section{Laminar Flamelets.}

The issue is how to produce free radicals $\left(\mathrm{CH}_{\mathrm{i}}, \mathrm{NH}_{\mathrm{i}}\right)$ under conditions where they would not normaily exist, namely under fuel lean conditions and at low temperatures. A diffusion flamelet, containing locally steep gradients of temperature and species concentrations and originating from large turbulent diffusion flames can exist under such overall environments. It may, in fact, sweep through the surrounding gases, and serves to produce large quantities of super-equilibrium free radicals, which, upon diffusing into the cooler neighboring regions which contain NO, react with it to form $\mathrm{N}_{2}$ on their path to low equilibrium values. This process is hereafter denoted as the "Breen Hypothesis", after Bernard P. Breen, who first enunciated it.

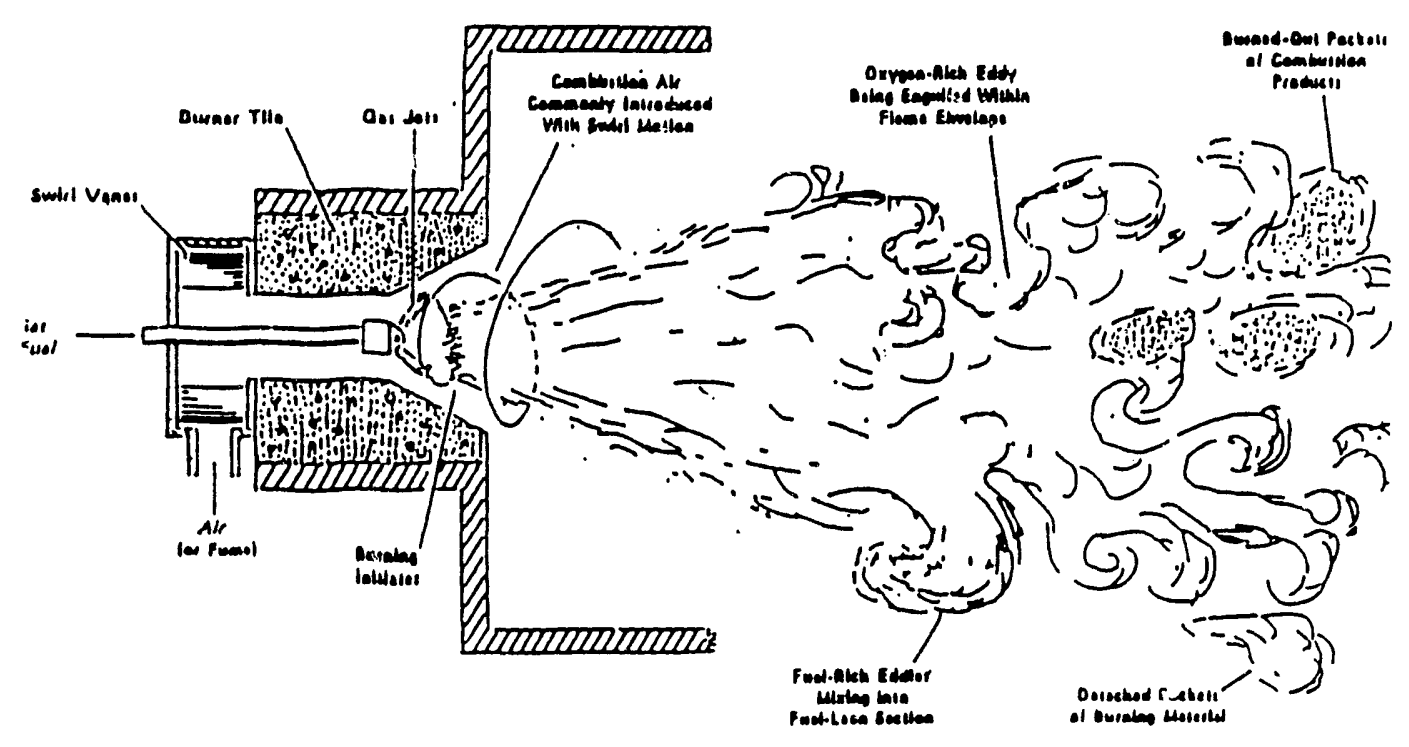

Figure 2: Schematic of a Diffusion Mixed Burner

A crude schematic of a large diffusion mixed burner is shown on Figure 2. The actual burning process is an extremely complicated one, and there are many chemical and physical processes occurring simultaneously. Only in a relatively thin interface is there a combustible mixture, and this governs the formation of a (fluctuating) sheet of flame. This sheet is very much warped and wrinkled, as eddies of fuel are swept out into the air section or as eddies of oxygen containing air move into the fuel. Pockets of flame will be carried into unignited regions, which will burst into new flames; nr they may be projected into zones that have already been burned out, whereupon the flame is diluted and quenched. The turbulent combustion process is, therefore, far different from one in which mixing occurs by 
an "eddy viscosity" or by "eddy diffusion". Rather it occurs through engulfment and stretched laminar flamelets, which represent the burning interfaces between fuel and air.

That stretched laminar flamelets can be used to describe turbulent diffusion flames has been shown experimentally by Drake (1986) and theoretically by Peters (1986) amongst others. The discovery of coherent structures in turbulent flames (Roshko, 1974) reactivated the idea that the turbulent flame is composed of an ensemble of laminar flamelets, each of which is stretched in its own plane (Chigier and Yule, 1979). Marble and Broadwell (1977) postulated a model which involved a balance equation for flame density, where the rate at which reactants are consumed in a volume (which is small compared to the turbulent motion, but large compared to the flame thickness) is set equal to the product of the flame density (flame surface per unit volume) and the rate of reactant consumption per unit area. This is illustrated in Figure 3. On a micro-scale, laminar flame fronts are continuously stretched and deformed by turbulent motion. The straining, which increases the area of the laminar diffusion flamelet, has a definite effect on the rate of reaction per unit area, affecting in this form the rate of formation and destruction of various intermediate species.

\section{Counterflow Diffusion Flames}

A schematic of a counterflow diffusion flame is shown on Figure 4. Fuel and air streams impinge from two opposed parallel plates, to form a thin, stretched, diffusion flame sheet between them. This system can be described by the conservation equations for momentum, energy and species. If it is assumed that the plates are infinitely wide, the two dimensional conservation equations can be transformed using the following:

$$
\begin{aligned}
& v_{z}=v(z) \\
& v_{r}=r \psi(z) \\
& \rho=\rho(z) \\
& T=T(z) \\
& x_{i}=x_{i}(z) \quad i=1, \ldots \ldots, N \\
& p=\varphi(z)-Q r^{2}
\end{aligned}
$$

where $Q$ is a constant and an eigenvalue of the system when velocities at both burners are specified. This similarity transformation is only valid at low Mach Numbers, when changes in pressure are small compared to its absolute value.

Applying the transformations shown in Equation (14) to the conservation equations yields: 


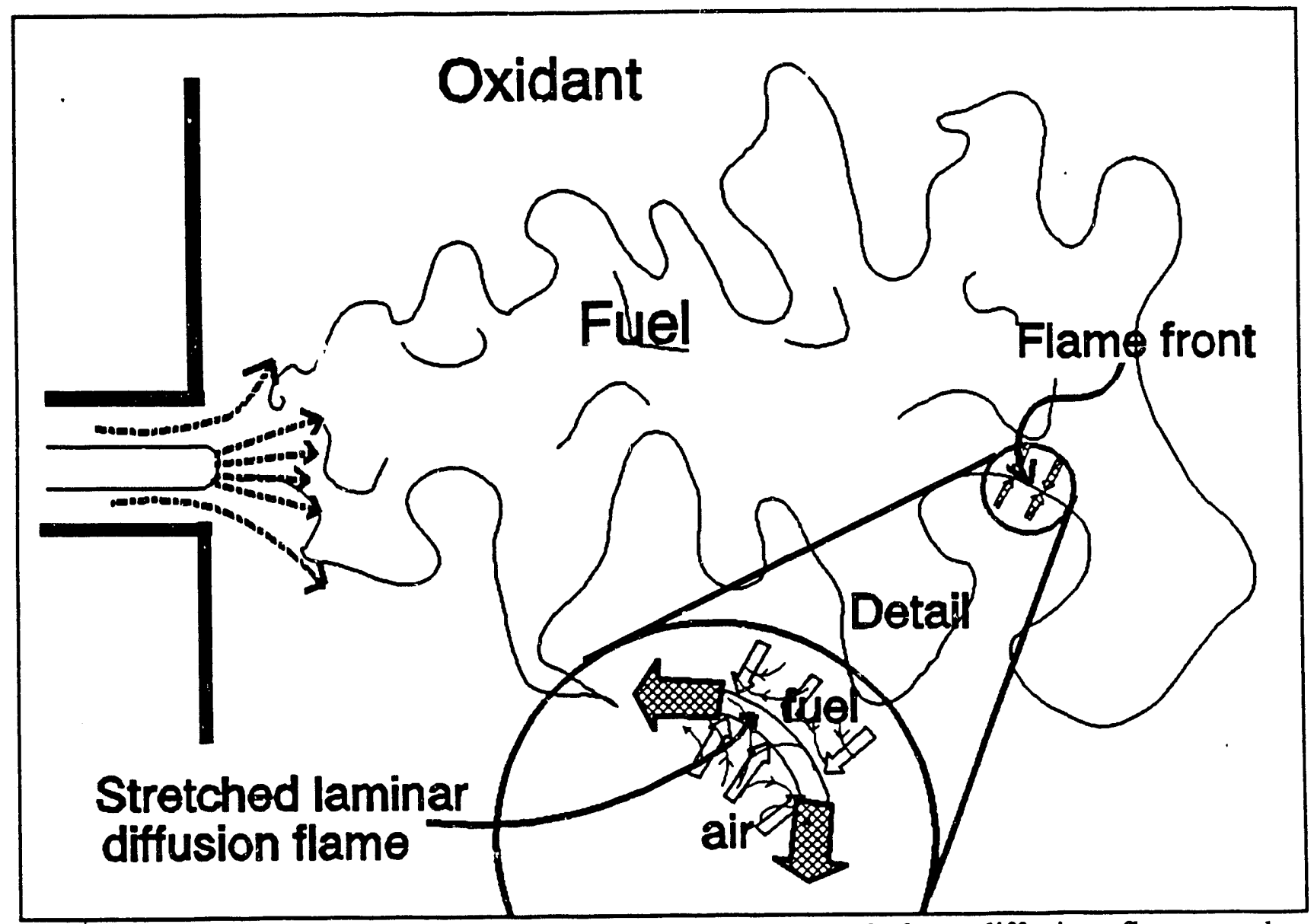

Figure 3: Schematic showing relationship between a turbulent diffusion flame and a stretched laminar flamelet. 


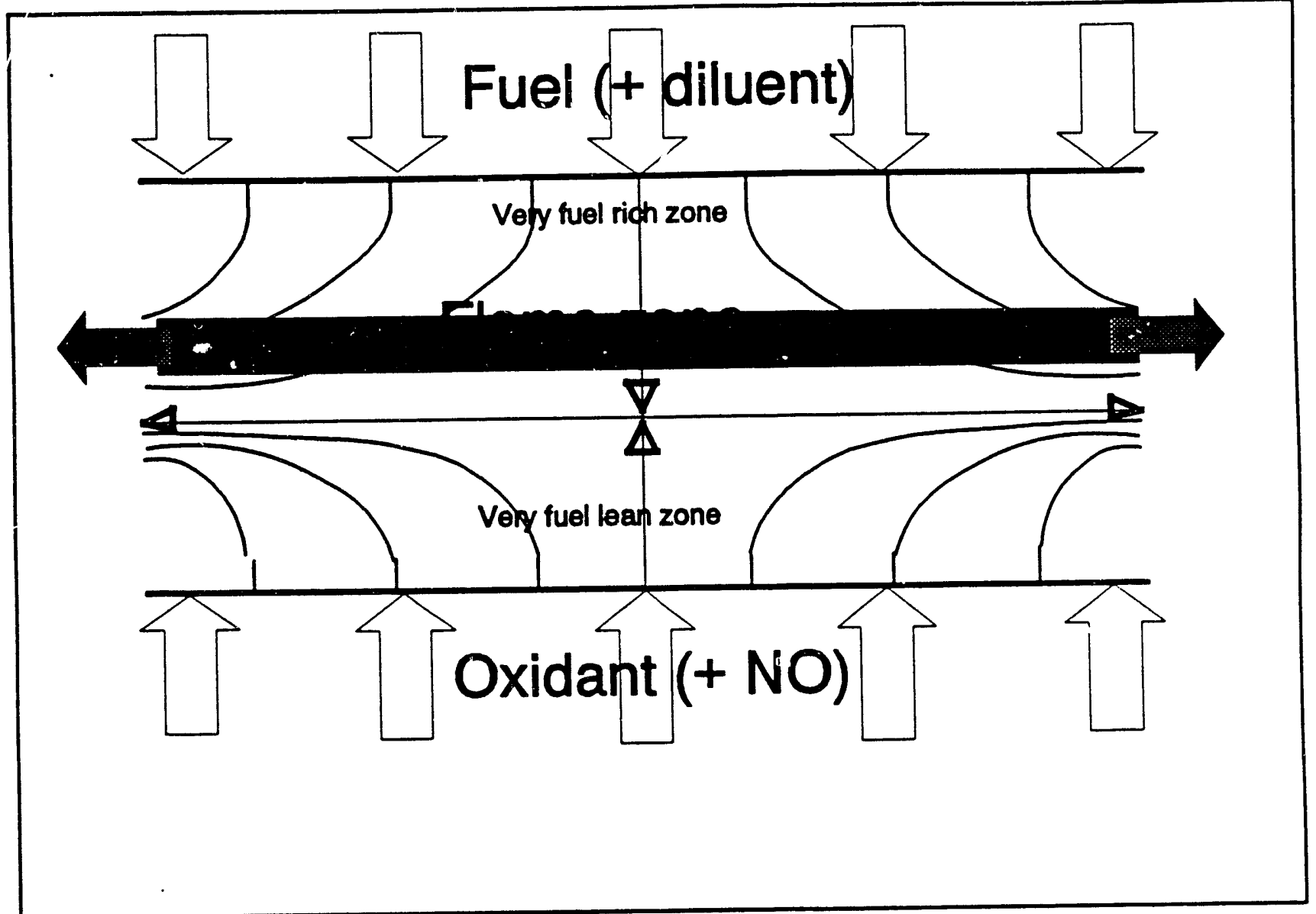

Figure 4: The flat, laminar, opposed jet, diffusion flame. 
Continuity:

$$
\frac{d \rho v}{d z}+2 \rho \psi=0
$$

r-Momentum:

$$
\psi^{2}+v_{z} \frac{d \Psi}{d z}=-2 \frac{Q}{\rho}+\frac{1}{\rho} \frac{d}{d z}\left(\mu \frac{d \psi}{d z}\right)
$$

Species: $(\mathrm{i}=1, \ldots . ., \mathrm{N})$

$$
D_{i m} \frac{d^{2} x_{i}}{d z^{2}}+\left\{\frac{1}{c} \frac{d\left(c D_{i m}\right)}{d z}-v_{z}\right\} \frac{d x_{i}}{d z}+\left\{\frac{v_{z}}{M} \frac{d M}{d z}\right\} x_{i}=-\frac{R_{i}}{c}
$$

Energy:

$$
\frac{\lambda}{\rho C_{p}} \frac{d^{2} T}{d z^{2}}+\left\{\frac{1}{\rho C_{p}}\left[\frac{d \lambda}{d z}+\sum_{i=1}^{N} \rho C_{p_{i}} D_{i m}\right]-v_{z}\right\} \frac{d T}{d z}=\frac{1}{\rho C_{p}} \sum_{i=1}^{N} H_{i} R_{i}
$$

where pseudo binary diffusion has been assumed and thermal diffusion has been neglected.

The approach used to solve this system of equations is to solve the equations of rmomentum, energy and species conservation in a fully implicit manner after discretizing in the spatial domain. A time dependence was added to allow iteration to a steady state from an initial guess. In all, $\mathrm{N}+2$ second order ODE's were solved in this way, where $\mathrm{N}$ is the number of species appearing in the reaction set used. Continuity was solved at each time step, using Simpson's Rule, and this updated the axial velocity field.

The momentum, energy and species conservation have the general form:

$$
A_{i}(z) \frac{d^{2} Y_{i}}{d z^{2}}+B_{i}(z) \frac{d Y_{i}}{d z}+D_{i}(z) Y_{i}=F_{i}(z) \quad i=1, \ldots, N+2
$$

The following problems arise when attempting a solution:

1. Stiffness through the forcing function $F_{i}(z)$ due to detailed reaction mechanisms.

2. Coefficient $B_{i}(z)$ changes sign, causing a regular first order turning point. 
3. Steep spatial gradients occur, especially near the flame zone.

4. Instabilities due to numerical approximations.

5. Step-size and convergence criteria.

6. The eigenvalue nature of the problem, where $Q$ is an eigenvalue consisten! with specification of upper and lower velocities.

Stiffness was addressed by expanding $F_{i}(z)$, which contain the stiff kinetics, in a Taylor Series about the $k$ 'th time step values, giving:

$$
F_{i}^{k+1}=F_{i}^{k}+\left.\sum_{j=1}^{N} \frac{d F_{i}}{d Y_{j}}\right|^{k}\left(Y_{j}^{k+1}-Y_{j}^{k}\right)
$$

The problem associated with steep spatial gradients was soived by using a modified, weighted, finite difference formulation, as described by Hahn and Wendt (1985) and Corley and Wendt (1985):

$$
\frac{d Y}{d z}=\frac{W_{p+1,1} Y_{p+1}-W_{p-1,1} Y_{p-1}}{2 h}+W_{1}^{0}
$$

and:

$$
\frac{d^{2} Y}{d z^{2}}=\frac{W_{p+1,2} Y_{p+1}-2 Y_{p}+W_{p-1,2} Y_{p-1}}{h^{2}}+W_{2}^{0}
$$

where the actual expressions for the weighting functions, $W_{i, k}$, depend on whether the roots of the characteristic equation of the second order ODE are real and distinct, complex, or real and equal, and the $\mathrm{W}_{\mathrm{i} 0}$ arise fro. $\mathrm{n}$ inclusion of the forcing function in the development.

The ensuing system of equations to be solved at each time step, defines a block, tridiagonal matrix, where the diagonal blocks are full matrices containing the Jacobian, and the off diagonal blocks are diagonal matrices. This system was solved using LU decomposition.

The eigenvalue nature of the problem is handled in a simple and straightforward manner. A value of $Q$ is selected, based on the approximation: 


$$
Q=\frac{\left[\rho_{\text {fuel }}^{1 / 2} v_{\text {fuel }}+\rho_{a x}^{1 / 2} v_{a x}\right]^{2}}{L_{\text {spains }}^{2}}
$$

Specifying boundary conditions for $T$, , and reactants, the fuel-side burner velocity is set. The converged solution yields the value for $v_{o x}$ consistent with $Q$. If the oxidant side velocity is different than the experimental value, a new value of $Q$ is selected and the process repeated until a match is found.

\section{EXPERIMENTAL EQUIPMENT}

\section{Laminar Counterflow Burner}

A schematic of the experimental system is shown on Figure 5. The burners were four inches in diameter, and enclosed in 3 chamber as shown. The oxidant to simulate flue gas that contains NO were introduced at the bottom, while fuel diluted with nitrogen was introduced at the top. The burners were made of stainless steel tubes which were filled with glass beads as shown in Figure 6 and sealed at the ends with stainless steel porous disks. The purpose of the beads is to randomize the flow pattern in the burner thus avoiding the formation of a velocity profile (Hahn,1979). All gas flows were measured using Matheson type Rotameter series $602-610$ at 50 psi back pressure. The feed lines and sampling lines were made of teflon tubing connected with Swagelock fittings. No brass fittings were used.

Modification to the burner design adopted for later experiments consisted of a 1.81 inch diameter stainless steel pipe coaxially arranged in a 4 inch pipe as shown in Figure 7. NO was fed via the inner pipe while the oxidant gases went through both the inner and outer pipes. This is denoted as Configuration C-4. Both flows passed through a half inch thick bronze porous plate. A double seal arrangement was adopted to prevent edge leaks from the burner cap due to warping, which was a persistent problem when a thin stainless steel disk was used. The purpose of this modification is to increase the portion of NO that reaches the flame front. However, as shown on Figure 8, this configuration did not achieve one dimensionality until some distance away from the burner. Future work should improve precision of the experimental conditions examined and that of the ensuing data, if any comparison with the model described above is to be meaningful.

\section{Sampiing and Analysis}

A schematic of the analysis train is also shown in Figure 5. The sample gas was drawn by a vacuum pump at constant rate either from the exhaust line or from the in-flame sampling probe. In the case of flame region sampling the rate of sampling was adjusted to a level where no visual disturbance on the flame due to sampling was observed. 
The sample was passed to an expansion flask jacketed in ice to remove water in the sample gas. The sample train was then divided into two streams for simuitaneous analysis of $\mathrm{NO}_{x}$ and other (stable) species. The $\mathrm{NO}_{x}$ analysis was done by a (TECO) Model 10A self contained chemiluminescent $\mathrm{NO} / \mathrm{NO}_{x}$ analyzer with a (TECO) Model 300 Molybdenum NO-NO ${ }_{2}$ convertor. The analysis of other species was inade through an analytical Gas

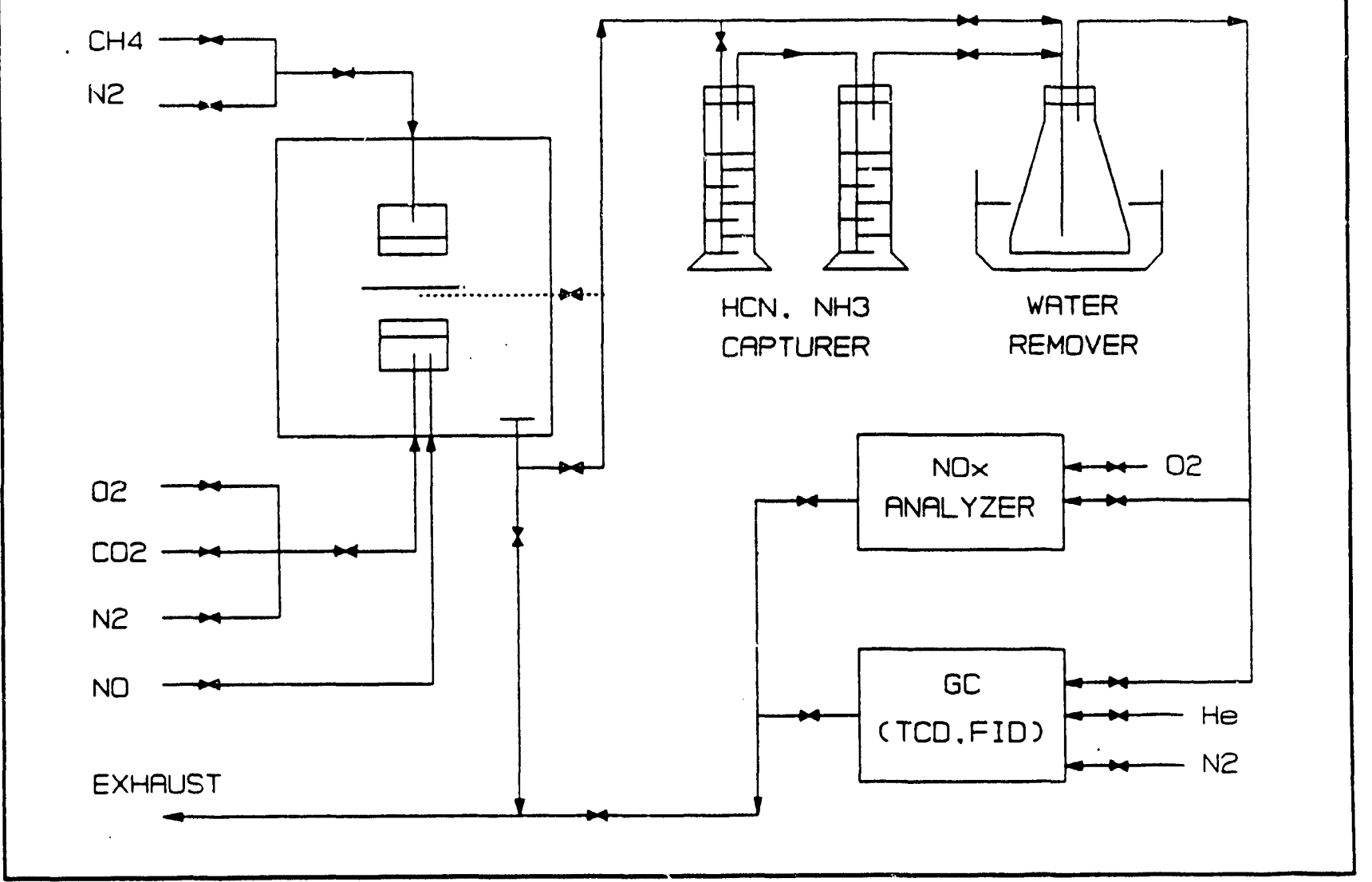

Figure 5: Experimental System.

Chromatography. Specially ordered for this project was a GC completed with a digital Integrator (model SP4400, Spectra-Physics) with 4K RAM storage capacity. The GC, model 01311-SP, manufactured by Hach Carle Chromatography, consists of TCD and FID that can be ope rated independently and simultaneously. The highest sensitivity for the instrument can be achieved with helium as the carrier gas. In all the experiments presented in this report, helium was used.

A schematic sketch of the GC flow system is shown in Figure 9. The GC consists of 2 columns each requiring a carrier gas flow rate of $20 \mathrm{ml} / \mathrm{min}$. It is important to maintain these flow rate as constant as practically possible. Regular check of the flow rates was carried out using a simple soap bubble meter. 

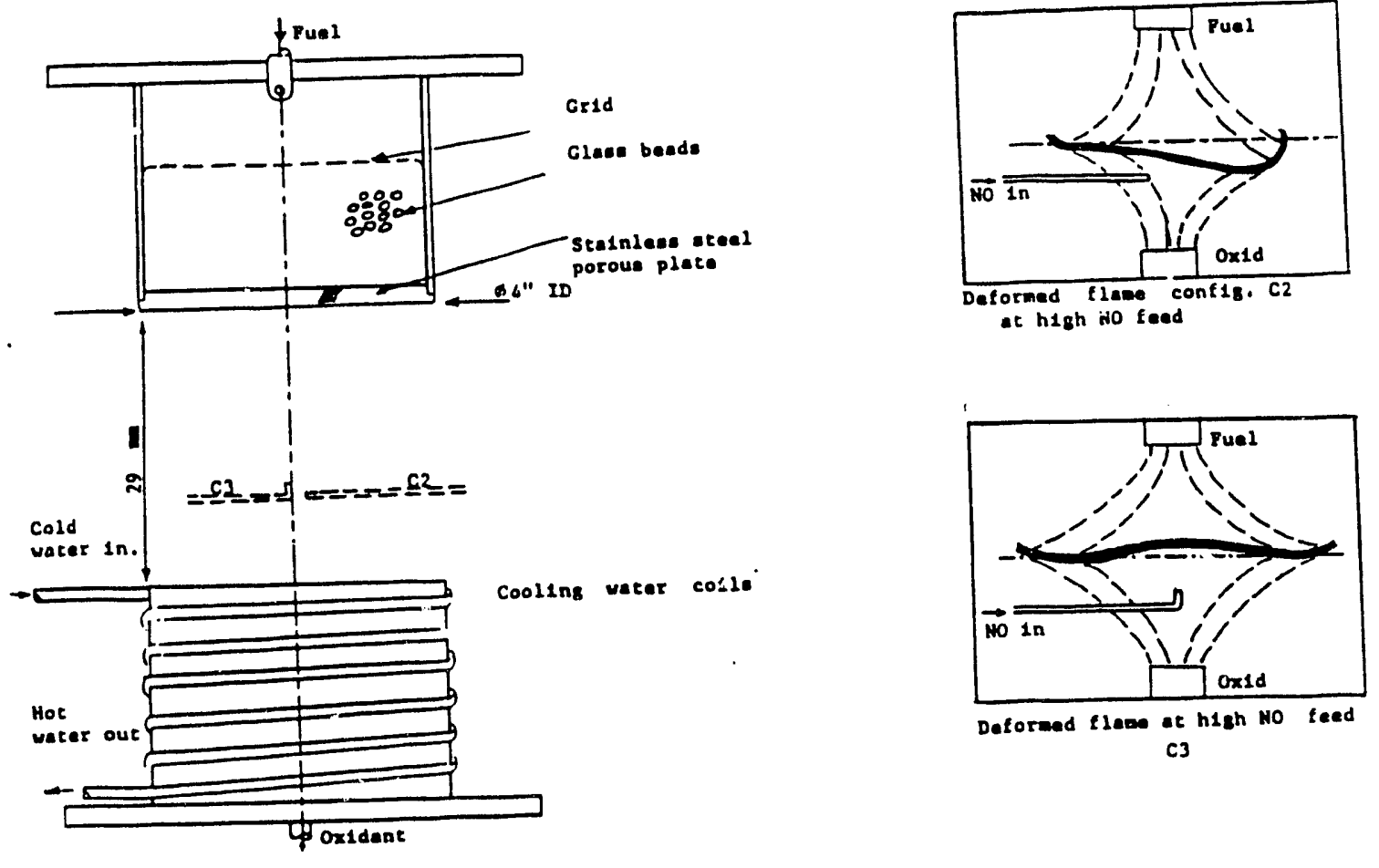

C3

Figure 6: Opposed jet diffusion flame: burner details.

The combined GC integrator arrangement gave readings of resolution of $\pm 0.001 \%$ of a species in sample. The species analyzed this way were $\mathrm{CH}_{4}, \mathrm{CO}_{2}, \mathrm{CO}, \mathrm{O}_{2}, \mathrm{~N}_{2}, \mathrm{H}_{2}, \mathrm{C}_{2} \mathrm{H}_{2}$, $\mathrm{C}_{2} \mathrm{H}_{4}$ and $\mathrm{C}_{2} \mathrm{H}_{6}$. Trace species of $\mathrm{NH}_{3}$ and $\mathrm{HCN}$ were further analyzed using standard wet chemistry electrode tests.

\section{EXPERIMENTAL RESULTS}

\section{Parametric Studies}

The objective of the parametric screening studies was to determine, through integral input/output measurements of NO destruction in our apparatus, whether diffusion flames might be more efficient for destroying NO than premixed flames, as hypothesized by Breen. These experiments were also necessary to determine whether NO destruction was likely under overall fuel lean conditions. Furthermore, these studies also helped define more precisely, issues requiring resolution.

Input/output measurements consist of species concentrations and flows. Unknown quantities were $N_{d}$, the $d r y$ molar flow rate of the exhaust, per $100 \mathrm{moles} / \mathrm{min}$ of total flow 


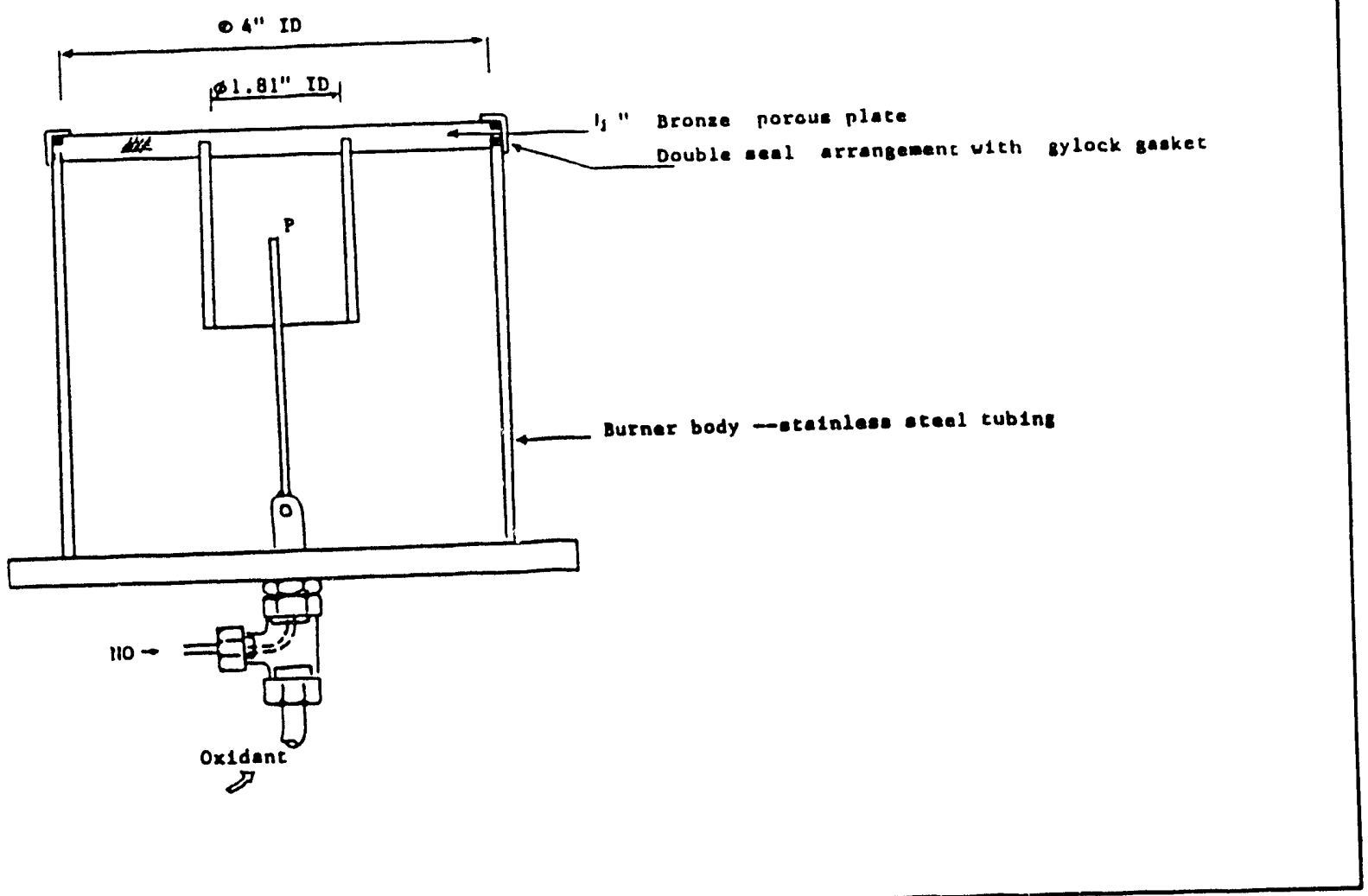

Figure 7: Modified coaxial bottom burner.

in, and $\mathrm{N}_{\mathrm{H} 2 \mathrm{O}}$, the moles/min of water in the exhaust, per $100 \mathrm{moles} / \mathrm{min}$ of total flow in.

The carbon balance:

$$
\left\{\% \mathrm{CH}_{4}+\% \mathrm{CO}_{2}\right\}_{\text {inlet }}=\frac{N_{d}}{100}\left\{\% \mathrm{CO}+\% \mathrm{CO}_{2}+2 \sum_{i=2,4,6} \% \mathrm{C}_{2} \mathrm{H}_{i}\right\}_{\text {exhous }}
$$

yields $N_{d}$, since all other quantities in Equation (24) are measured.

The oxygen and hydrogen balances:

$$
2\left\{\% \mathrm{O}_{2}+\% \mathrm{CO}_{2}\right\}_{\text {inlex }}=\frac{N_{d}}{100}\left\{\% \mathrm{CO}+2 \% \mathrm{CO}_{2}+2 \% \mathrm{O}_{2}\right\}_{\text {exhaus }}+\mathrm{N}_{\mathrm{H}_{2} \mathrm{O}}
$$

were solved simultaneously to yield values for $N_{d}$ (independently of that calculated by Equation (24)) and $\mathrm{N}_{\mathrm{H} 2 \mathrm{O}}$. Everything else in Equations (25) and (26) was measured. For all runs reported here, the two values of $N_{d}$ (calculated by Equation (24) and Equations (25) 


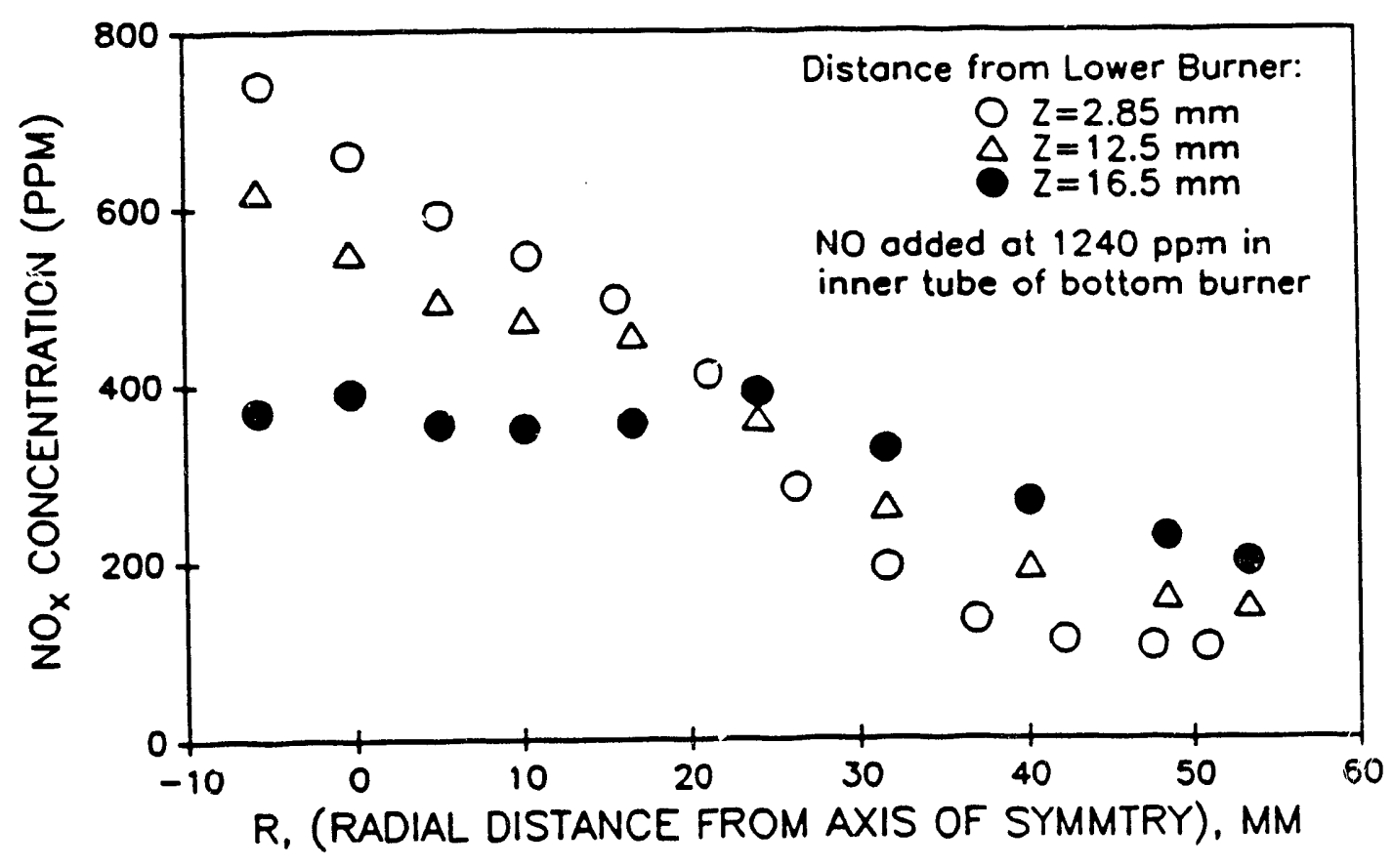

Figure 8: Radial profiles of $\mathrm{NO}_{x}$ for Configuration C-4.

$$
4\left\{\% \mathrm{CH}_{4}\right\}_{\text {iler }}=\frac{\mathrm{N}_{d}}{100}\left\{2 \% \mathrm{H}_{2}+4 \% \mathrm{CH}_{4}+2 \% \mathrm{C}_{2} \mathrm{H}_{2}+4 \% \mathrm{C}_{2} \mathrm{H}_{4}+6 \% \mathrm{C}_{2} \mathrm{H}_{6}\right\}_{\text {exhauss }}+2 \mathrm{~N}_{\mathrm{H}_{2} \mathrm{O}}
$$

\& (26) together) were within $3 \%$ of each other, indicating that all our concentration and flow measurements were consistent, and that there were no leaks diluting the exnaust sample. Details are found on the tables of results following. This is important, since our conclusions from this phase of the work hinge on our being able to close all mass balarces accurately.

In the presentation of results that follows, raw data can be found in the tables in the Appendix, while data in the figures represent ppm values which, in order to account for any dilution effects, have been reduced to the inlet molar flow rate, thus:

$$
\left\{N O_{x}\right\}_{p p m, \text { reduced }}-\frac{N_{d}}{100}\left\{N O_{x}\right\}_{p p m, \text { measered }}
$$

Integrated input/output results from four burner configurations (C-1 through C-4) are presented. It was not easy to stabilize a steady stretched diffusion flame at perceived optimum values of overall stoichiometric ratio, flue gas oxidant concentrations, diluent concentrations, and flame stretching rates (as determined from burner velocities). 


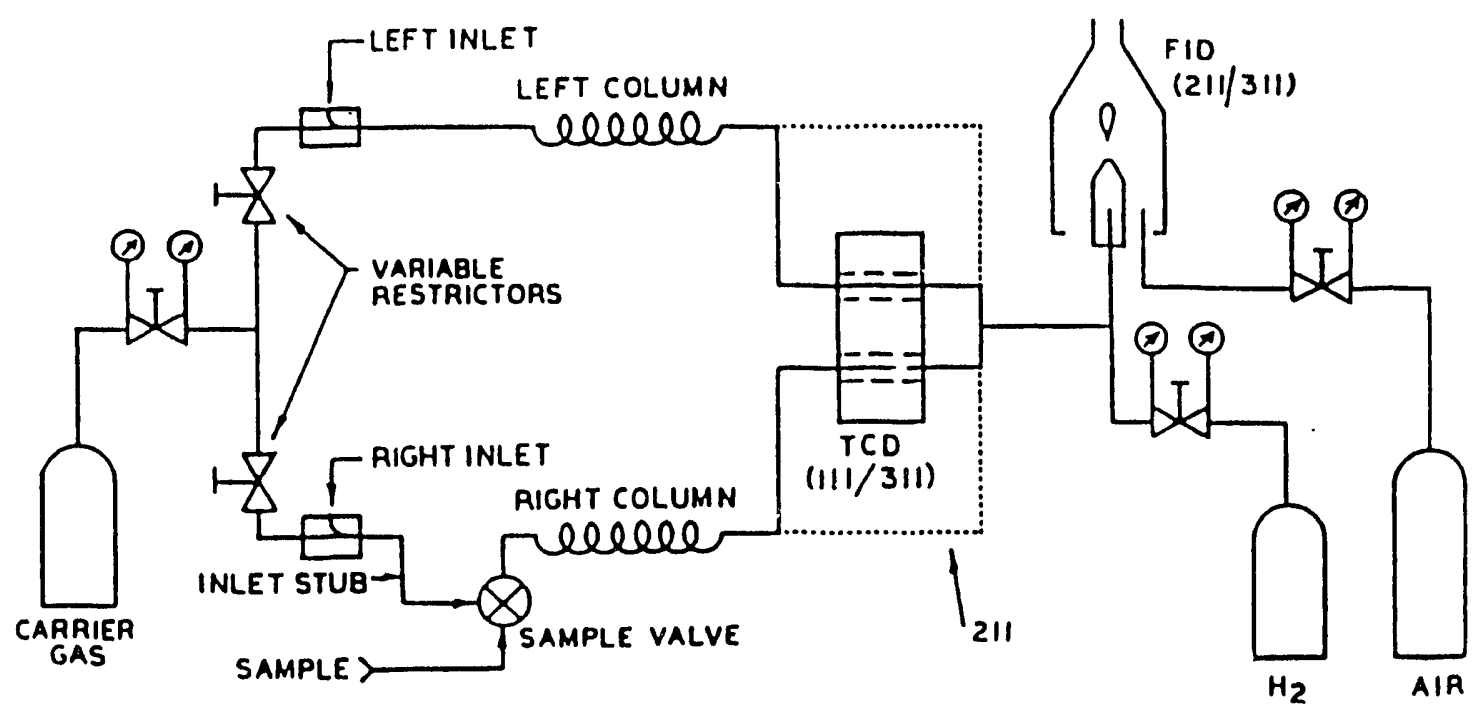

Figure 9: Schematic of flow system in Model AGC 01311 chromatograph.

Therefore, in this preliminary effort, we focussed on overall fuel lean flames, and on high levels of $\mathrm{O}_{2}$ in the "flue" gas. It will be shown later, through theoretical analysis, that at lower oxygen concentrations, stable diffusion flames can only be established at high inlet temperatures.

The first set of results was obtained with the burner configuration shown on Figure 6. Here, NO was distributed uniformly across the bottom burner exit, and so a large fraction of the inlet NO failed to ever reach the (finite width) flame. Experimental results are shown on Tables 1 and $1 \mathrm{a}^{1}$, and the NO ppm in the exhaust, shown by filled circles, is compared to that in the total inlet on Figure 10. The solid line depicts what the results would be were zero NO destroyed. It is evident that at higher inlet NO values, a significant portion of the NO is destroyed, even though the overall stoichiometric ratio was fuel lean and even though only a fraction of NO actually enters the diffusion flame front.

In order to force more NO to enter the flame front, tests in which pure NO was injected through a very small diameter tube into the oxidant stream, were conducted. In configuration $C 2$, the pure NO was introduced horizontally, with the results shown on Tables 2 and 2a. Exhaust levels of NO were extremely low, until, at a high inlet flow rate, the NO

${ }^{1}$ Tables are located in the Appendix. 


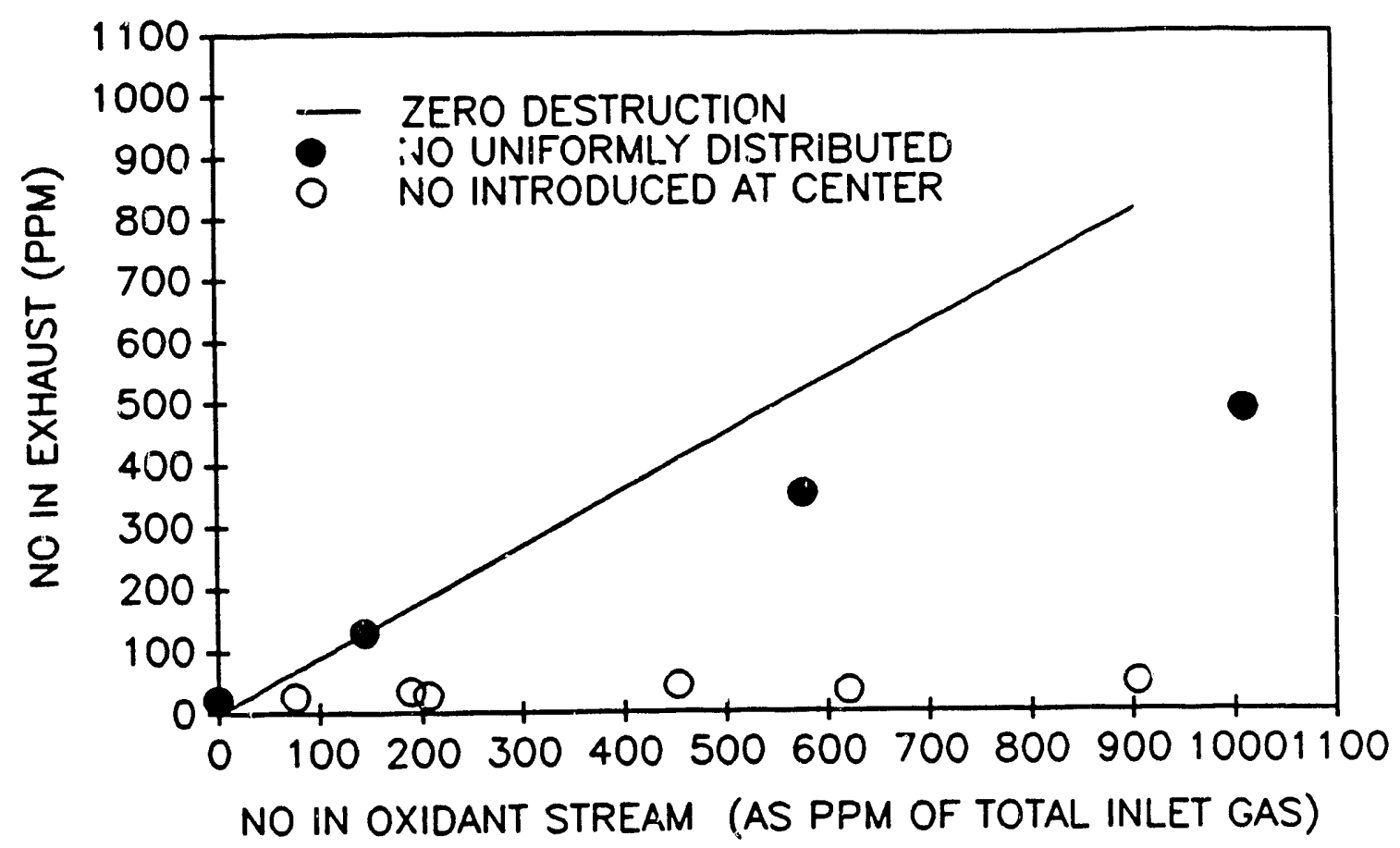

Figure 10: NO destruction in diffusion flames $1 \mathrm{C}-1$ and $1 \mathrm{C}-3$.

stream broke through the combustion zone and NO exhaust levels rose steeply. In configuration $\mathrm{C} 3$, pure NO was introduced through a narrow tube oriented along the burner axis, and located at the center streamline. Experimental data are shown on Tables 3 and $3 \mathrm{a}$, and by the open symbols on Figure 10. The results are very encouraging, since they indicate that extremely high destructions of NO are possible, (in excess of $95 \%$ for the high NO case). Here all the NO, which was injected axially along the center stagnation streamline, came into contact with the flame, and was essentially completely destroyed.

It can be argued that in this experiment, the actual concentration of NO reaching the flame may be very high, because pure NO was injected down the center. Therefore we proceeded to configuration $\mathrm{C} 4$, consisting of two coaxial pipes in the bottom burner, as shown on Figure 7. Known quantities of NO were introduced into the center pipe, while the remaining oxidant mixture was the same in both inner and outer pipes. Here, there was more control over the concentration of NO seeing the flame. However, our radial NO profiles (Figure 8) indicated that our method of NO introduction into the burner could be improved, and there were some radial variations upon exiting from the lower burner. Therefore, these data are not as well defined as they might be. The actual overall stoichiometries of Flames 1C-4 through $6 \mathrm{C}-4$ were not equal to those calculated from the entering flows because a leak on the upper (fuel side) burner allowed substantial, but undetermined, quantities of methane to leak out into the container vessel, without being oxidized in the flame. Therefore, all true overall stoichiometries investigated, are very much more fuel lean than denoted on Tables 4 through 9 a. The NO destruction results, however, 


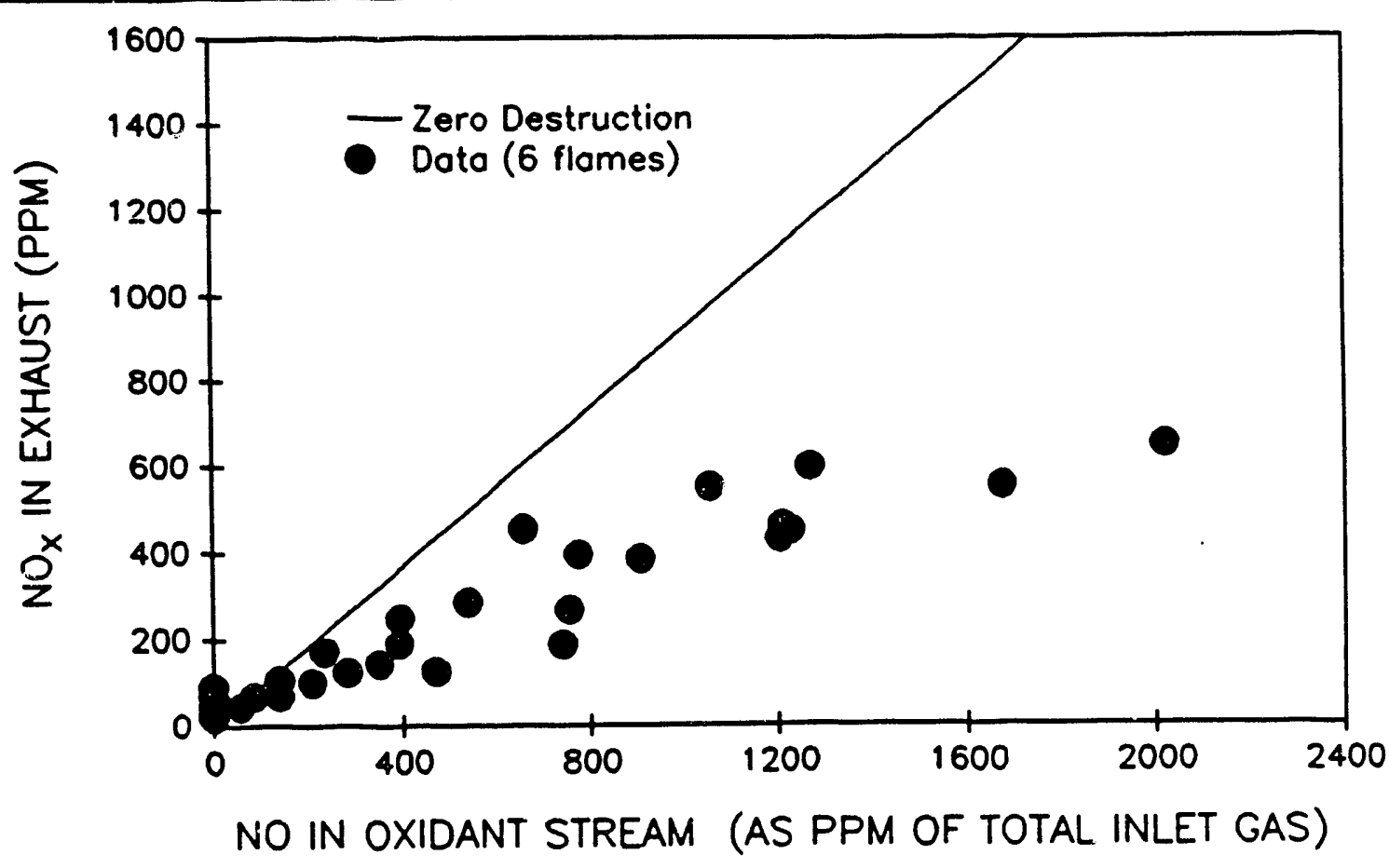

Figure 11: NO destruction in (overall) fuel lean diffusion flames (1C-4 through 6C-4).

are quite valid (since the atom balance calculations for exhaust flow rates still held), and are grouped together on Figure 11. In this, and subsequent, figures, the thermal NO, corresponding to the exhaust NO measured with zero NO addition to the oxidant was subtracted from the exhaust values.

The leak in the upper burner was fixed, and Flames $8 \mathrm{C}-4$ through $12 \mathrm{C}-4$ were investigated. Results are shown on Tables 10 through 13a, and are depicted on Figure 12. It appears that, in general, a most important variable is the location of the flame. As the flame was stabilized closer to the bottom burner, greater destructions of NO were observed. One might speculate that the key variable is the fraction of NO that "sees" the flame front. Again, it should be emphasized that these high values of NO destruction, shown on Figure 12 , were obtained under overall fuel lean conditions, indicating that phenomona in diffusion flames are very different than those in premixed systems.

Flame 11C-4 was chosen for more detailed studies. Results for four replicate runs are shown on Figure 13. $\mathrm{HCN}$ and $\mathrm{NH}_{3}$ values in the exhaust are shown on Figure 14. Clearly, $\mathrm{NO}$ is being destroyed, and is not leaving the system as $\mathrm{NO}_{2}, \mathrm{HCN}$ or $\mathrm{NH}_{3}$.

\section{Detailed Profiles.}

Flame 11-C4 was chosen as the prototype for measuring detailed axial species profiles. The purpose of this phase of the work was to provide a basis of comparison 
between the experiment and the model, which was capable only of predicting profiles, but not capable, at this time, of predicting integral input/ output results. The model would be essential in relating the steady state experimental findings to a transient practical application. Axial profiles for the case with zero NO added are shown on Figure 15. Note how appreciable thermal NO is formed in the frel rich part of the flame. Axial species profiles for the case with $250 \mathrm{ppm}$ (based on total bottom flow) NO added are shown on Figure 16. $\mathrm{HCN}$ and $\mathrm{NH}_{3}$ axial profiles are shown on Figure 17. It is noteworthy that appreciable quantities of NO are seen on the fuel rich side of the flame. This may be due to the fact that the fuel stream was heavily diluted with nitrogen, and may account for the very high destruction of $\mathrm{NO}$ entering the flame zone, that was observed. Although radial gradients had essentially disappeared at a distance of $16.5 \mathrm{~mm}$ from the bottom burner, their presence at lower axial positions may have influenced the axial profiles higher up.

\section{THEORETICAL MODEL}

The purpose of the theoretical modelling was to gain insight into the experimental results obtained, and to determine whether they could be modsled using a known kinetic mechanism.

\section{Kinetic Mechanism}

The reaction mechanism listed in Table $17^{2}$ involves 193 reactions and 40 chemical species. The first 50 reactions were taken from the existing reaction set for $\mathrm{CO} / \mathrm{H}_{2} / \mathrm{O}_{2} / \mathrm{He}$ flames (Corley, 1988) with Helium replaced by $\mathrm{N}_{2}$, the rate constants of which were taken from NIST (National Institute of Standards and Technology) Chemical Gas Kinetics Database (1989). The remaining reactions were selected from Glarborg, Miller and Kee's (GMK) mechanism developed for well-stirred reactors (1986), with the omission of reactions involving three reacting species, due to limitations in the current simulation code. This selection of combined mechanisms appeared to give superior flame stability to that using GMK mechanism alone. The subset used here contains only the first 151 reactions shown in Table 17, i.e., omitting the $\mathrm{C}_{2}$ chemistry. It was, however, confirmed that the exclusion of $\mathrm{C}_{2} \mathrm{X}$ reactions did not make a significant difference in this investigation.

\section{Thermochemical Data}

NASA polynomials (i.e. expressions consistent with the NASA chemical equilibrium program, and also with CHEMKIN) were adopted for the expressions of thermochemical properties, $C_{p}$ (heat capacity), $S$ (entropy) and $H$ (enthalpy). The coefficients of NASA polynomials are tabulated in Table 18 for each species. All the data have been updated to be consistent with the NASA polynomials of 1982 (Corley,1988). The data for HNO and-

\footnotetext{
${ }^{2}$ See Appendix
} 


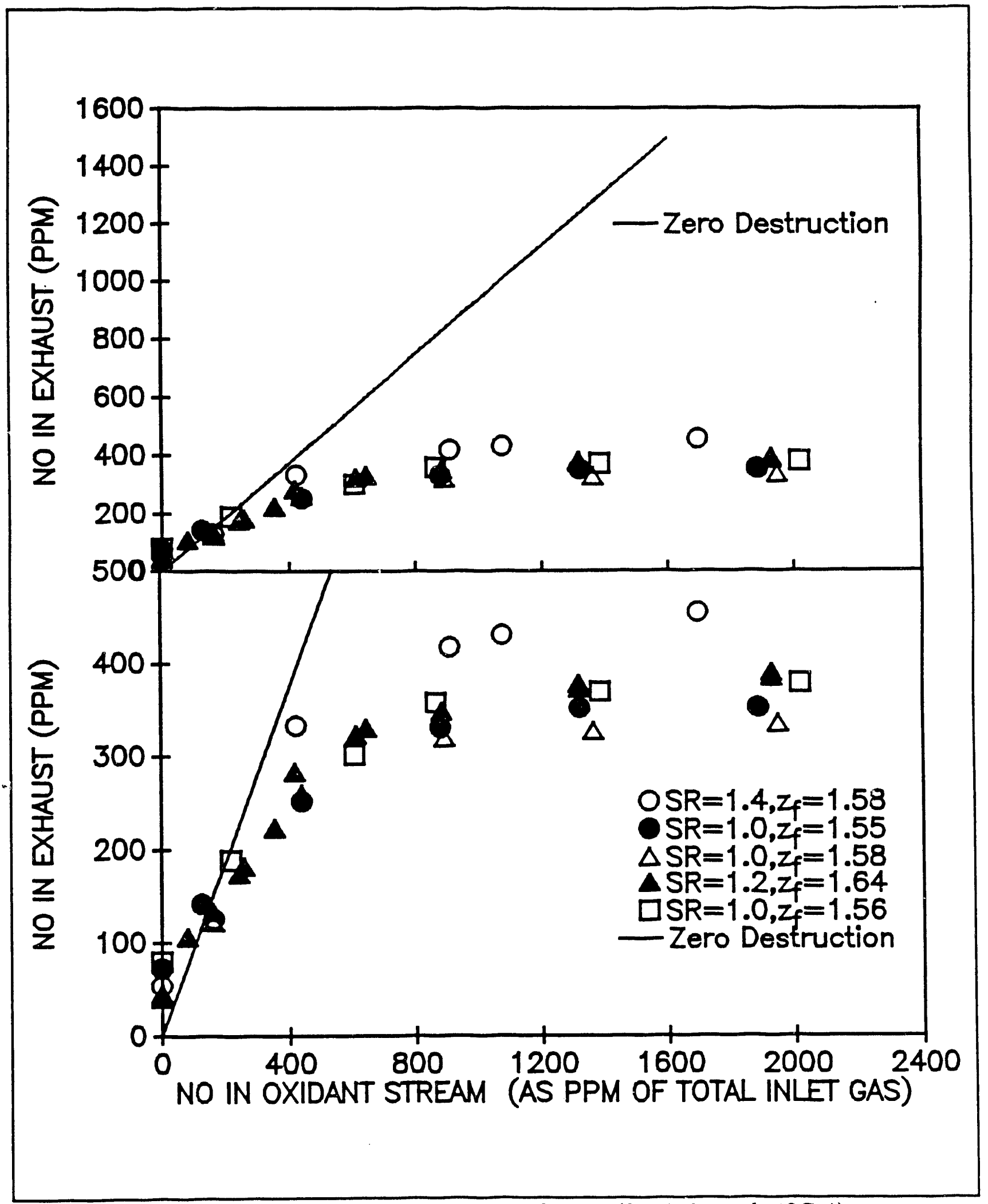

Figure 12: NO destruction in (overall) fuel lean flames (8C-4 through 12C-4). 


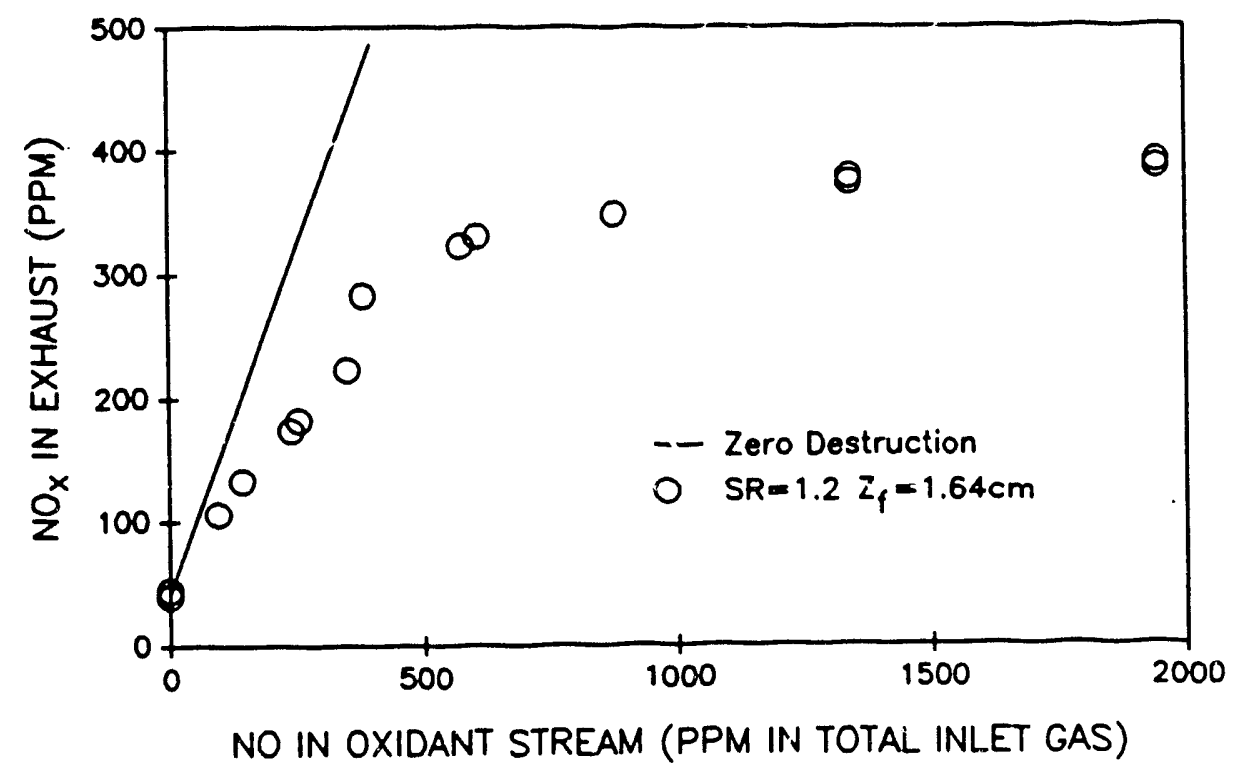

Figure 13: NO destruction in Flame 11C-4.

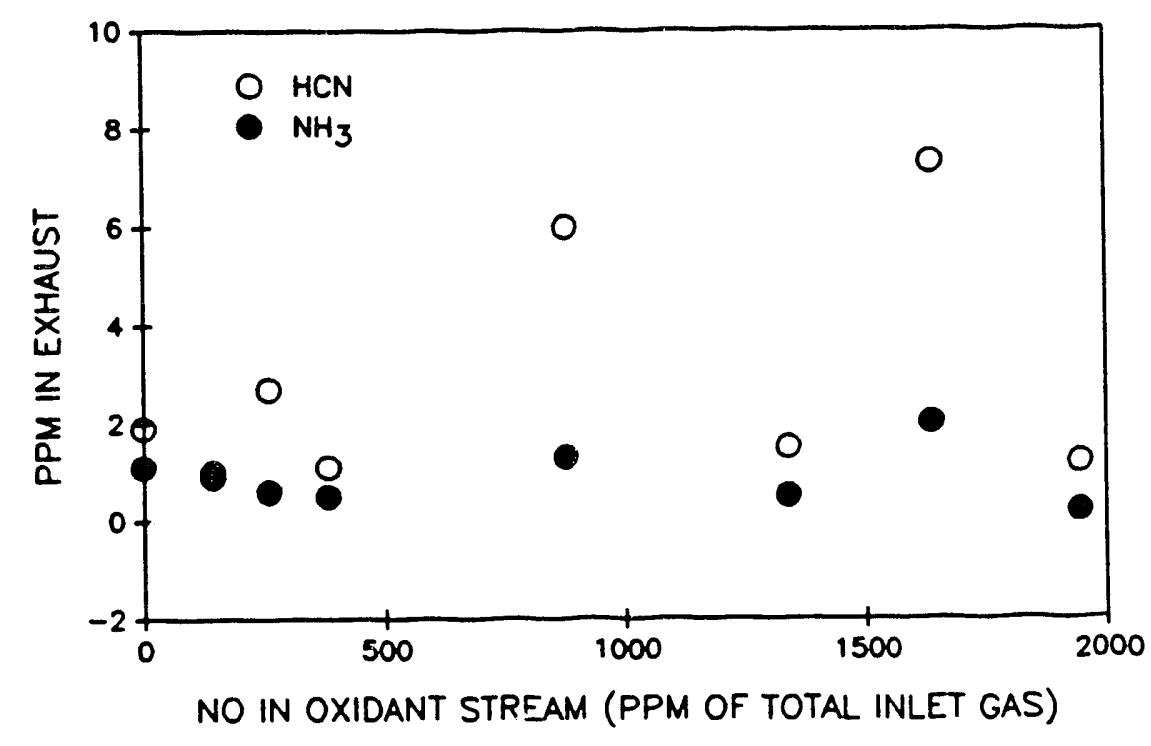

Figure 14: $\mathrm{H} \overline{\mathrm{CN}}$ and $\mathrm{NH}_{3}$ concentrations in exhaust (Flame 11C-4). 


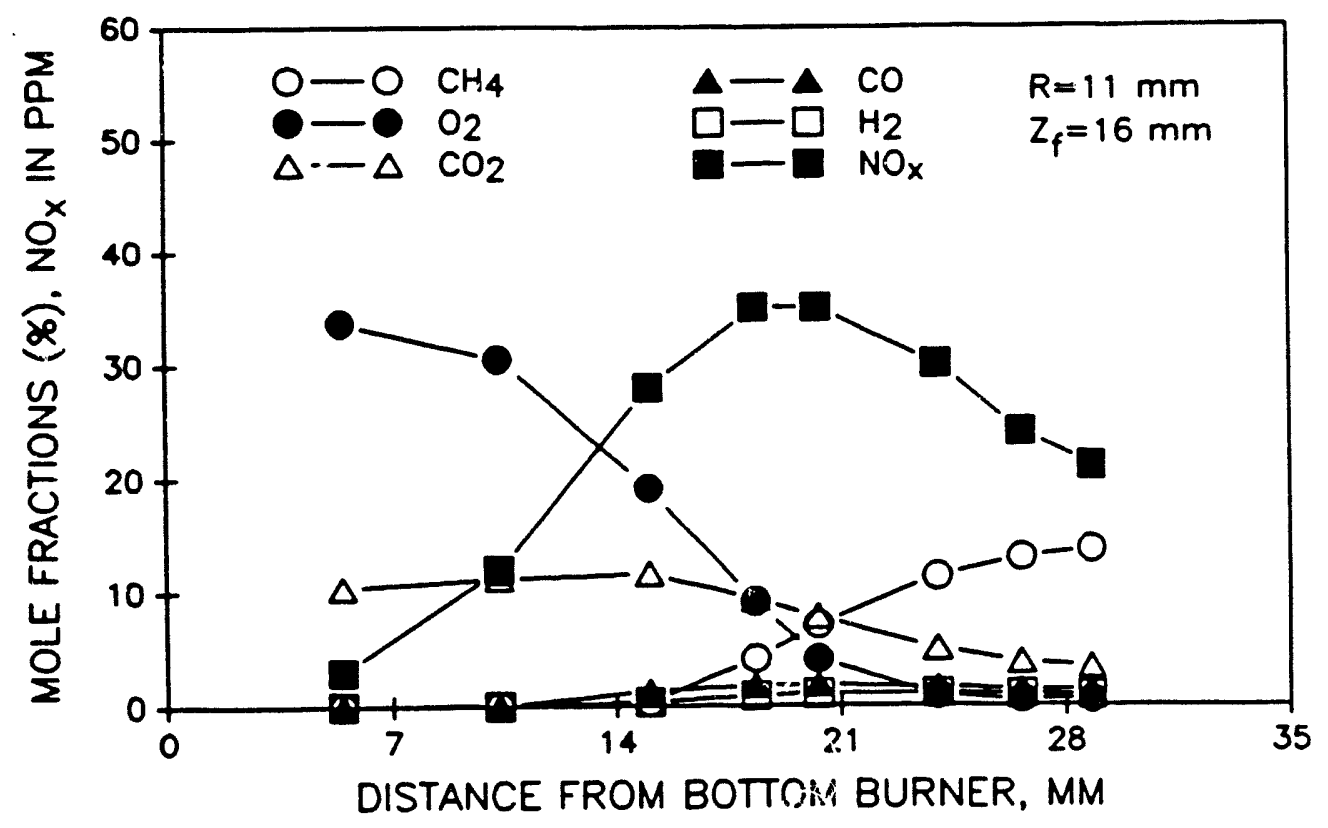

Figure 15: Axial species concentration profiles (Flame 11C-4 without NO added).

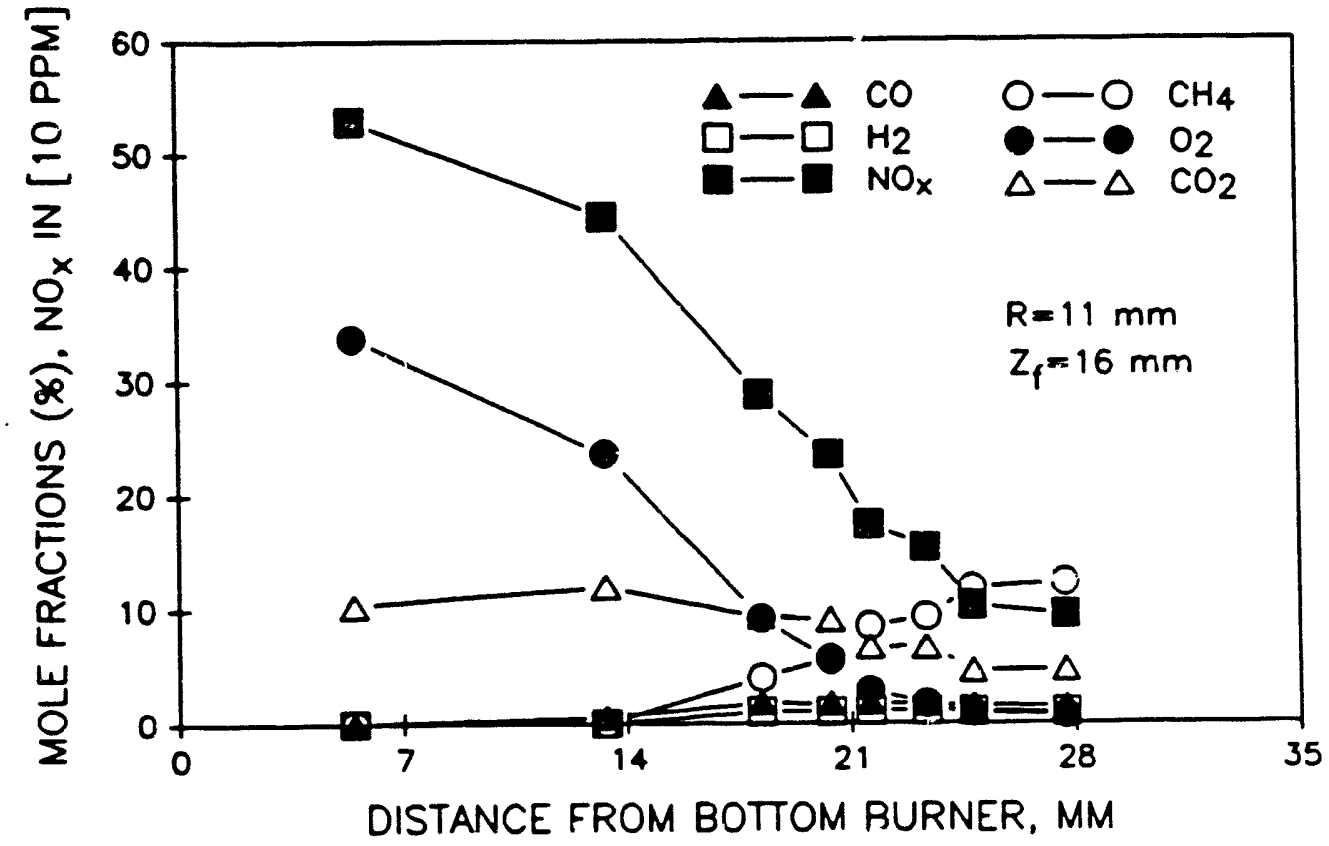

Figure 16: Axial species concentration profiles (Flame 11 C-4 with $250 \mathrm{ppm} \mathrm{NO}$ in oxidant). 


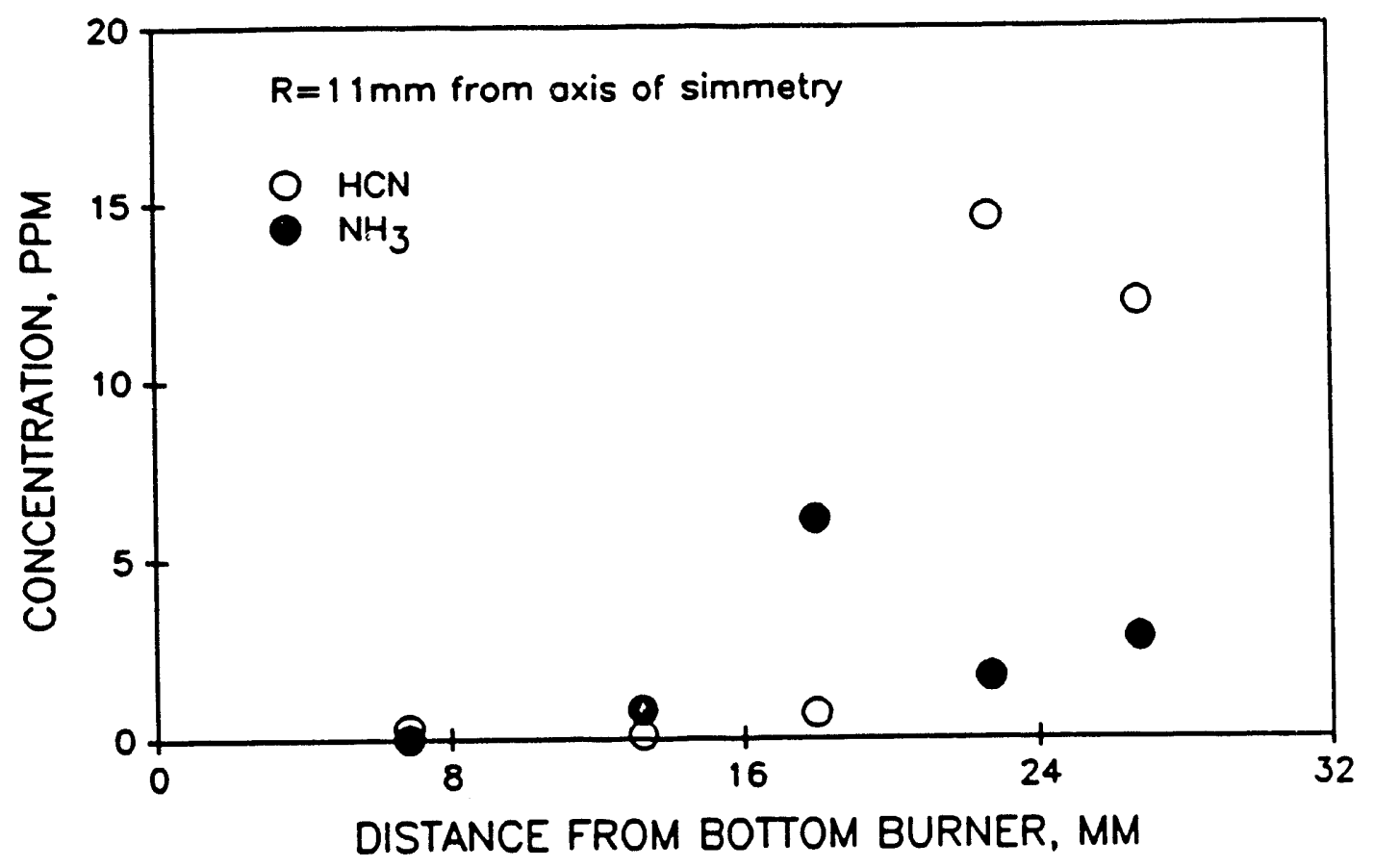

Figure 17: Axial concentration profiles of $\mathrm{HCN}$ and $\mathrm{NH}_{3}$ (Flame 11C-4).

$\mathrm{HO}_{2}$ were those updated by Corley (1988); those for $\mathrm{CH}_{3} \mathrm{O}$ and $\mathrm{CH}_{2} \mathrm{OH}$ were taken from Burcat and Kudchadker (1979). Data in Sandia Reports (SAND80-8003.UC4 \& SAND878215.UC4) were adopted for species $\mathrm{C}_{(\mathrm{s})}, \mathrm{C}, \mathrm{N}_{2} \mathrm{H}$ and $\mathrm{N}_{2} \mathrm{H}_{2}$. These data are necessary for evaluation of equilibrium constants, $\mathrm{K}_{\mathrm{p}, \mathrm{i}}$, which in turn determine the reverse rate constant $\left(k_{\mathrm{r}}\right)$ of each reaction with known forward rate constant $\left(\mathrm{k}_{\mathrm{f}}\right)$. Table $19^{2}$ lists the re:quired information for each species.

\section{Other Parameters}

In addition to the thermochemical data described above, the transport properties are necessary for the solution to the model. They were estimated using the correlations proposed by Reid and Sherwood (1958).

Diffusivities: In the combustion mixture pseudo binary diffusion has been assumed and the diffusivity of species $i$ in the mixture was calculated as:

where $D_{i j}$ was evaluated using the Chapman-Enskog relation:

where all symbols in Equation (29) have their usual connotations. 


$$
\begin{aligned}
& D_{i m}=\frac{1-y_{i}}{\sum_{j=1, j=i}^{N} \frac{y_{j}}{D_{i j}}} \quad i=1, \ldots ., N \\
& D_{i j}=\frac{0.001858 T^{3 / 2}\left[\frac{1}{M_{i}}+\frac{1}{M_{j}}\right]^{1 / 2}}{p \sigma_{i j}{ }^{2} \Omega_{D}}
\end{aligned}
$$

Viscosities: The viscosity of the combustion mixture was obtained as:

$$
\mu=\sum_{i=1}^{N} \frac{\mu_{i}}{1+\sum_{j=1, * i}^{n}\left(\frac{y_{j}}{y_{i}}\right) \phi_{i j}}
$$

where:

$$
\mu_{i}=2.6693 \times 10^{-5} \times \frac{\sqrt{M_{i} T}}{\sigma_{i}{ }^{2} Q_{\mu}}
$$

and:

$$
\phi_{i j}=\frac{\left[1+\left(\frac{\mu_{i}}{\mu_{j}}\right)^{1 / 2}\left(\frac{\mu_{j}}{M_{i}}\right)^{1 / 4}\right]^{2}}{2 \sqrt{2}\left[1+\frac{M_{i}}{M_{j}}\right]^{1 / 2}}
$$

Thermal conductivities: For the combustion mixture, the conductivity is approximated by:

$$
k=\sum_{i=1}^{N} \frac{k_{i}}{1+\sum_{j=1, v_{i}}^{N}\left(\frac{y_{j}}{y_{i}}\right) G_{i j}}
$$

where:

and: 


$$
\begin{aligned}
& k_{i}=1.9891 \times 10^{-4} \times \frac{\left(T / M_{i}\right)^{1 / 2}}{\sigma_{i}^{2} \Omega_{\mu}} \\
& G_{i j}=1.065 \frac{\left[1+\left(\frac{k_{i}}{k_{j}}\right)^{1 / 2}\left(\frac{M_{i}}{M_{j}}\right)^{1 / 4}\right]^{2}}{2 \sqrt{2}\left[1+\frac{M_{i}}{M_{j}}\right]^{1 / 2}}
\end{aligned}
$$

Estimates of the parameters of the 6-12 Lennard-Jones potential function for each species were facilitated by the Energy and Environmental Research Corporation Staff (1979) and Corley (1989). The data for species $\mathrm{C}_{2} \mathrm{H}, \mathrm{C}_{2} \mathrm{H}_{2}, \mathrm{C}_{2} \mathrm{H}_{3}, \mathrm{C}_{2} \mathrm{H}_{4}, \mathrm{C}_{2} \mathrm{H}_{5}, \mathrm{C}_{2} \mathrm{H}_{6}, \mathrm{~N}_{2} \mathrm{H}, \mathrm{N}_{2} \mathrm{H}_{2}$, $\mathrm{CH}_{2} \mathrm{CO}$, C, and $\mathrm{HNCO}$ were obtained from Sandia Report (SAND83-8209.UC-32). The parameters of transport properties are listed in Table 20.

\section{Implementation of Computer Code}

Figure 18 shows the various steps involved in solving the laminar opposed jet diffusion flame equations. Required first are the thermochemical and transport properties, the detailed reaction stoichiometry, the reaction rate coefficients, a starting initial guess for axial profiles, and a few other inputs. The thermochemical data were used to evaluate the values of $\mathrm{K}_{\mathrm{p}, \mathrm{i}}$ at different temperatures. Regression was then applied to obtain the coefficients $(\mathrm{A}, \mathrm{N}, \mathrm{E})$ of $\mathrm{K}_{\mathrm{p}, \mathrm{i}}$ as expressed in modified Arhenius form. The reaction set, with a known forward rate constant $\left(k_{f}\right)$ for each reaction, would then give the reverse rate constants $\left(\mathrm{k}_{\mathrm{r}}\right)$, through introduction of $\mathrm{K}_{\mathrm{p}, \mathrm{i}^{\circ}}$ Transport properties for all species were included in the main simulation code. The initial starting estimate of the solution (for axial profiles of temperature, species concentration, and axial velocity) was usually taken from the converged solution of a similar problem. The initial time step, burner spacing and eigenvalue $(Q)$ were then introduced, in order initiate the computation. A steady state solution is reached when, in the course of one iteration, with a significant time step, changes in all dependent variables are less than a set tolerance.

\section{THEORETICAL RESULTS}

\section{Stability Domains}

Strained diffusion flamelets are not stable under all conditions. Indeed, the experimental work quickly demonstrated that stable diffusion flames could only exist under 


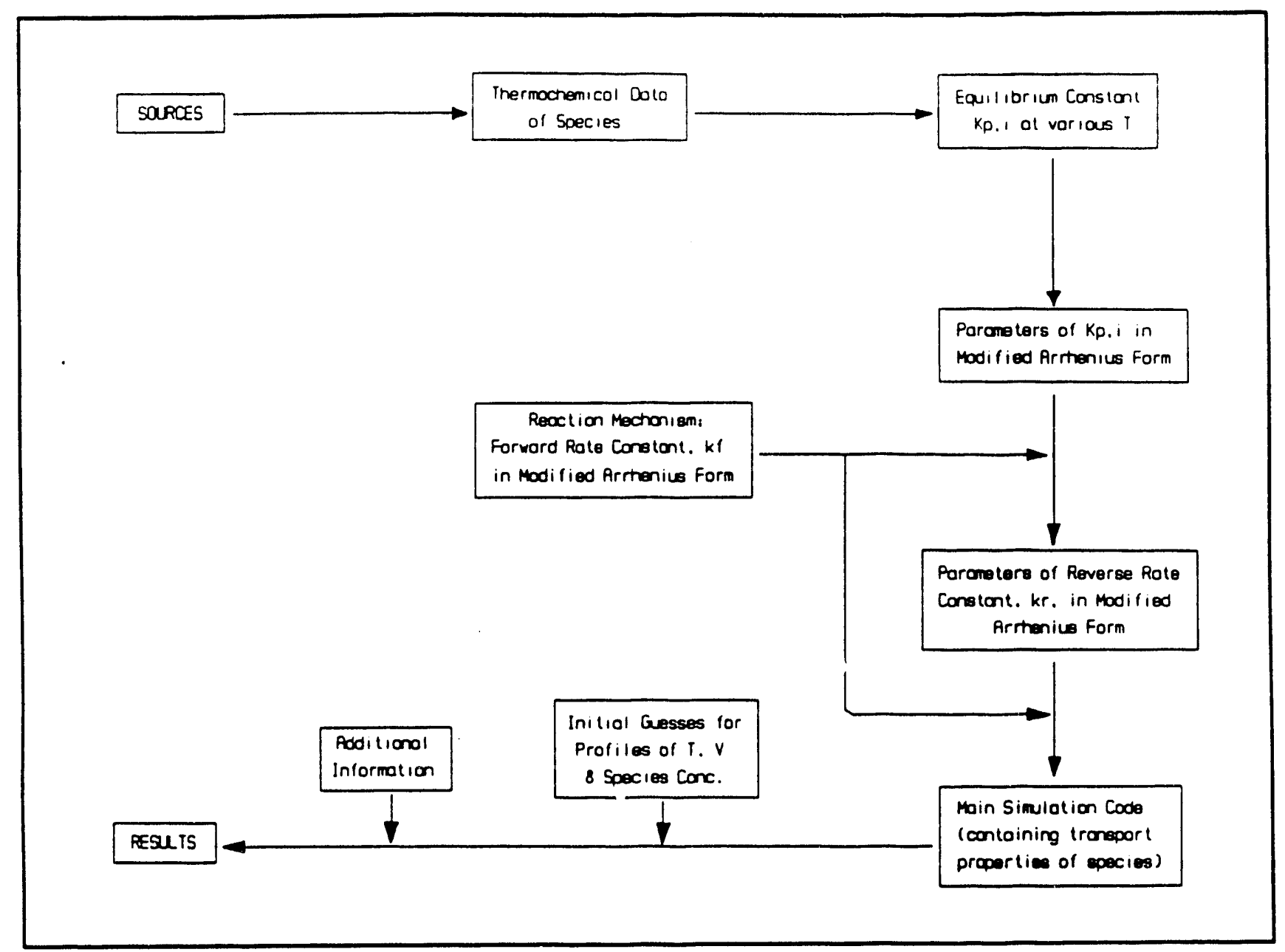

Figure 18: Implementation of laminar, opposed jet, computer code.

a restricted set of $\mathrm{P}_{\mathrm{O} 2}, \mathrm{~T}$ and strain rate conditions. Therefore, this problem was investigated theoretically. A reaction subset involving neither nitrogenous nor $\mathrm{C}_{2}$ - species was used in this investigation. In order to investigate blow off conditions, it was necessary to perform a very large number of numerical experiments. Results are shown in Figure 19. With same stretching rate, higher inlet temperature $\left(T_{0}\right)$ of flue gas provides higher stability. At lower oxidant temperatures $\left(T_{0}=298 \mathrm{~K}\right)$, flame stability is sensitive to flame stretching rate (determined by the eigenvalue, $Q$ ), while this trend becomes less obvious as $T_{0}$ increases to $1200 \mathrm{~K}$. Figure 20 shows that the peak flame temperature $\left(T_{\max }\right)$ increases as $T_{0}$ increases, and as stretching rate increases. Peak temperature must be minimized if thermal NO is to be avoided. Figure 21 shows the temperature profiles corresponding to the upper curve $\left(T_{0}=1200 \mathrm{~K}\right)$ in Figure 20. As is shown, steeper temperature gradients result at higher stretching rates. 


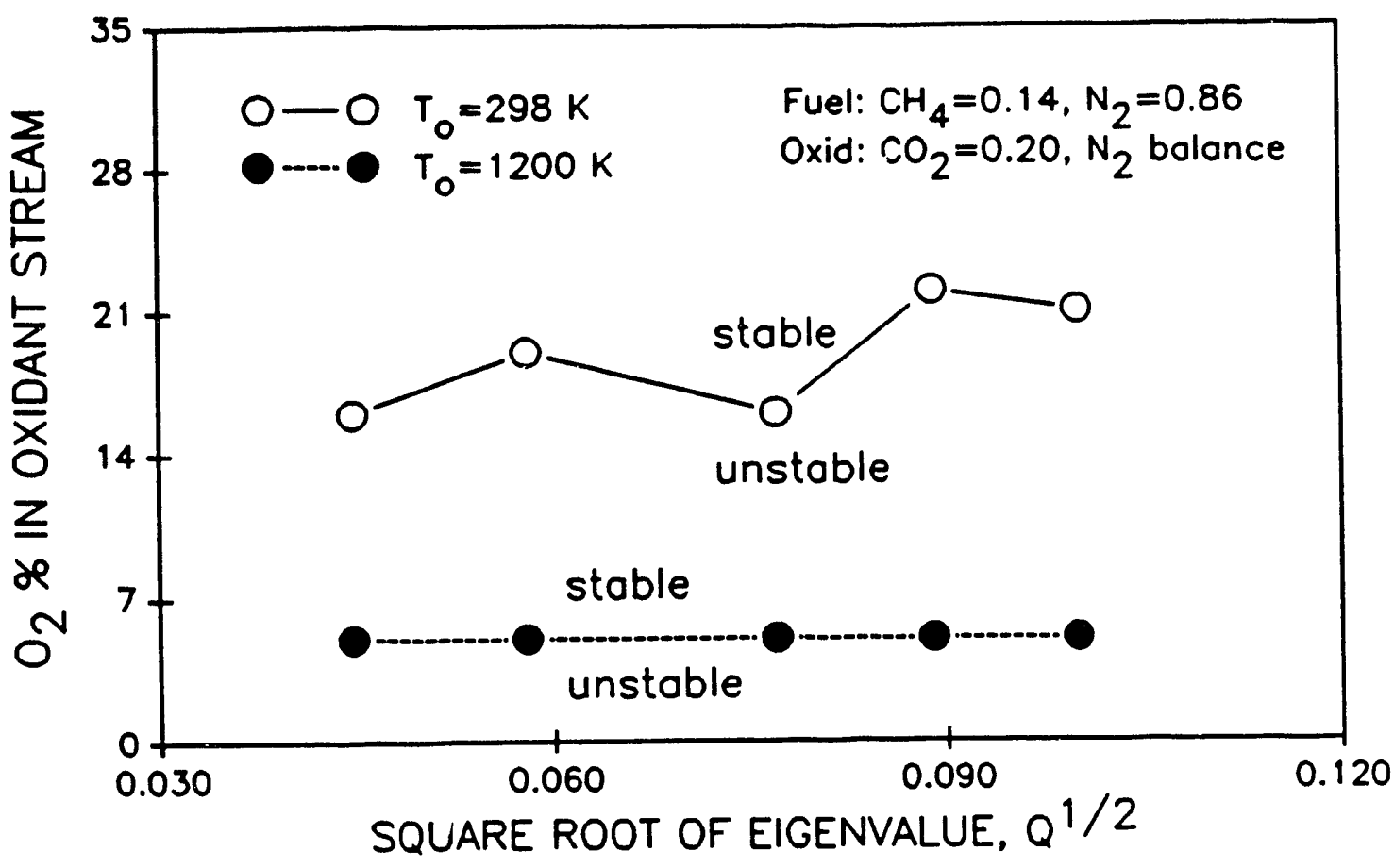

Figure 19: Stability domain of opposed jet diffusion flames as a function of $\mathrm{P}_{\mathrm{O} 2}$, oxidant temperature, and stretching rate, the latter given by the eigenvalue, $Q$ (see Equations 14 and 23 in text).

\section{Axial Profiles}

Flame 11C-4 was simulated using the computer code described above. Since the code solves the conservation equations for infinitely wide burners, it is difficult to compare the theoretical results to the integral input/output experiments described above. Rather, at this time, we present predicted axial profiles of temperature, velocities, and major and minor species. These predicted profiles allow comparison between theoretical predictions and data.

Figure 22 and 23 show predicted temperature and axial velocity profiles for Flame 11-C4. The predicted heat release profile is shown in Figure 24, while major species are shown in figure 25 . Figure 26,27 and 28 show axial profiles of nitrogenous species for zero NO, $250 \mathrm{ppm}$ NO and $1240 \mathrm{ppm}$ NO added (in oxidant stream) respectively. Figures 29, 30 and 31 depict comparisons between predictions and data for Flame 11C-4. There are severe discrepancies between predictions and data, due in part to non-uniformity in the radial profiles of NO, as shown in Figure 8. Other experimental errors relating to poor precision may also play a role in these preliminary, screening data. In the absence of more precise data, and a more precise experimental configuration, we feel that it may be 


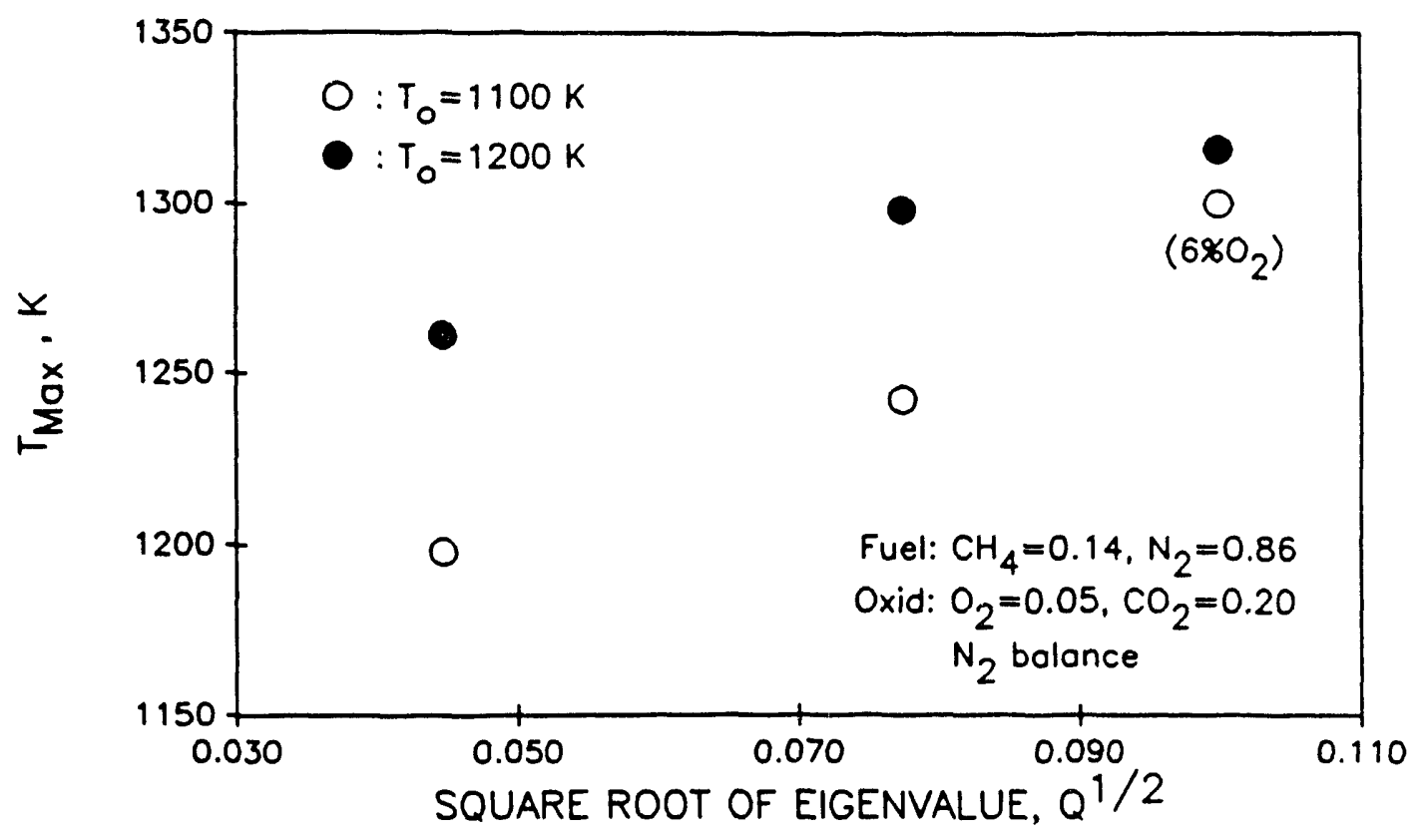

Figure 20: Predicted maximum temperatures of opposed jet flames, as a function of inlet oxidant temperature and stretching rate.

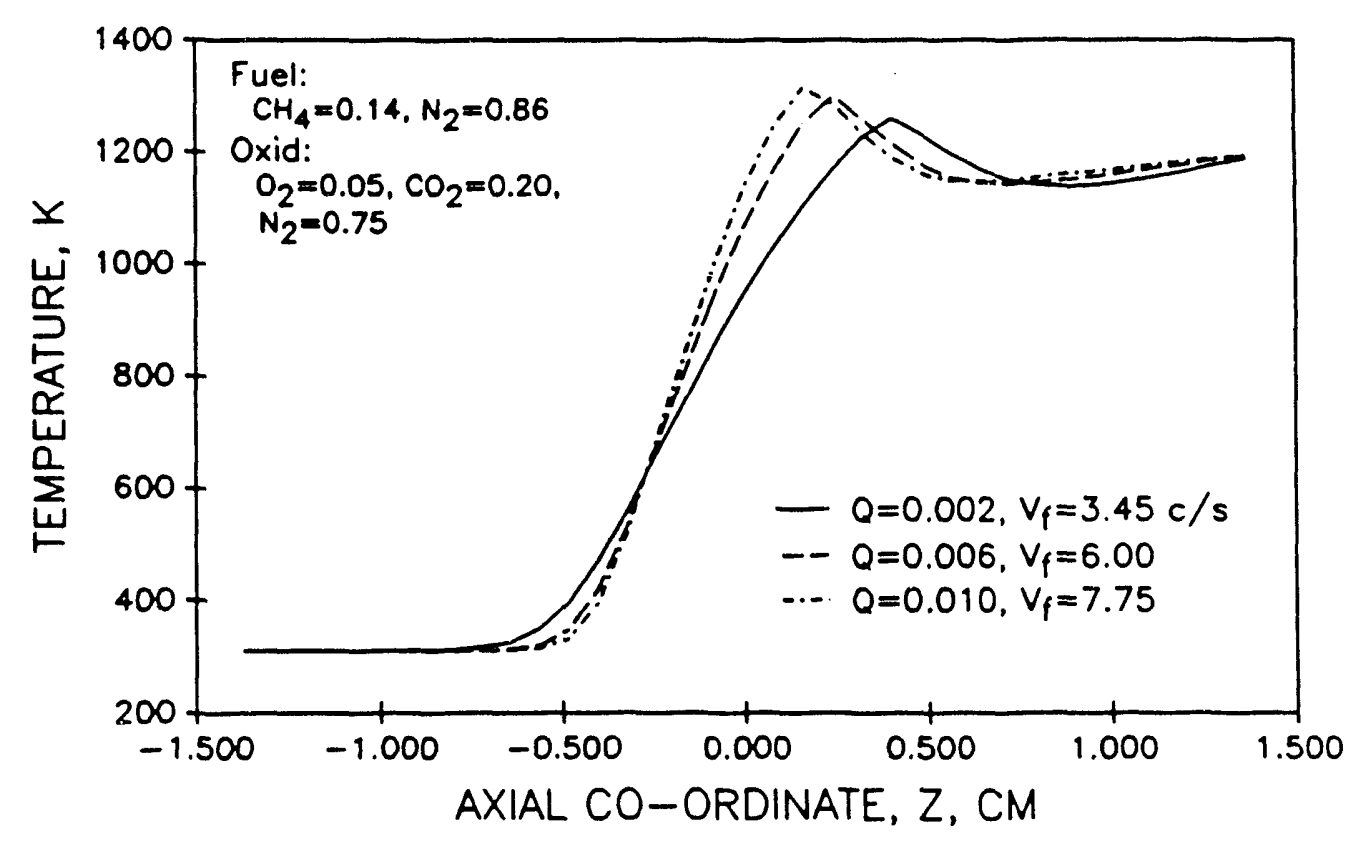

Figure 21: Predicted axial temperature profiles. 


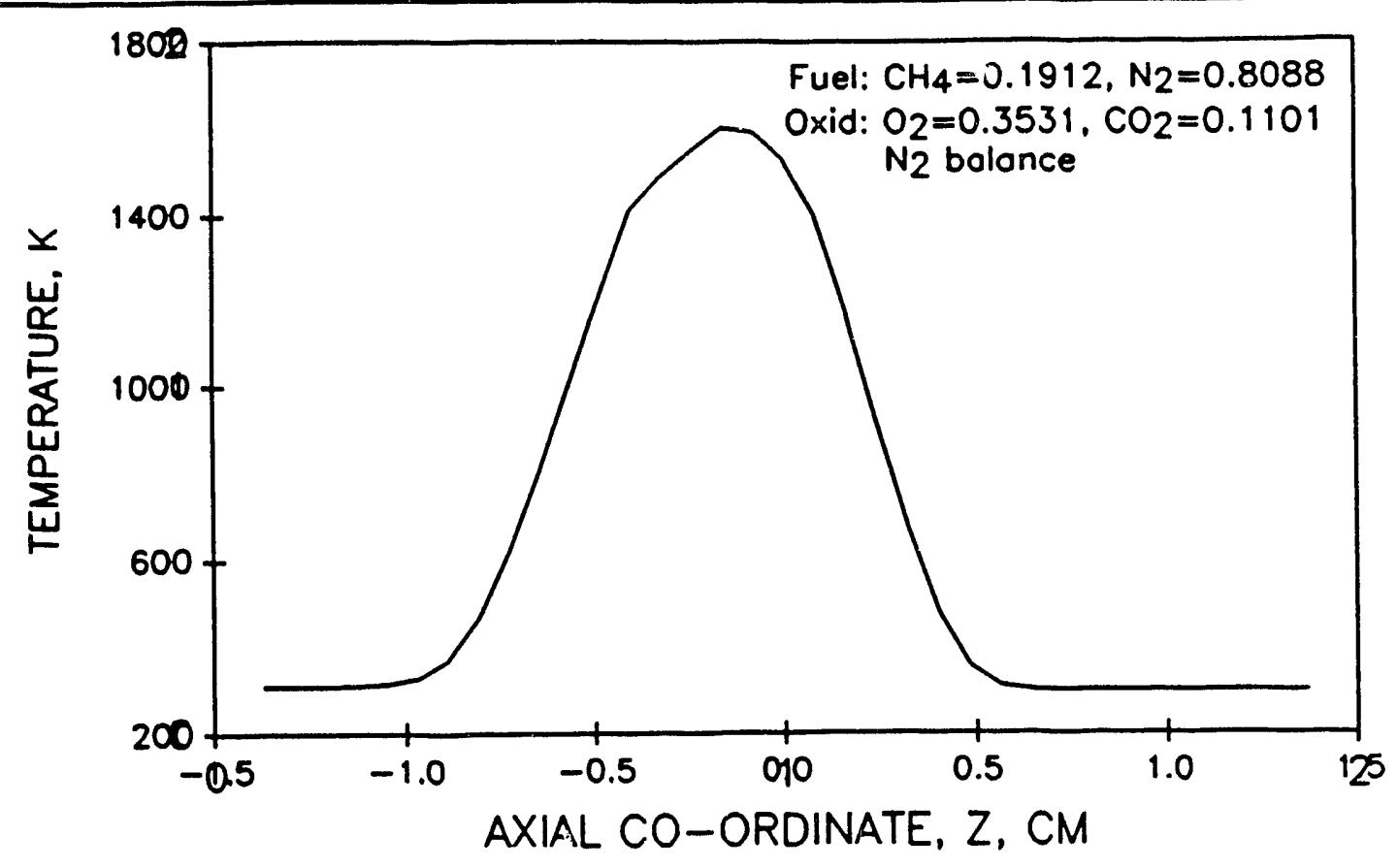

Figure 22: Predicted axial temperature profile for Flame 11C-4.

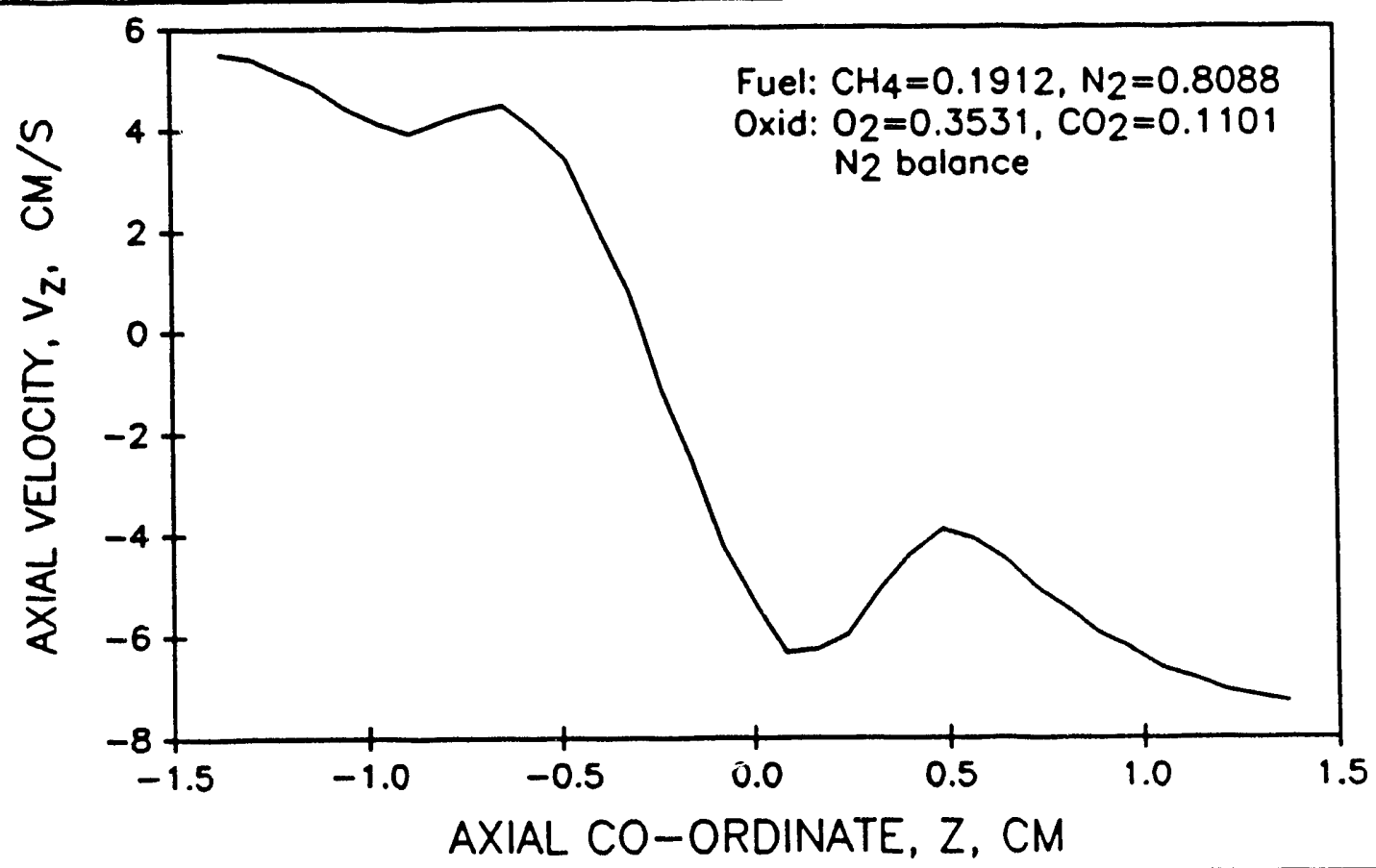

Figure 23: Predicted axial velocity profile for Flame 11C-4. 


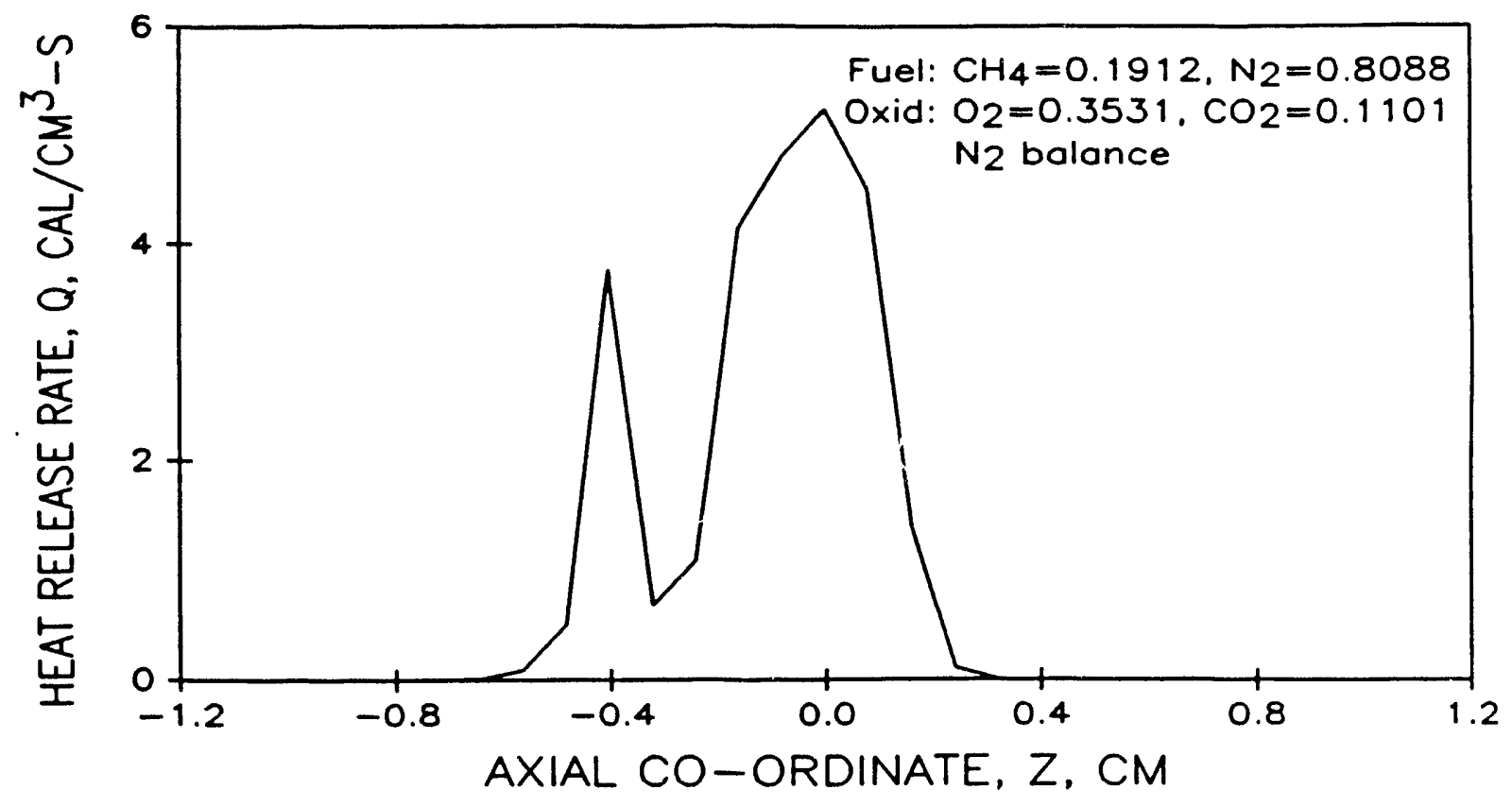

Figure 24: Predicted axial profile of the heat release rate, for Flame 11C-4.

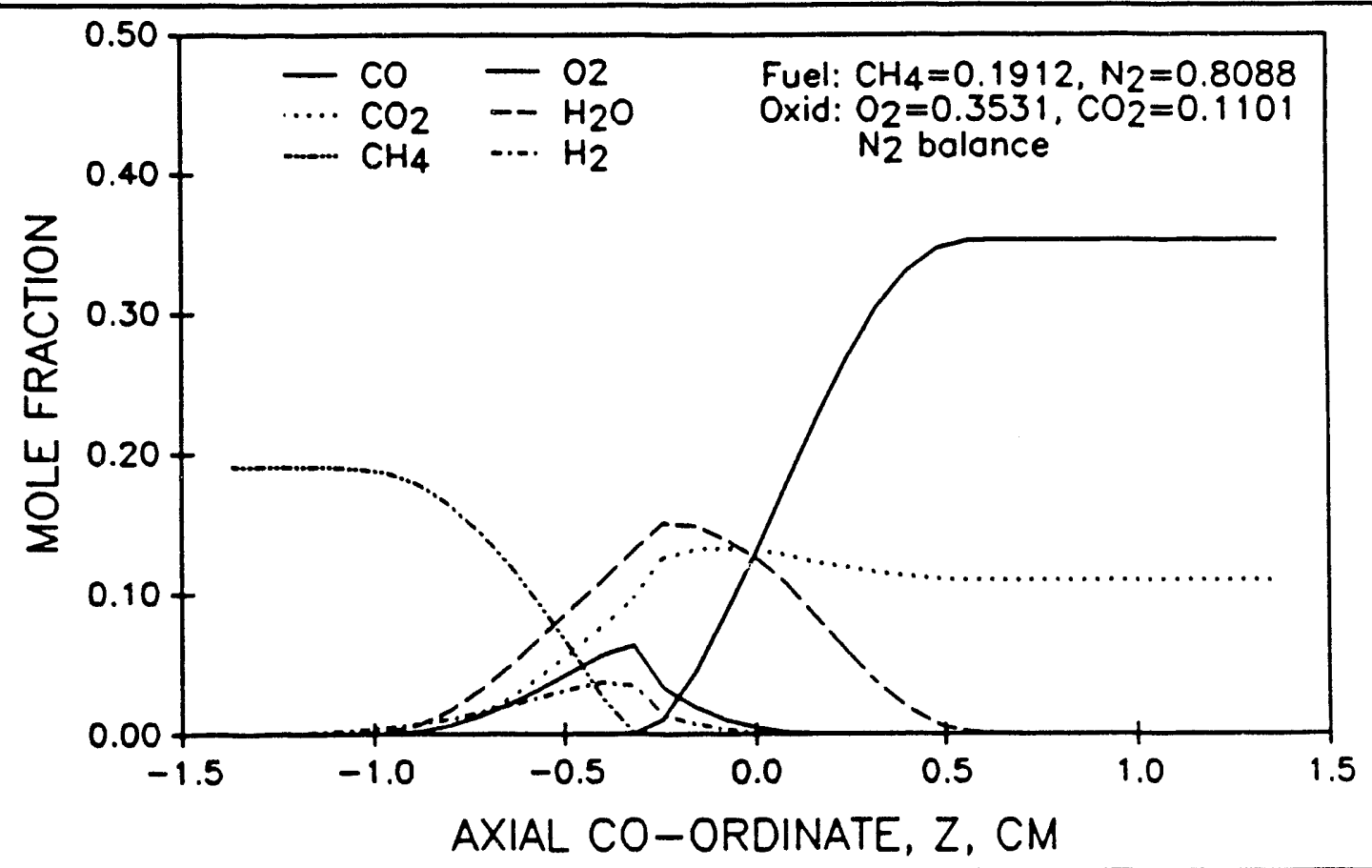

Figure 25: Predicted axial profiles of major species mole fractions. 


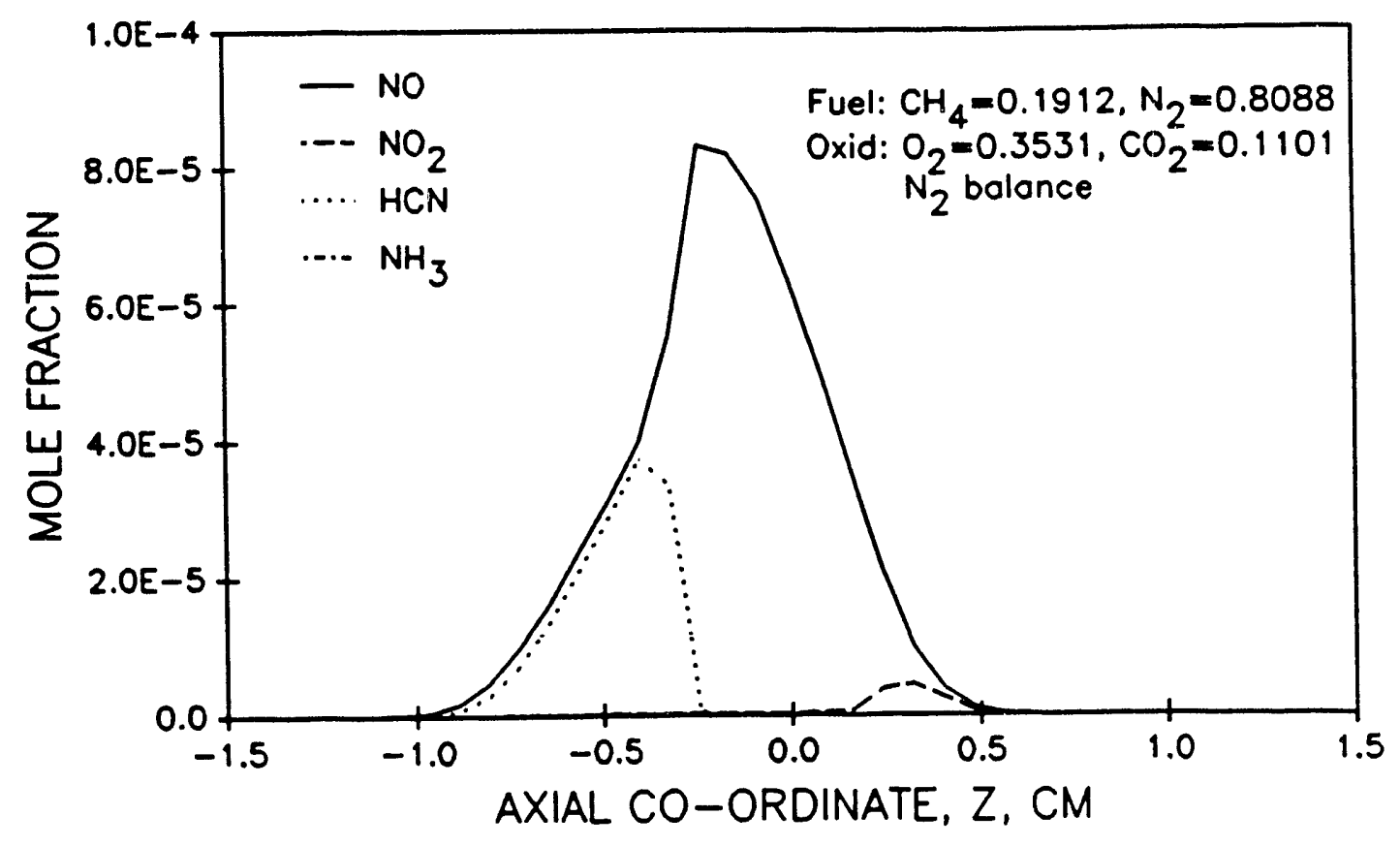

Figure 26: Predicted axial profiles of nitrogenous species- Flame 11C-4 without NO addition.

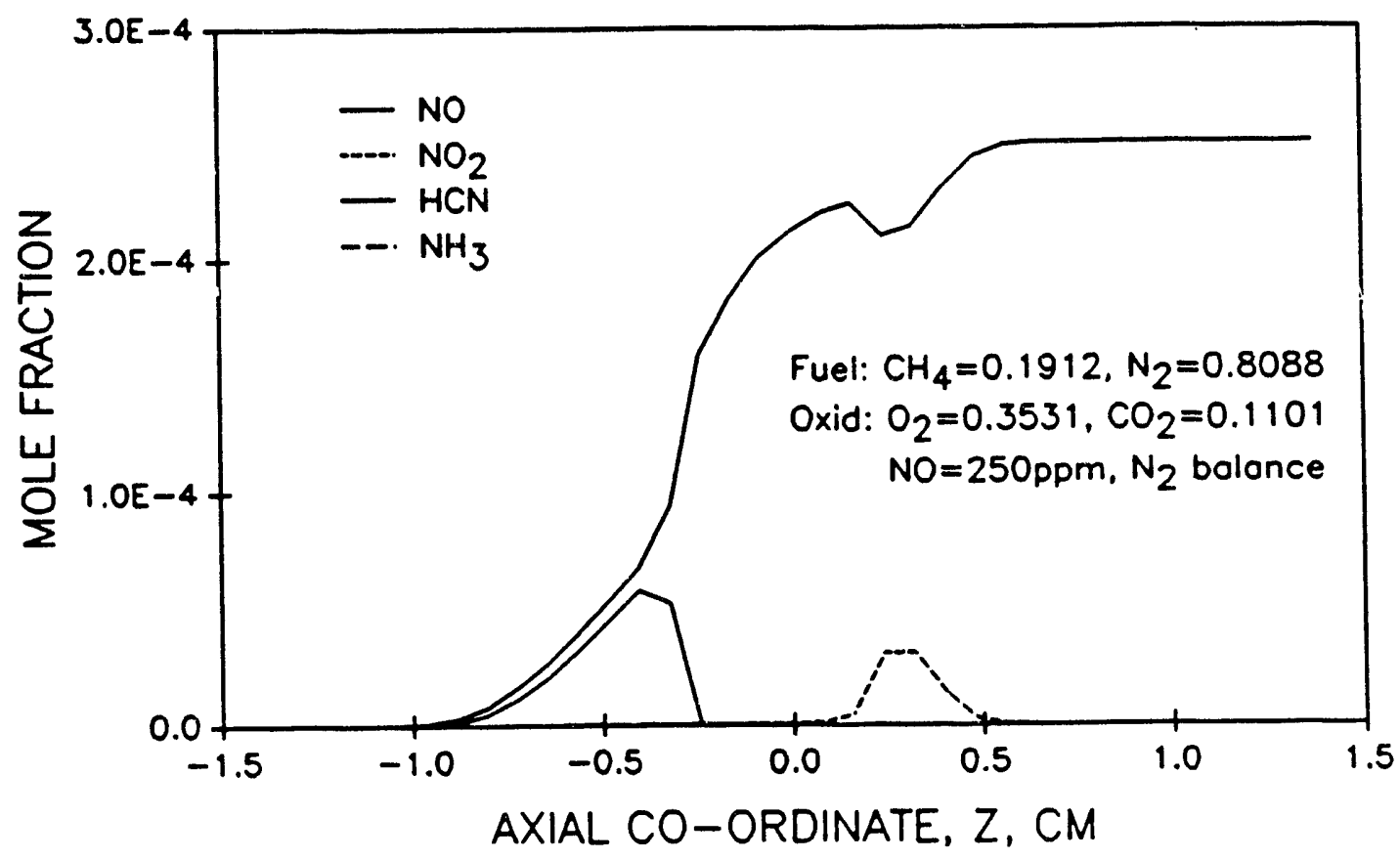

Figure 27: Predicted axial profiles of nitrogenous species -Flame 11C-4 with $250 \mathrm{ppm}$ NO added to oxidant. 


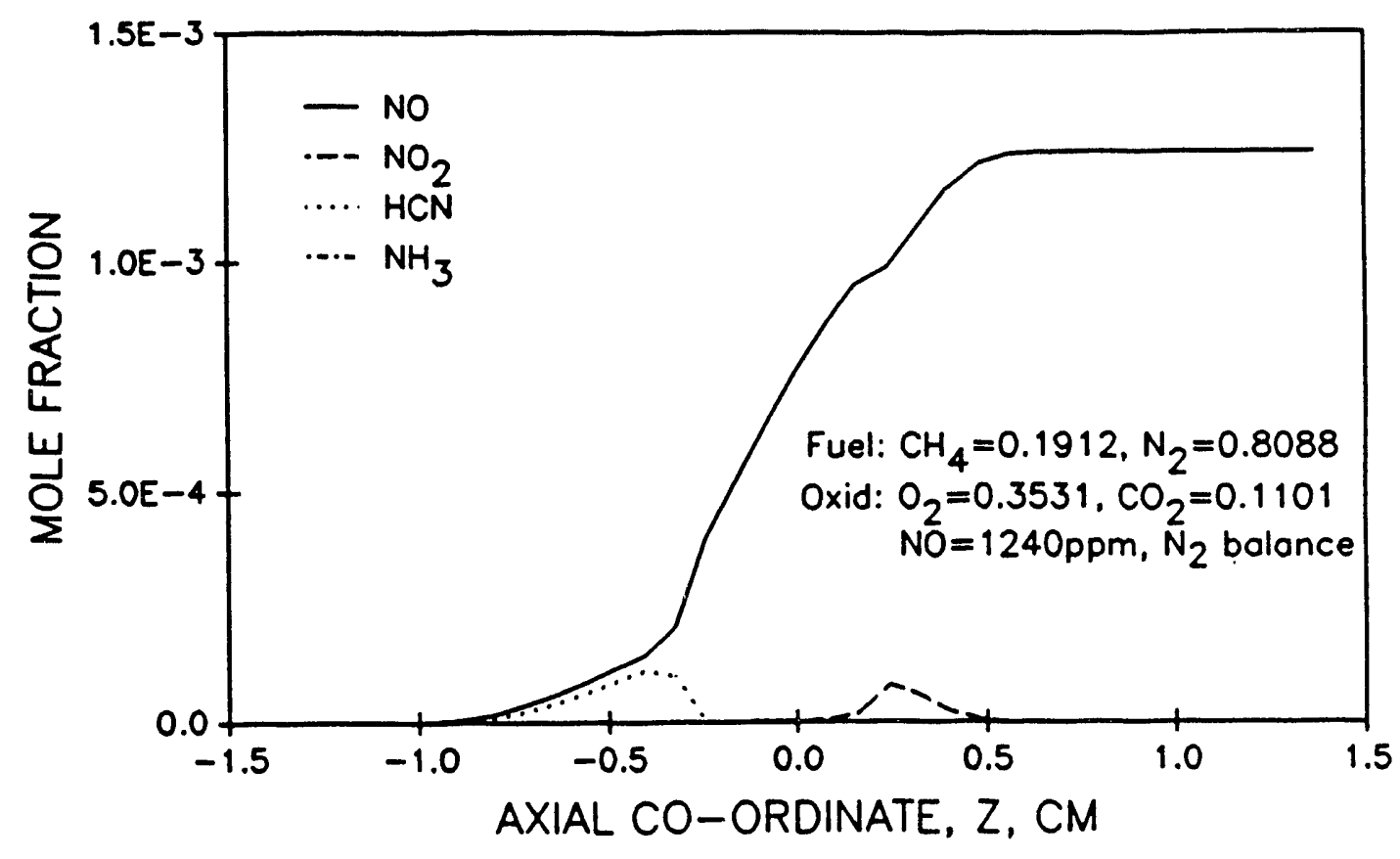

Figure 28: Predicted axial profiles of nitrogenous species- Flame 11C-4 with $1240 \mathrm{ppm}$ NO added to oxidant.

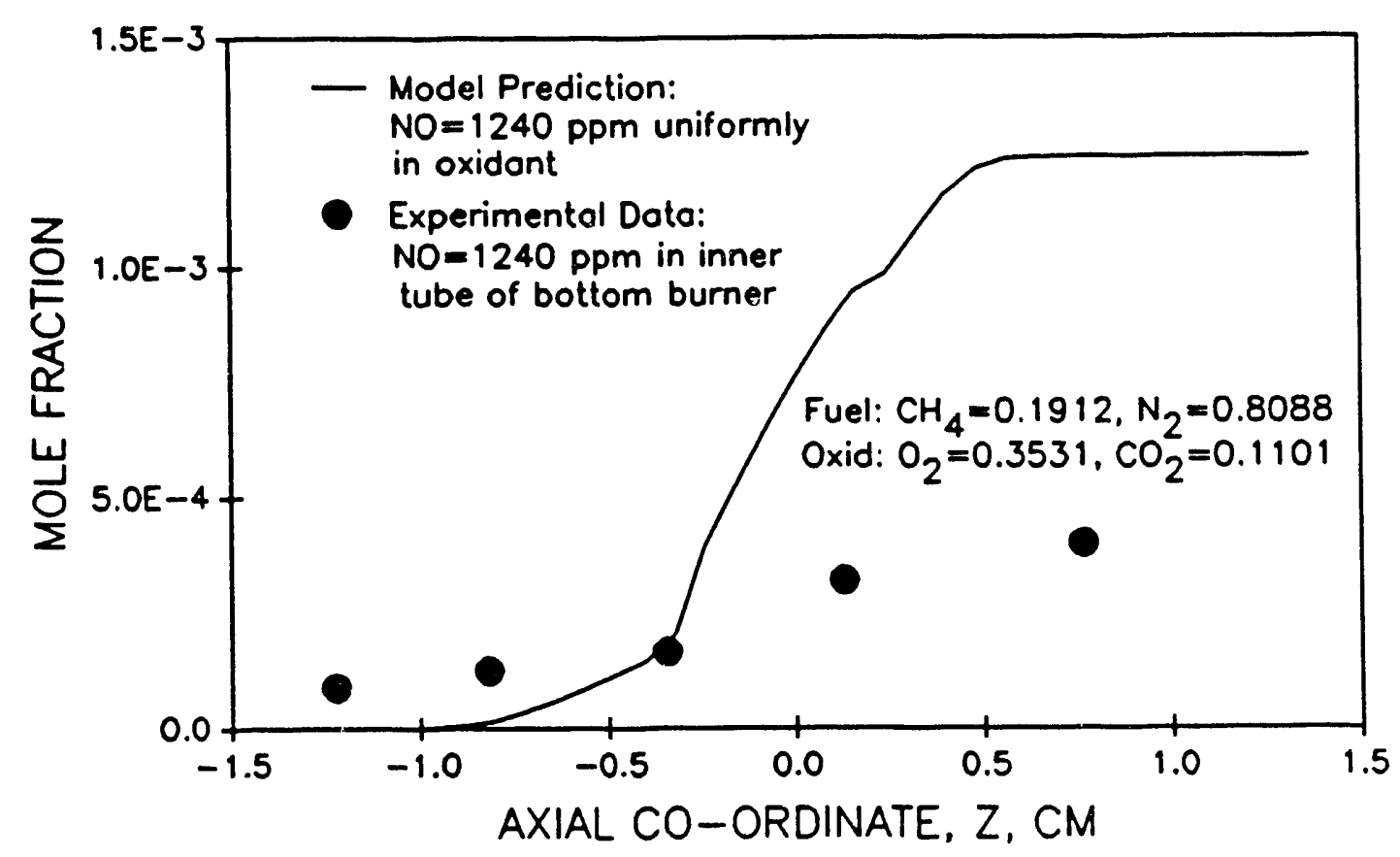

Figure 29: Predictions and data- NO concentration profiles in Flame 11C-4 


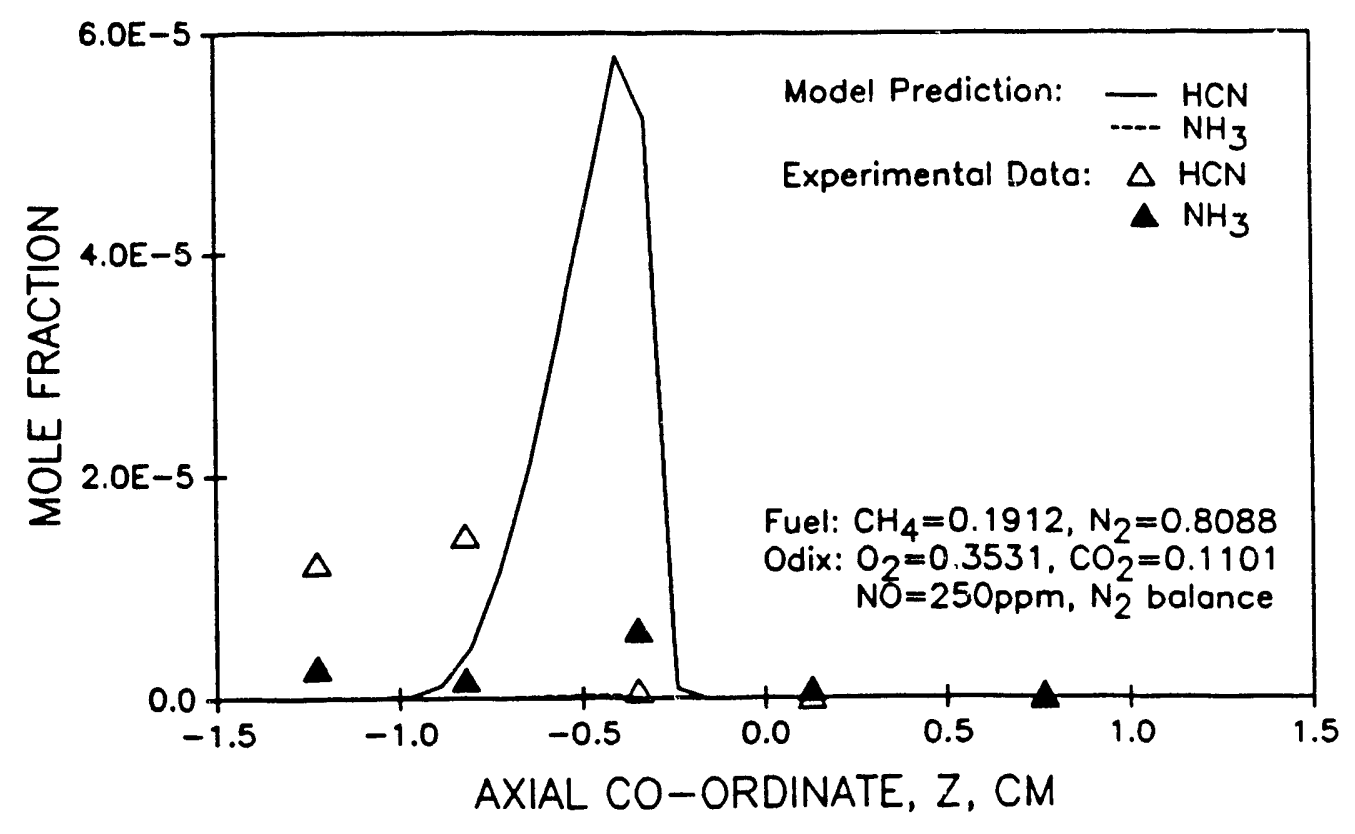

Figure 30: Predictions and data- $\mathrm{HCN}$ and $\mathrm{NH}_{3}$ profiles for Flame 11C-4.

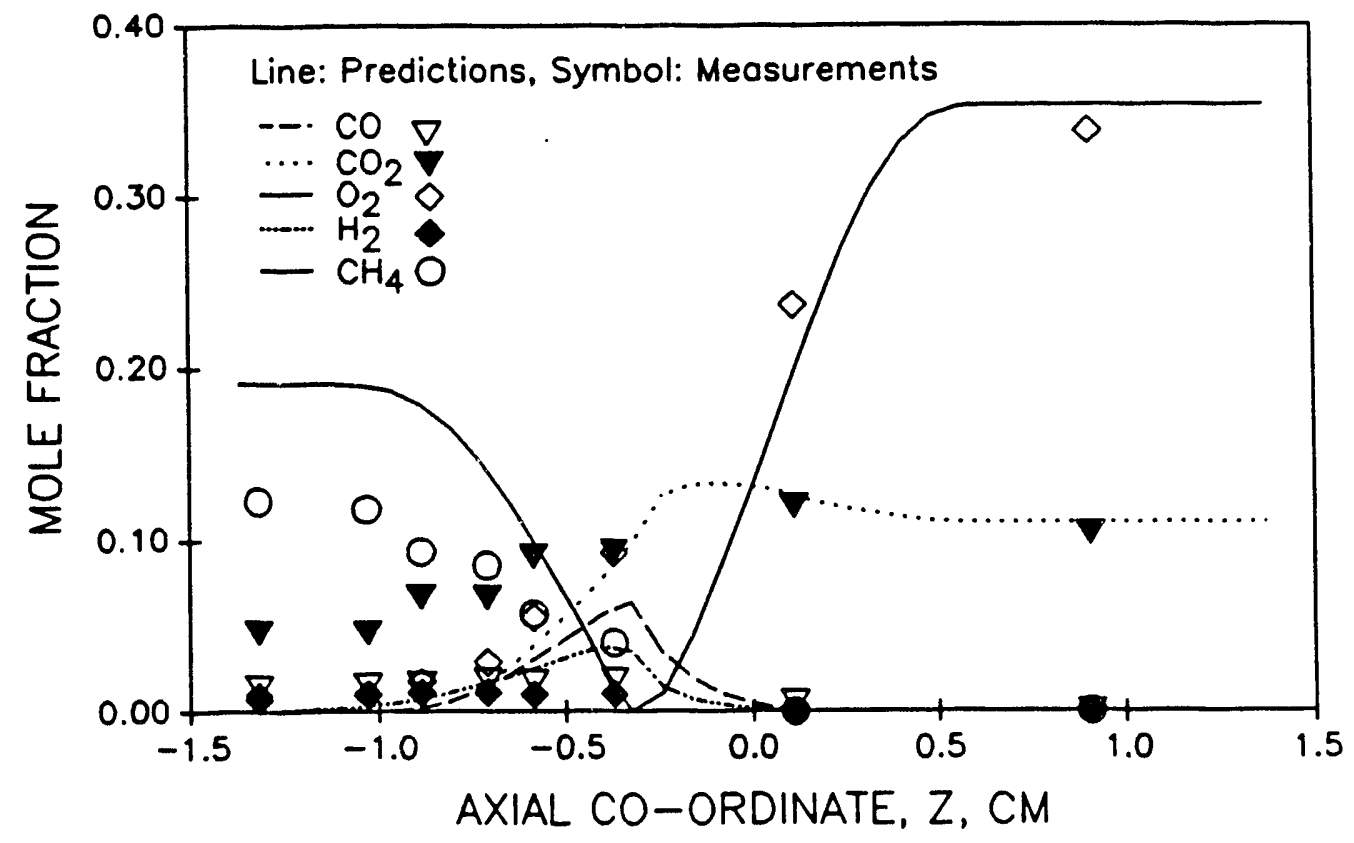

Figure 31: Predictions and data- major species profiles for Flame 11C-4. 
premature to put too much weight on discrepancies shown on Figures 29 through 30 . Future work will hopefully resolve them.

\section{CONCLUSIONS AND FUTURE WORK}

This research should be viewed as only a preliminary study to determine whether diffusion flame phenomena can be explnited to yield reburning efficiencies much greater than those obtainable in premixed systems. The experimental results are very encouraging. They show that in diffusion flames NO can be destroyed under overall very fuel lean conditions, and that destruction can be in excess of $95 \%$.

We do not yet understand the reasons behind the phenomena uncovered. Mathematical modelling is useful to allow us to refine kinetic sets by comparing predicted and measured axial profiles. Some refinement in both experimental technique and kinetic set development is still required, and should be the subject of future work.

The key issue now is how to apply these results to practical systems. Can a diffusion flame front be made to sweep through flue gases to destroy NO via mechanisms uncovered here? Can these data, showing very large NO destructions, be exploited and implemented in practical systems? We believe that future experimental and theoretical work should be oriented towards two issues:

1) what are the mechanisms by which NO is destroyed in such large amounts in laminar counterflow diffusion flames?

and

2) how can these mechanisms be exploited in practical systems, to allow greater reburning effectiveness under more benign furnace conditions?

\section{REFERENCES}

Bose, A.C. and Wendt, J.O.L., 22nd Symposium (International) on Combustion, p. 1127, The Combustion Institute, 1988.

Breen, B.P., J. Gabrielson and H. E. Lange. U. S. Patent Number 4,779,545 "Apparatus and Method of Reducing Nitrogen Oxide Emissions" Assignee: Consolidated Natural Gas (1988)

Chen, S.L., McCarthy, J.M., Clark, W.D., Heap, M.P., Seeker, W.R. and Pershing,D.W., 21st Symposium (International) on Combustion, p. 1159, The Combustion Institute, 1986.

Chigier, N.A. and A.J.Yule, "The Structure of Eddies in Turbulent Flames- $I$ " Project SQUID Technical Report US-1-PU, March, 1979 
Corley, T.L., and J.O.L. Wendt: "Computational Aspects of the Numerical Analysis of Laminar Opposed Jet Diffusion Flames", 1985 Fall Meeting, Western States Section/The Combustion Institute, Davis, CA, October 21-22, 1985.

Corley, T.L., and J.O.L. Wendt: "Analysis of Complex Thermal Reaction Pathways In Laminar Opposed Jet Diffusion Flames", Paper 10a, presented at 1984 Annual Meeting of the AIChE, San Francisco, CA, November 1987.

Dimotakis, P.E., R.C. Miake-Lye, and D.A. Papantoniou, Phys.Fluids, 26,3185-92, (1983)

Dimotakis P.E. and G.L.Brown, J. Fluid Mech. 78, 535-560 (1976)

Dixon Lewis, G. et al, 20th Symposium (International) in Combustion, pp1893-1904, The Combustion Institute, Pittsburgh, PA (1984)

Drake, M.C., 21st Symposium (International) on Combustion, p1579, The Combustion Institute, Pittsburgh, PA (1986)

Fenimore, C.P., 17 th Symposium (International) on Combustion, p. 661, The Combustion Institute, 1979.

Fenimore, C.P., 13th Symposium (International) on Combustion, p. 373, The Combustion Institute, 1973.

Glarborg, P., Miller, J.A. and Kee, R.J.: Comb. Flame, 65, 177:202, (1986).

Hahn, W.A. and J.O.L. Wendt, "Integration of the Stiff Boundary Valued ODE's for the Laminar Opposed Jet Diffusion Flame" in Stiff Computation ed. Aiken, Oxford University Press (1985)

Hahn, W.A. and J.O.L. Wendt, 18th Symposium (International) on Combustion, pp121-131 The Combustion Institute, Pittsburgh, PA (1981)

Haynes, B.S., Comb. Flame, 28, 113 (1977).

Haynes, B.S., Comb. Flame, 28, 81 (1977).

Kee, R.J., Rupley, F.M., and Miller, J.A., Sandia Report, SAND83-8209.UC-32, printed March, 1983.

Kee, R.J., Warnatz, J., and Miller, J.A., Sandia Report, SAND87-8215.UC-4, printed April, 1987. 
Kee, R.J., Miller, J.A., and Jefferson, T.H., Sandia Report, SAND80-8003.UC-4, reprinted July, 1987.

Marble, F.E., and J.E. Broadwell, "The Coherent Flame Model for Turbulent Chemical Reactions", Project SQUID Report (1977)

Mereb, J.B. and Wendt, J.O.L, Reburning Mechanisms in a Pulverized Coal Combustor", in press, 23rd Symposium (International) on Combustion, The Combustion Institute, Pittsburgh, $\mathrm{Pa}(1990)$

NIŚT Chemical Gas Kinetics Database, Standard Reference Database 17,National Institute of Standards and Technology, May, 1987.

Peters, N., 21st Symposium (International) on Combustion, p1231-1250, The Combustion Institute, Pittsburgh, PA (1986)

Reid, R.C., and Sherwood, T.K., The Properties of Gases and Liquids, McGraw and Hill, New York, 1958.

Roshko, A., in Turbulent Mixing in Non-Reactive and Reactive Flows, ed. S.N.B. Murthy, p 295,(1974)

Smooke, M.D., Puri, I.K, and Seshadri, K, 21st (International) on Combustion, pp178317£2, The Combustion Institute, Pittsburgh, PA (1986).

Smooke, M.D., Seshadri, K, and I.K. Puri, 22nd Symposium (International) on Combustion, pp1555-1563, The Combustion Institute, Pittsburgh, PA (1988)

Wendt, J.O.L, and Mereb, J.B. "Mechanismen der Nachverbrennung bei der Kohlersstaubverbrennung" Presented at VGB Congress "Kraftwerke 1990" Essen, W. Germany, 18-21 September 1990.

Wendt, J.O.L, Sternling, C.V. and Matovich, M.A.: 14th Symposium (International) on Combustion, p. 897, The Combustion Institute, 1973. 


\section{APPENDICES AND TABLES}

Experimental Data, Tables 1 through 16.

Detailed Reaction Kinetic Mecłanism, Table 17.

Thermochemical Data, Table 18

Equilibrium Constants, Table 19

Transport Parameters, Table 20 


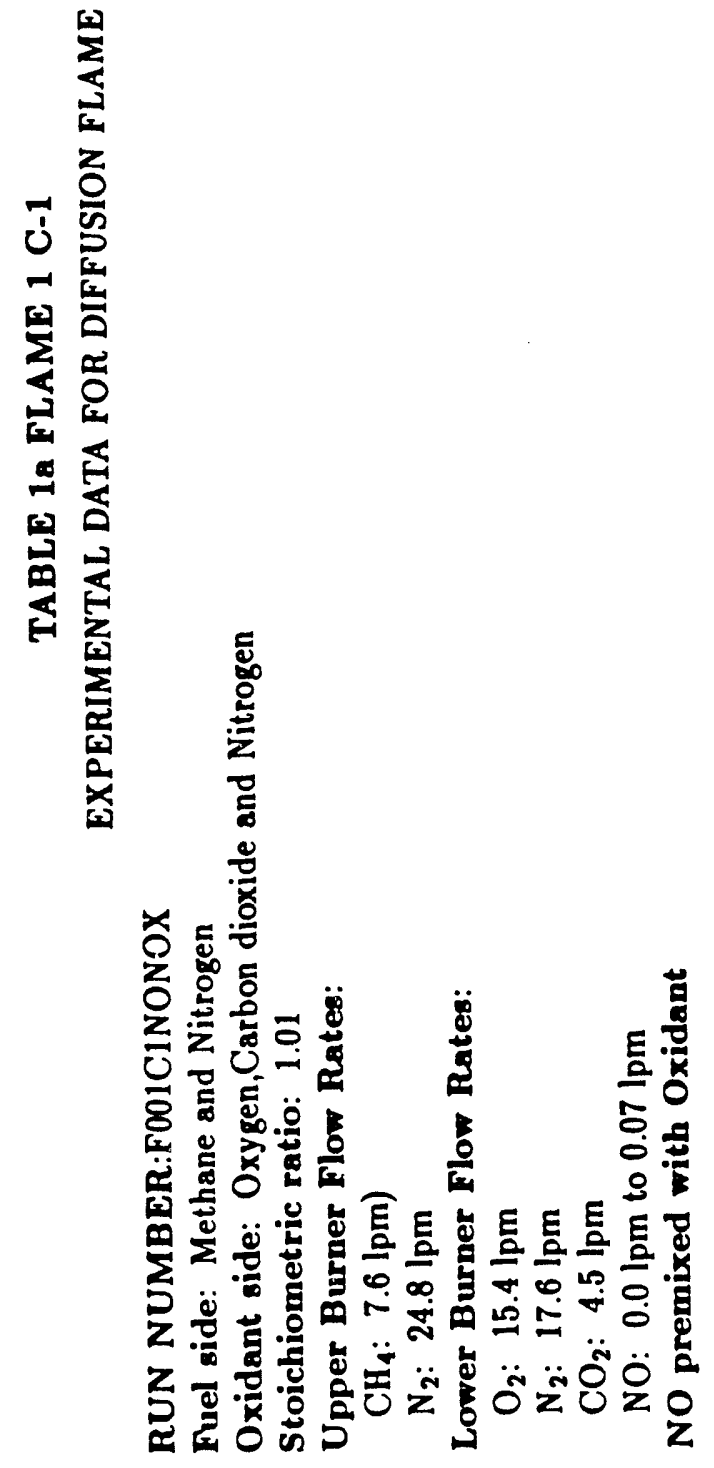

\begin{tabular}{|c|c|c|}
\hline & 尝高 & ส \\
\hline & $\delta \Phi$ & 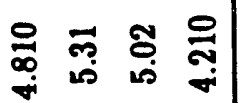 \\
\hline 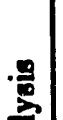 & $8 \Phi$ & 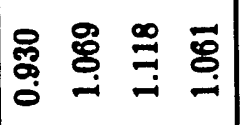 \\
\hline & 要 & 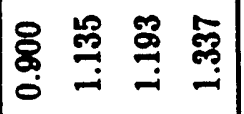 \\
\hline & स्से & 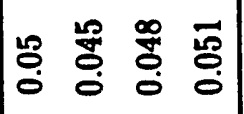 \\
\hline & : & 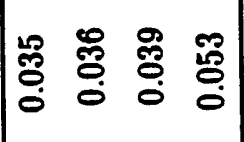 \\
\hline & : & 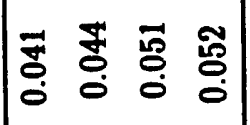 \\
\hline & 8 & 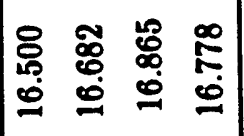 \\
\hline & $\approx$ & 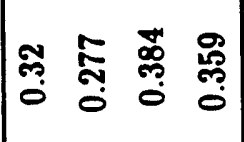 \\
\hline & 层高 & , 용 용 \\
\hline 8 & 80 & 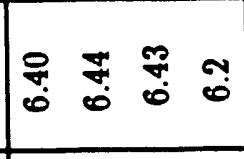 \\
\hline 这 & 08 & 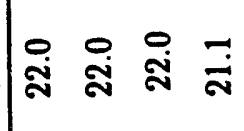 \\
\hline & 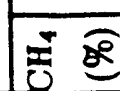 & 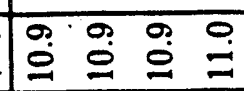 \\
\hline
\end{tabular}




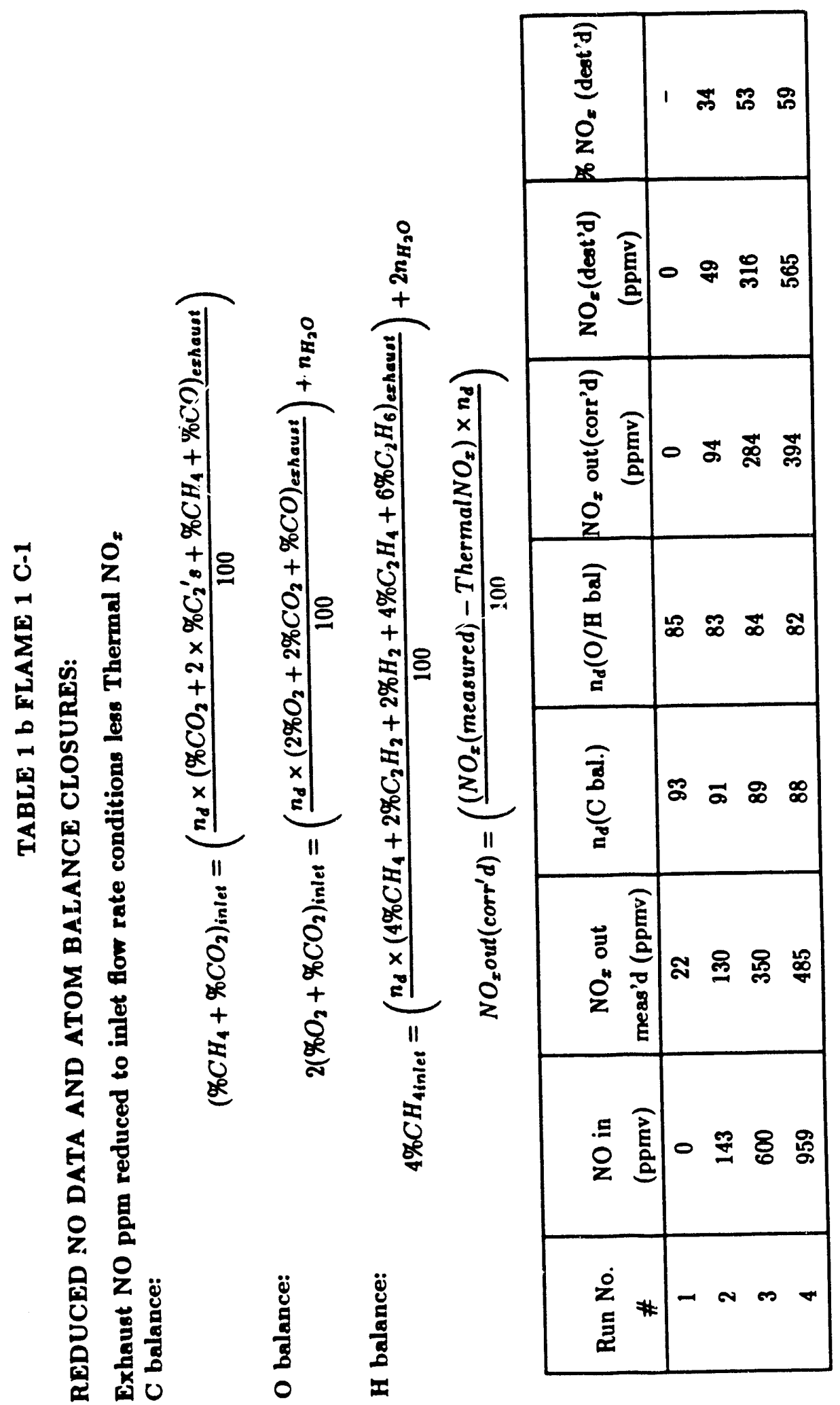




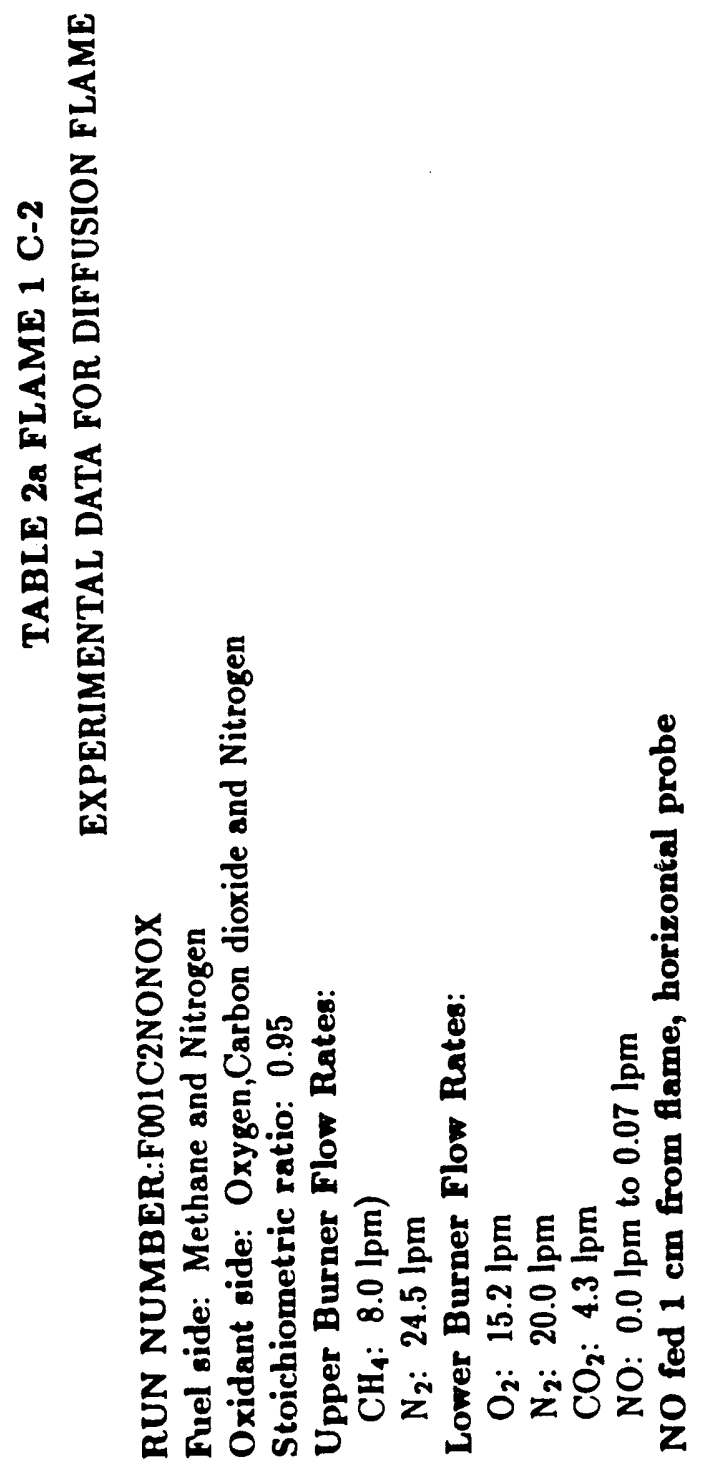

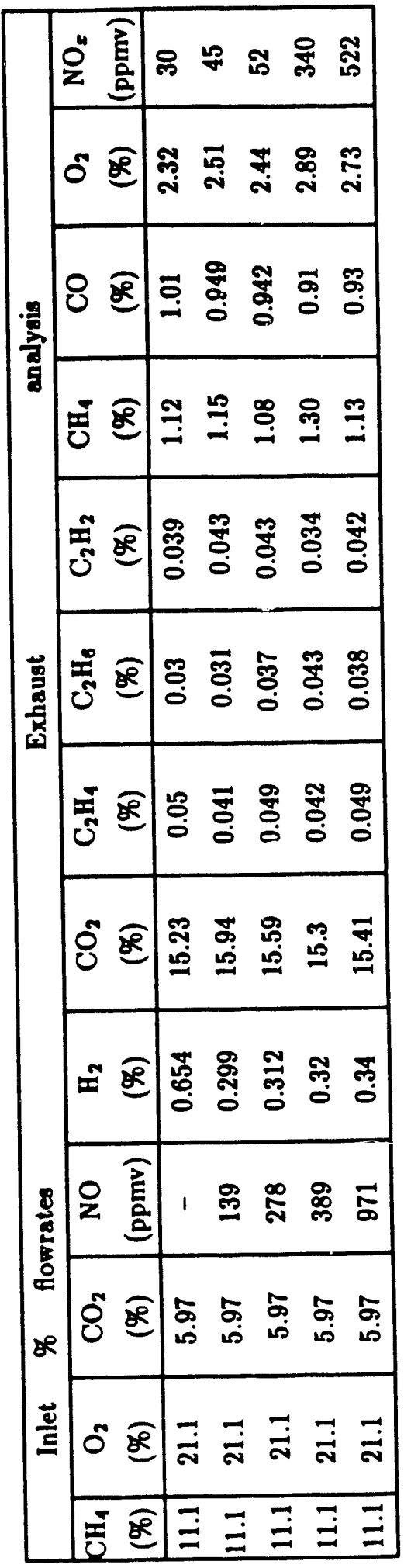




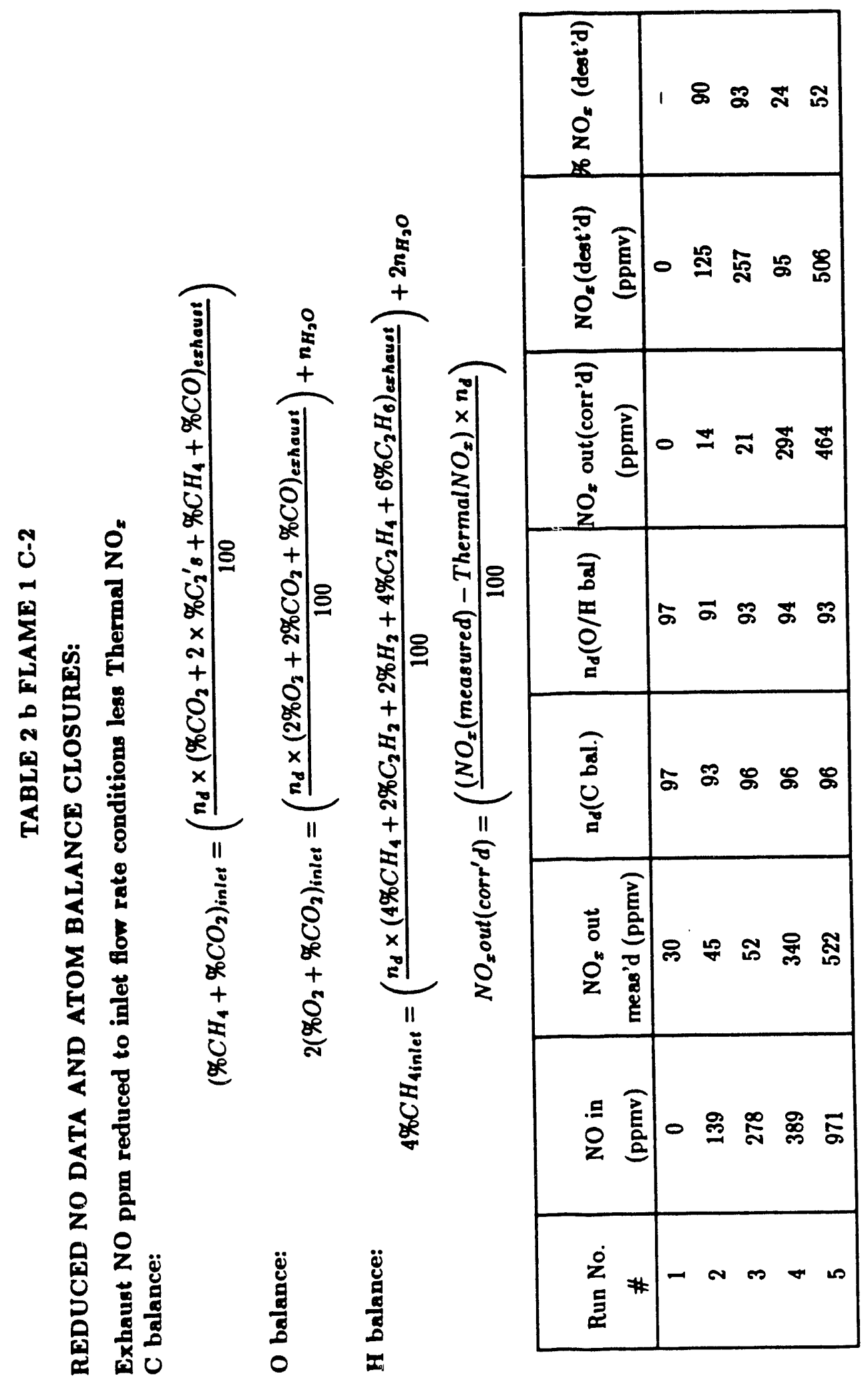




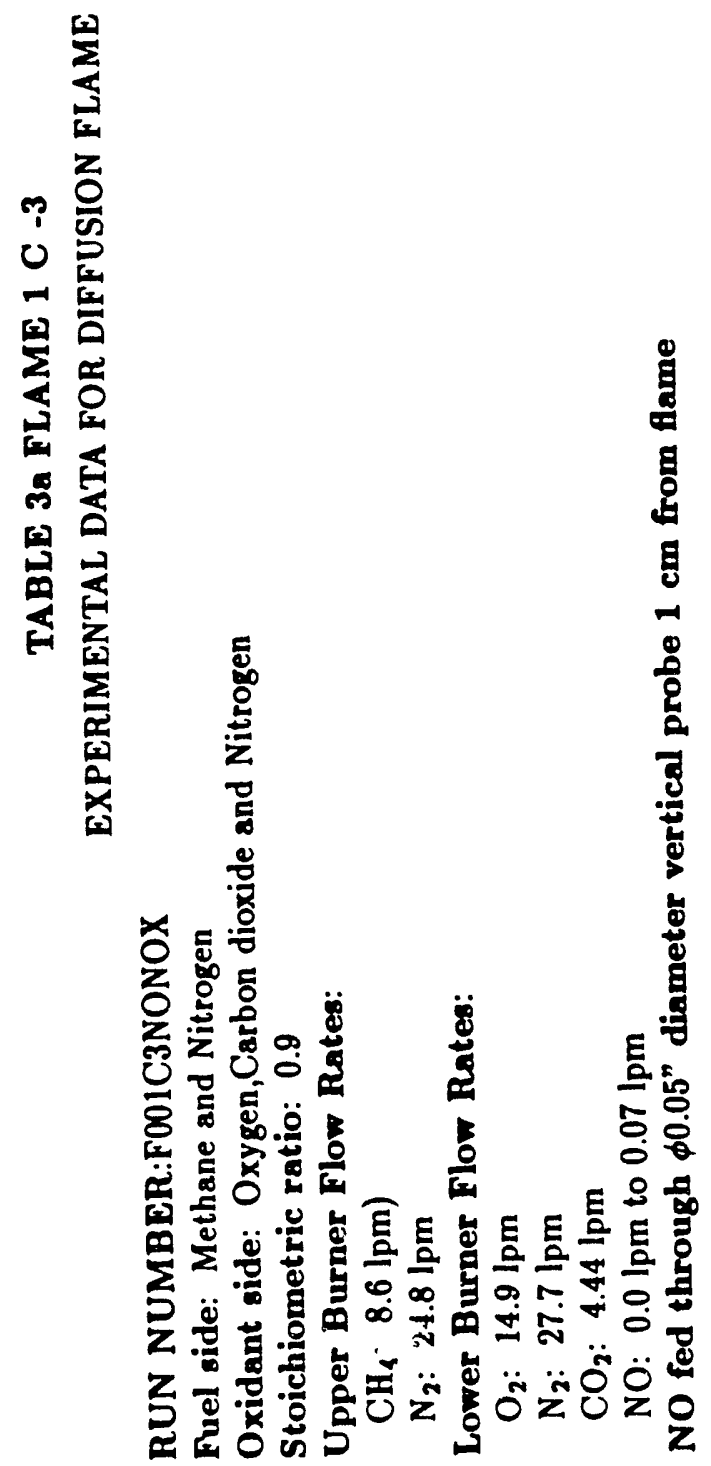

\begin{tabular}{|c|c|c|}
\hline & 尝产 & ส \\
\hline & 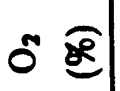 & డ్ల \\
\hline & $8 \longdiv { \Xi }$ & 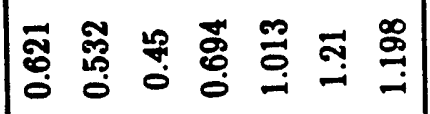 \\
\hline & 离 & 局 \\
\hline & 今્ & 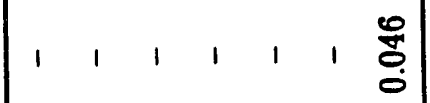 \\
\hline & : & 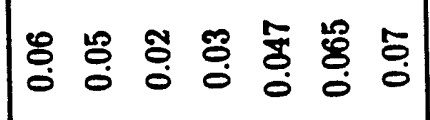 \\
\hline & 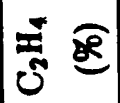 & 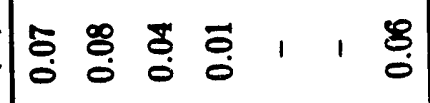 \\
\hline & 8 & 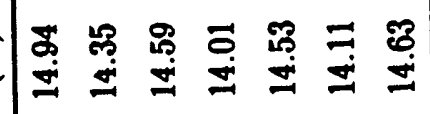 \\
\hline & $=\Phi$ & 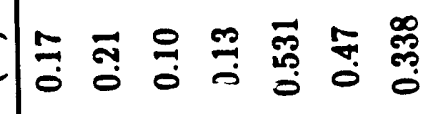 \\
\hline & 次 & 1 송 \\
\hline 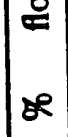 & 8 & 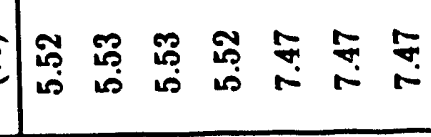 \\
\hline 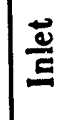 & 0 & 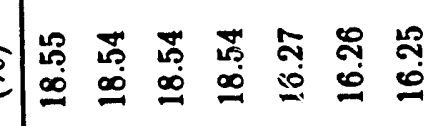 \\
\hline & 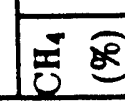 & 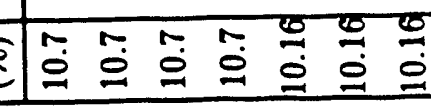 \\
\hline
\end{tabular}




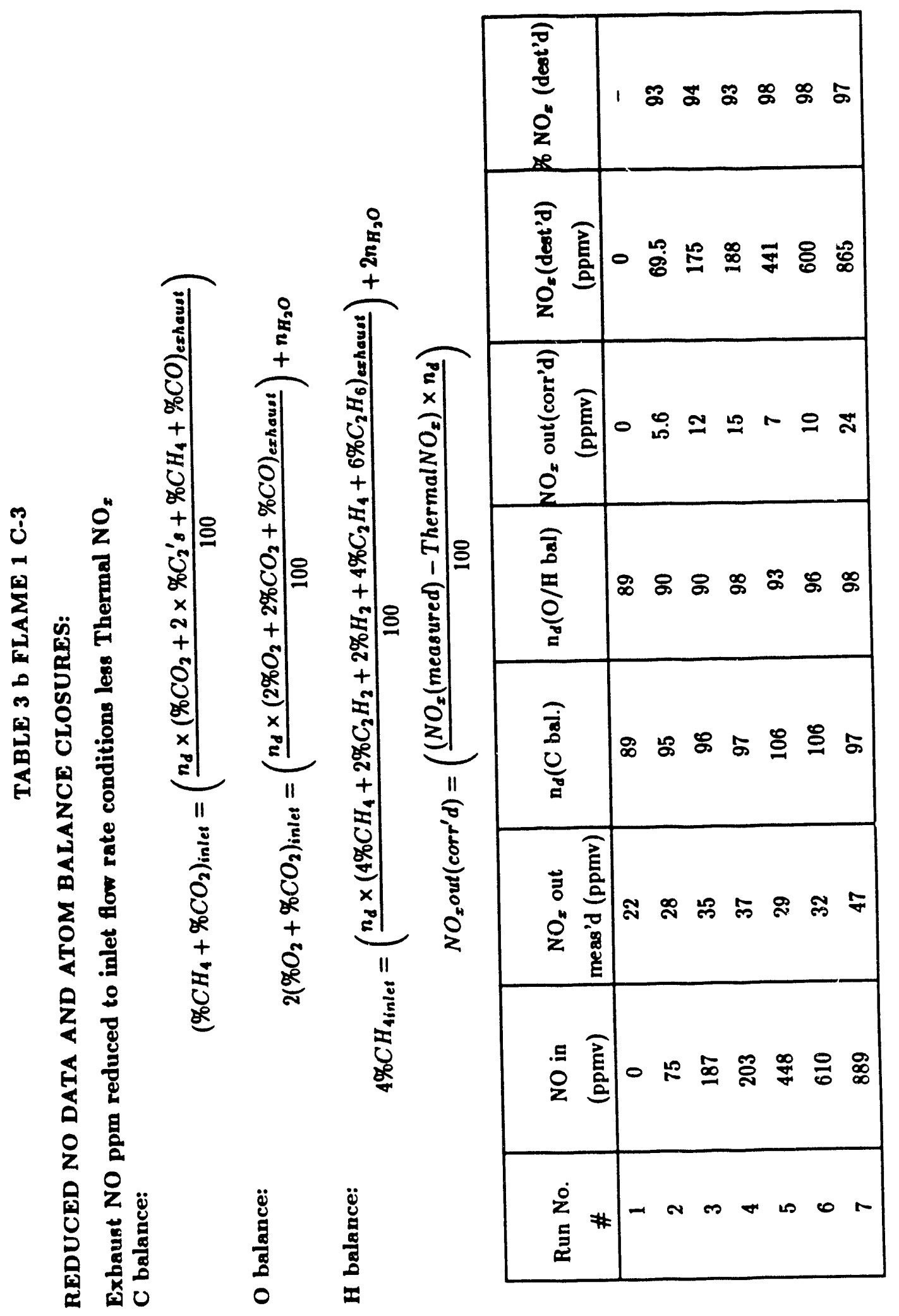




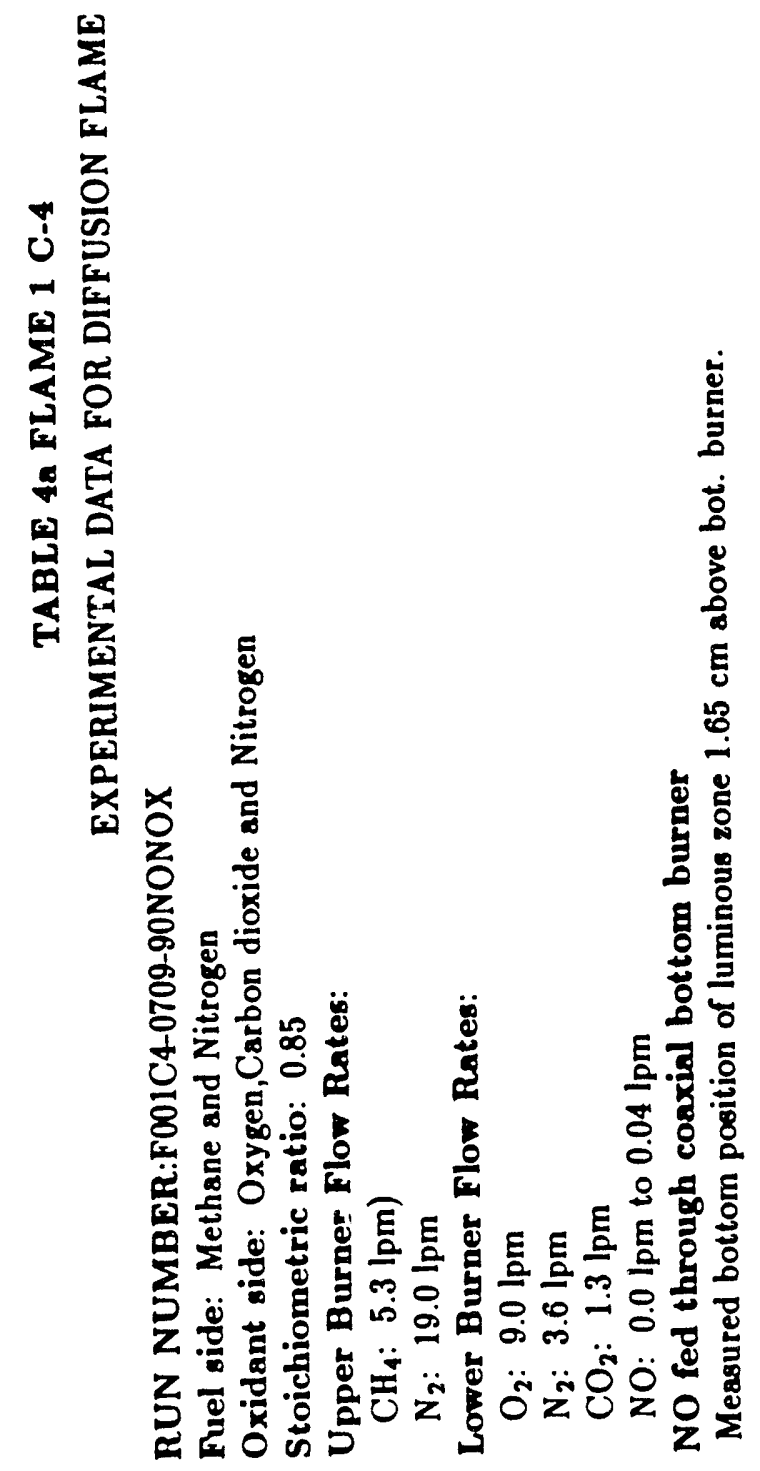

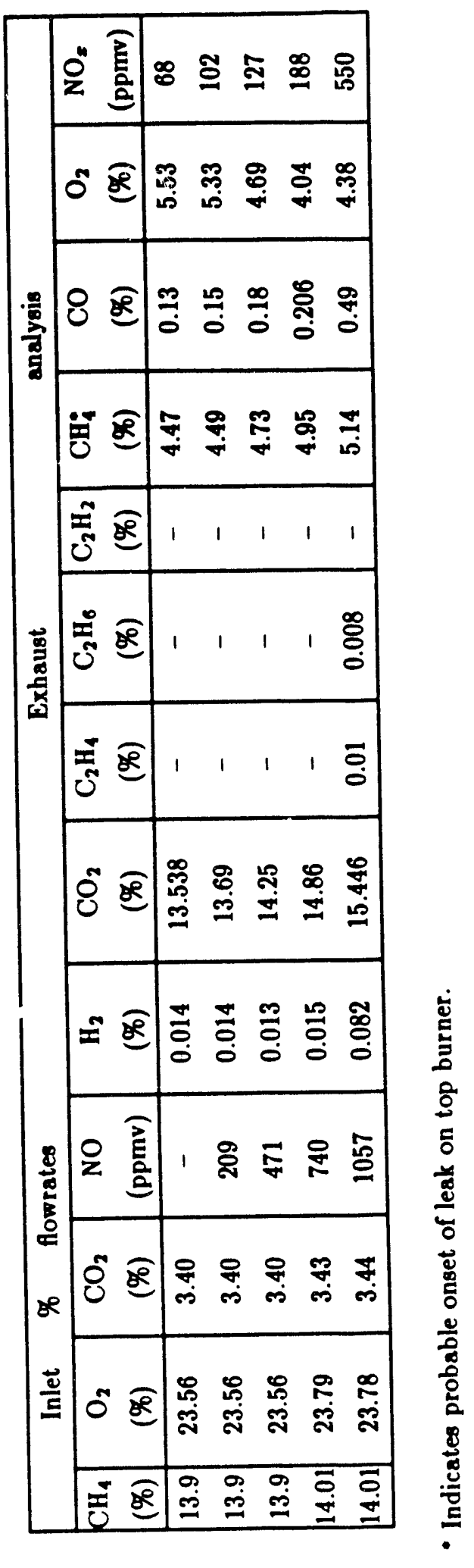




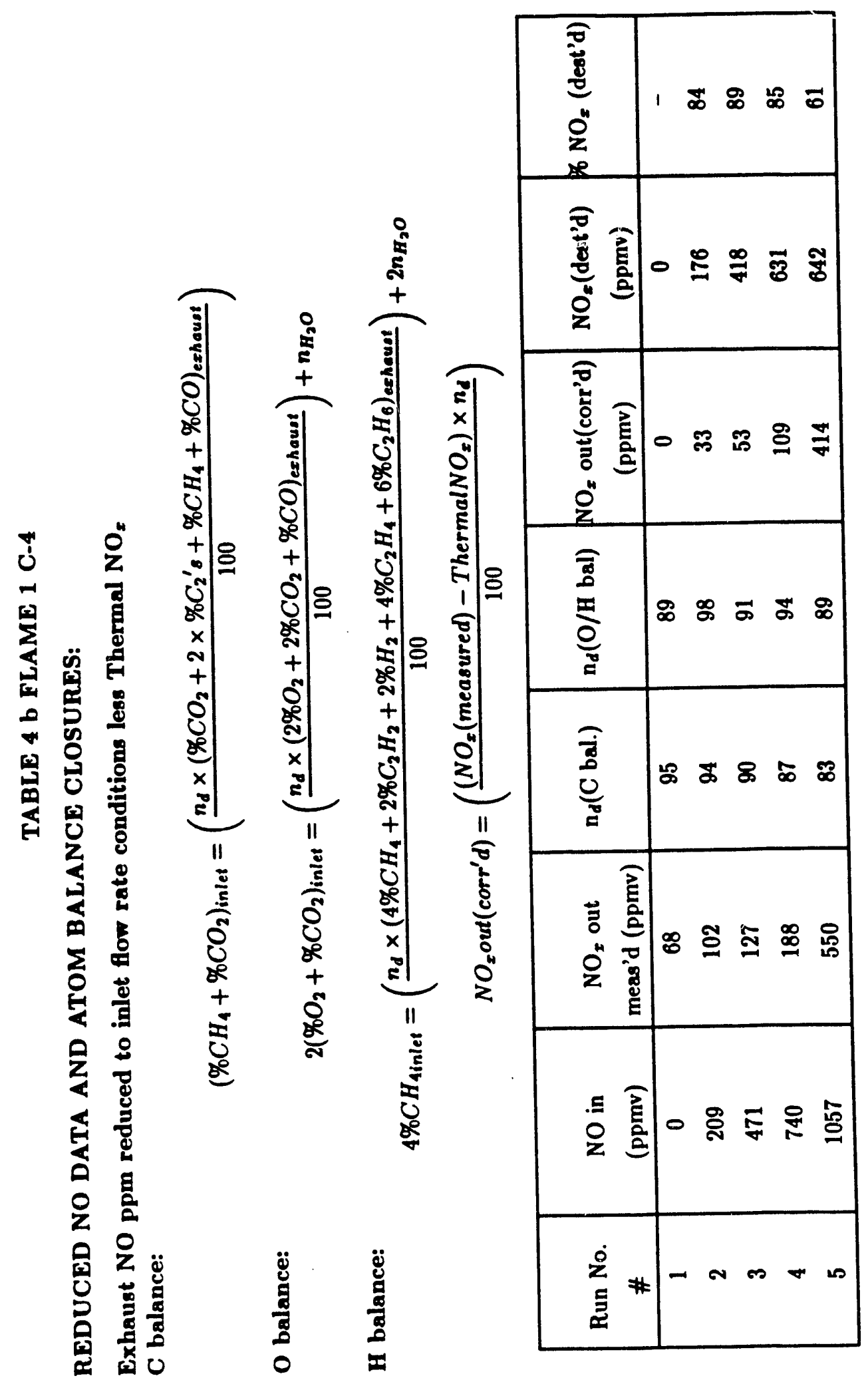




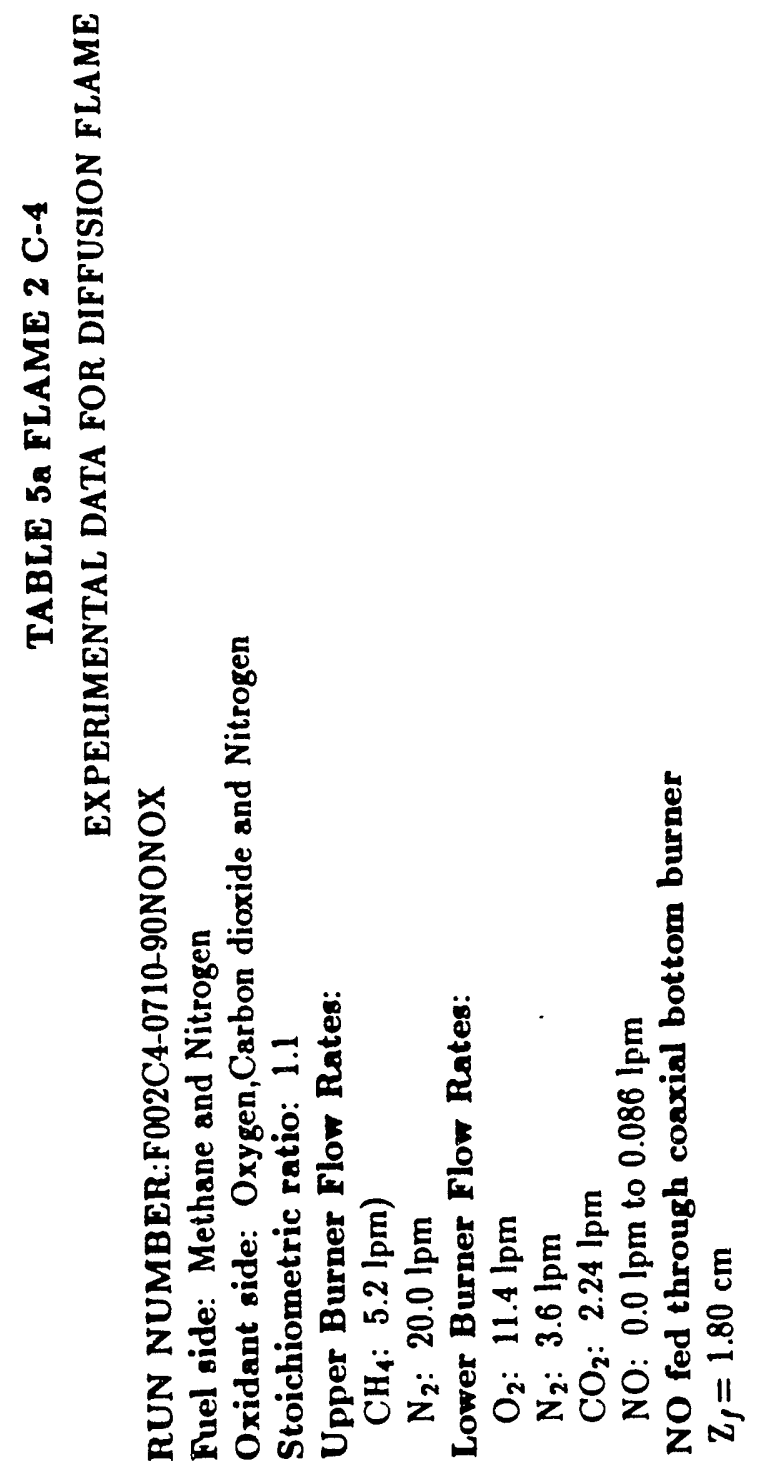

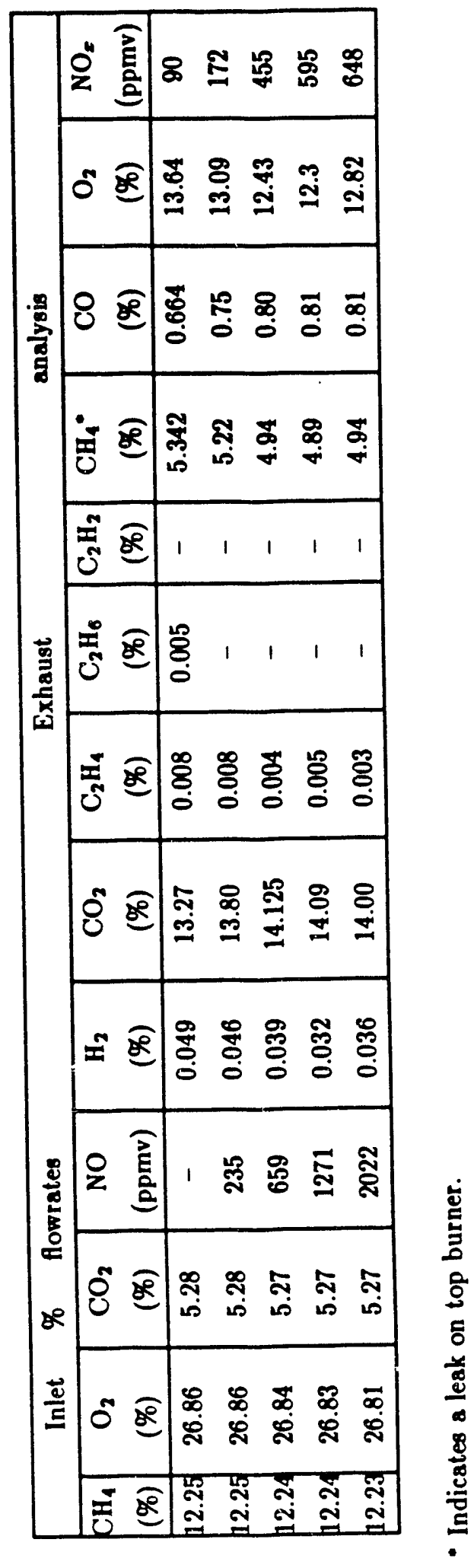




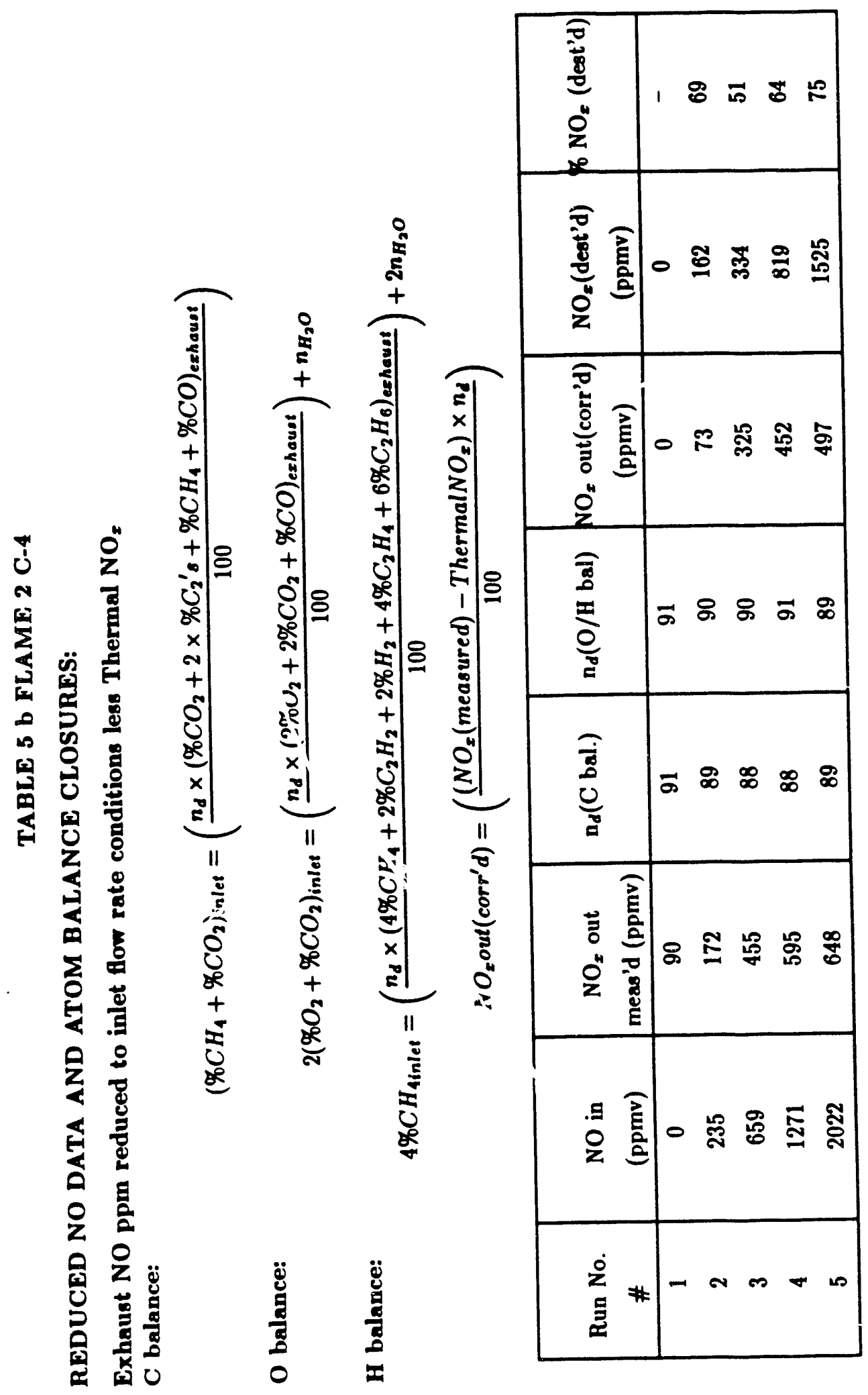




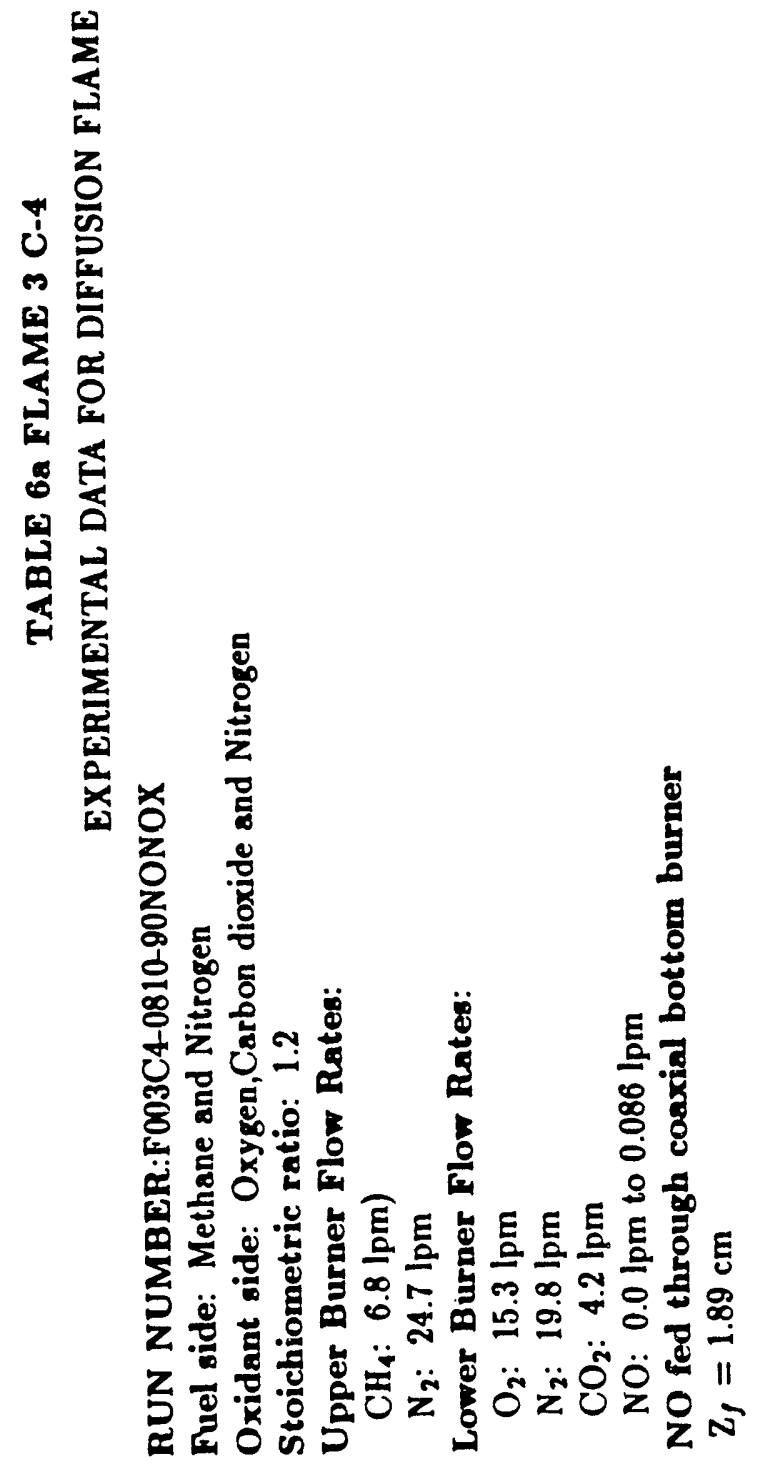

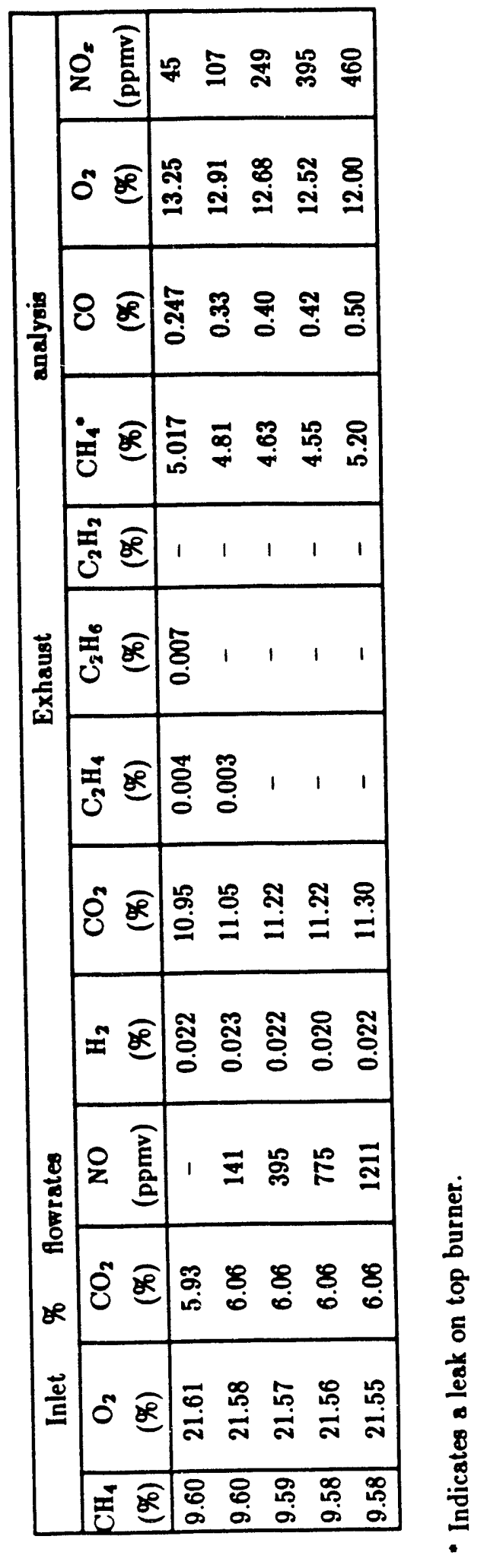




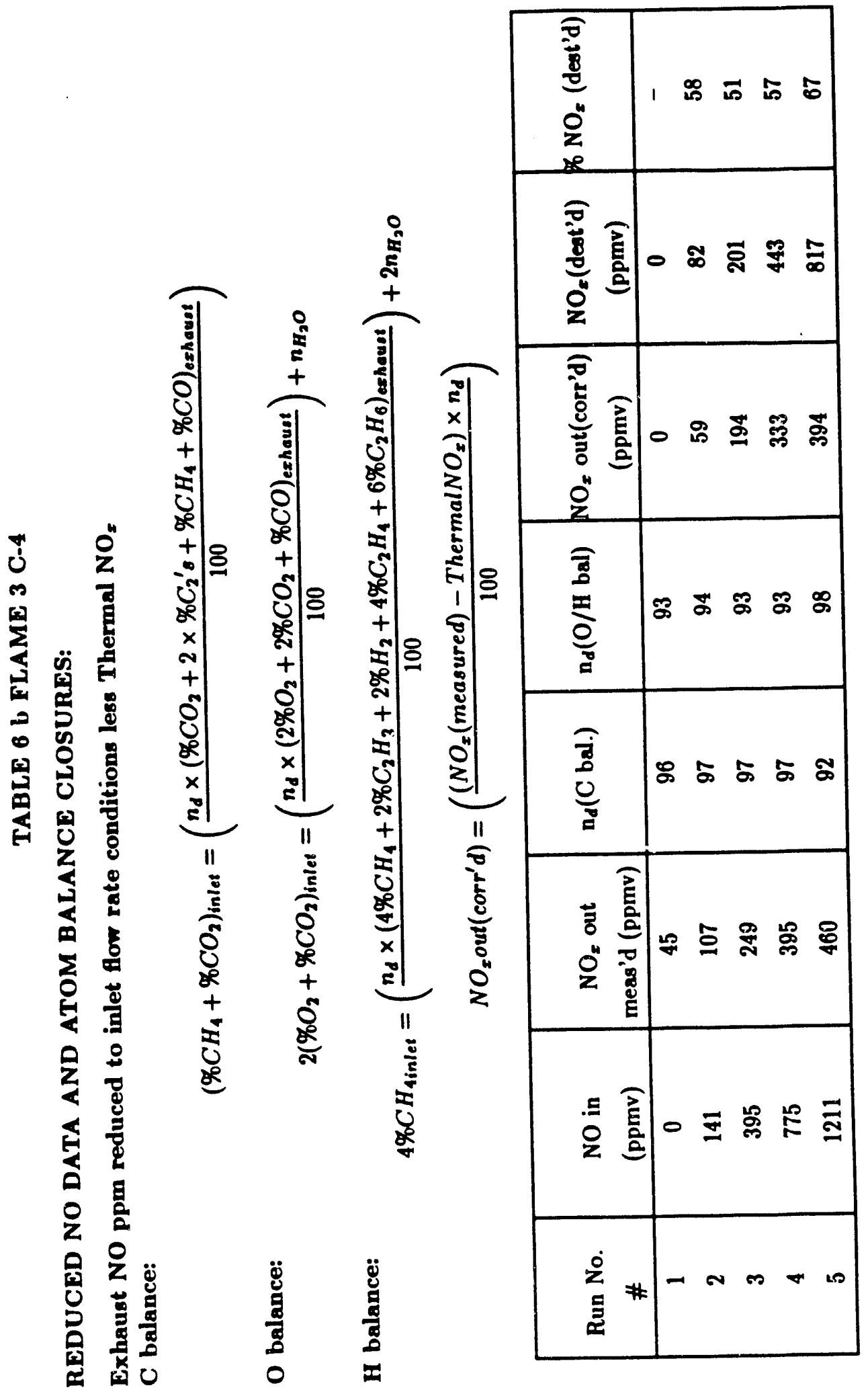




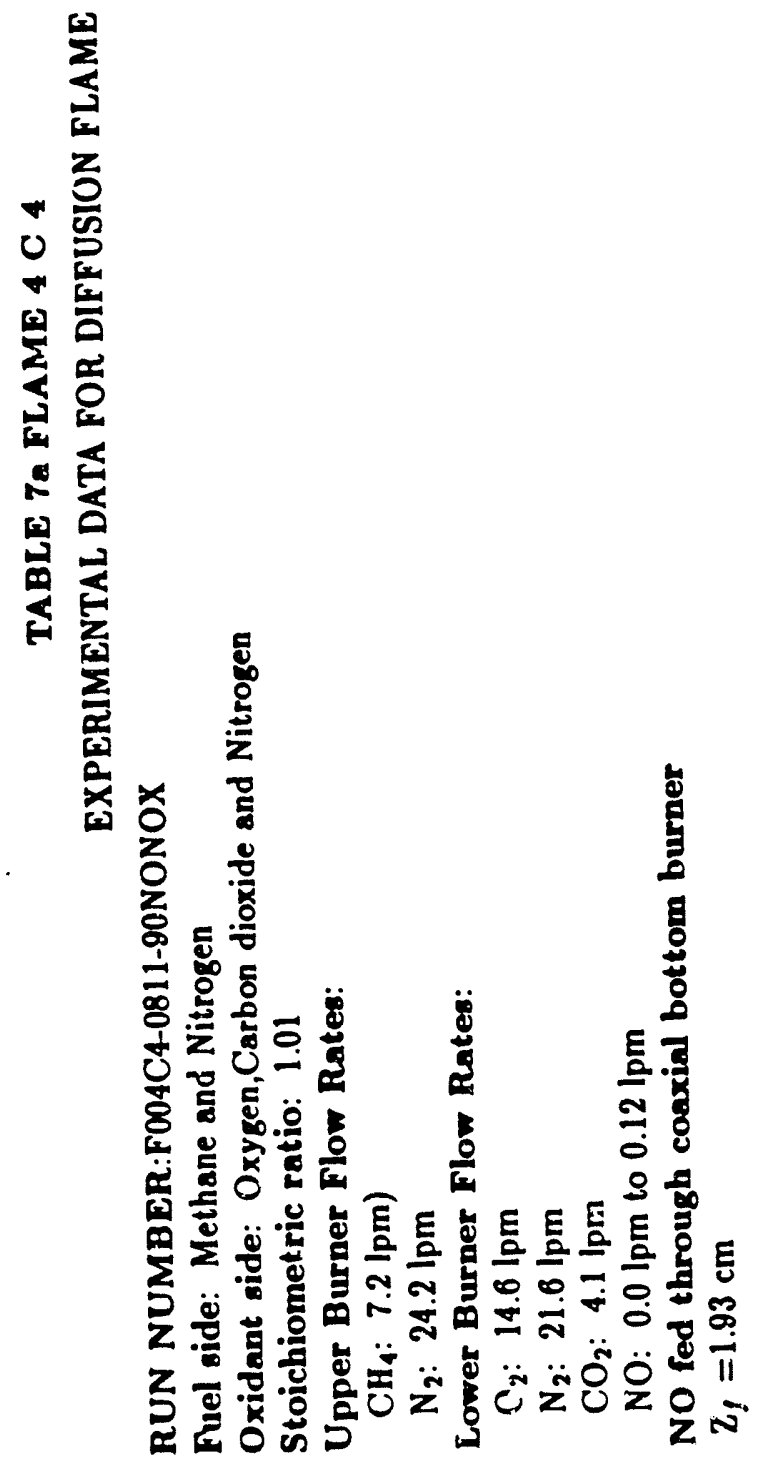

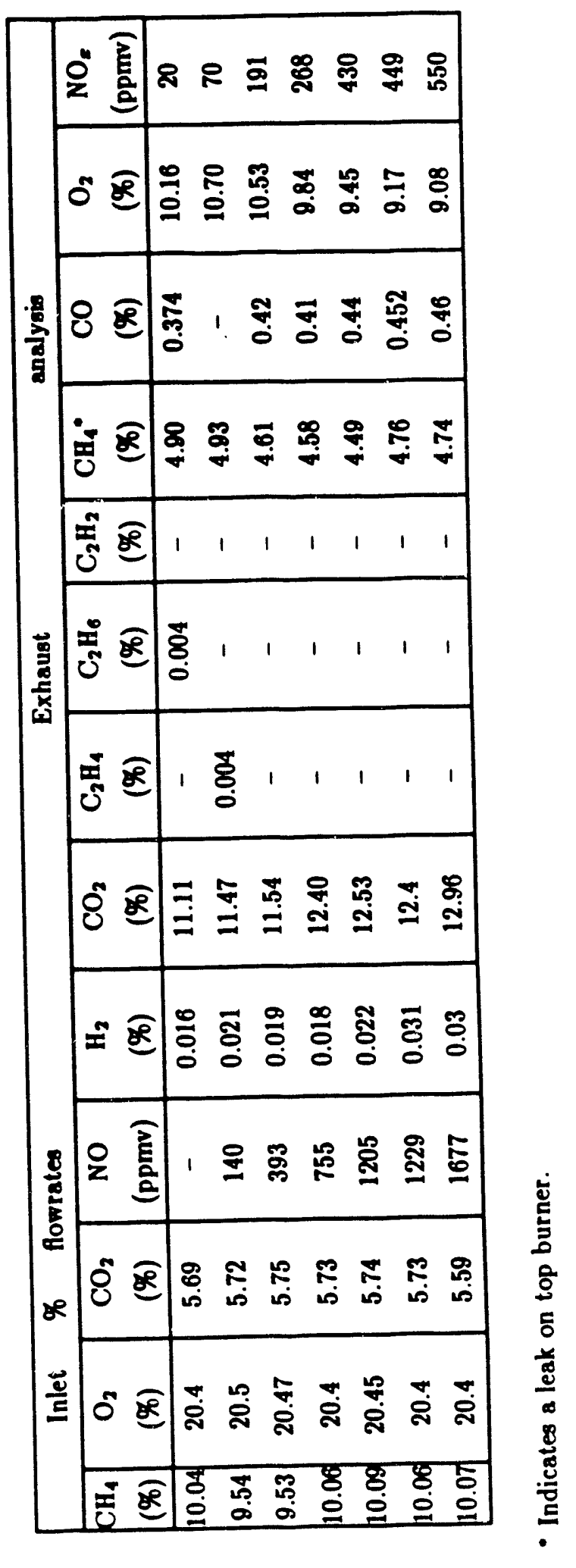




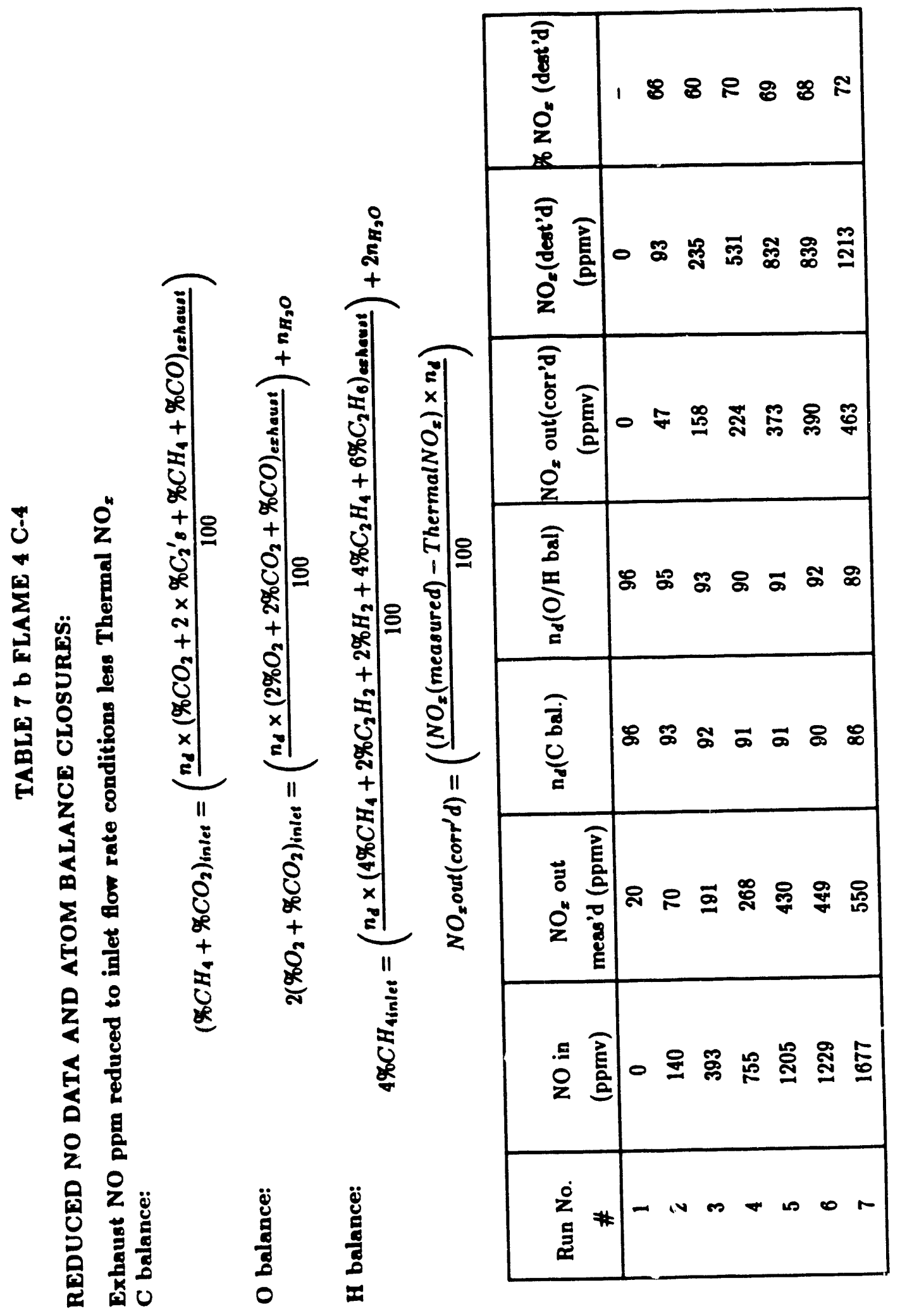




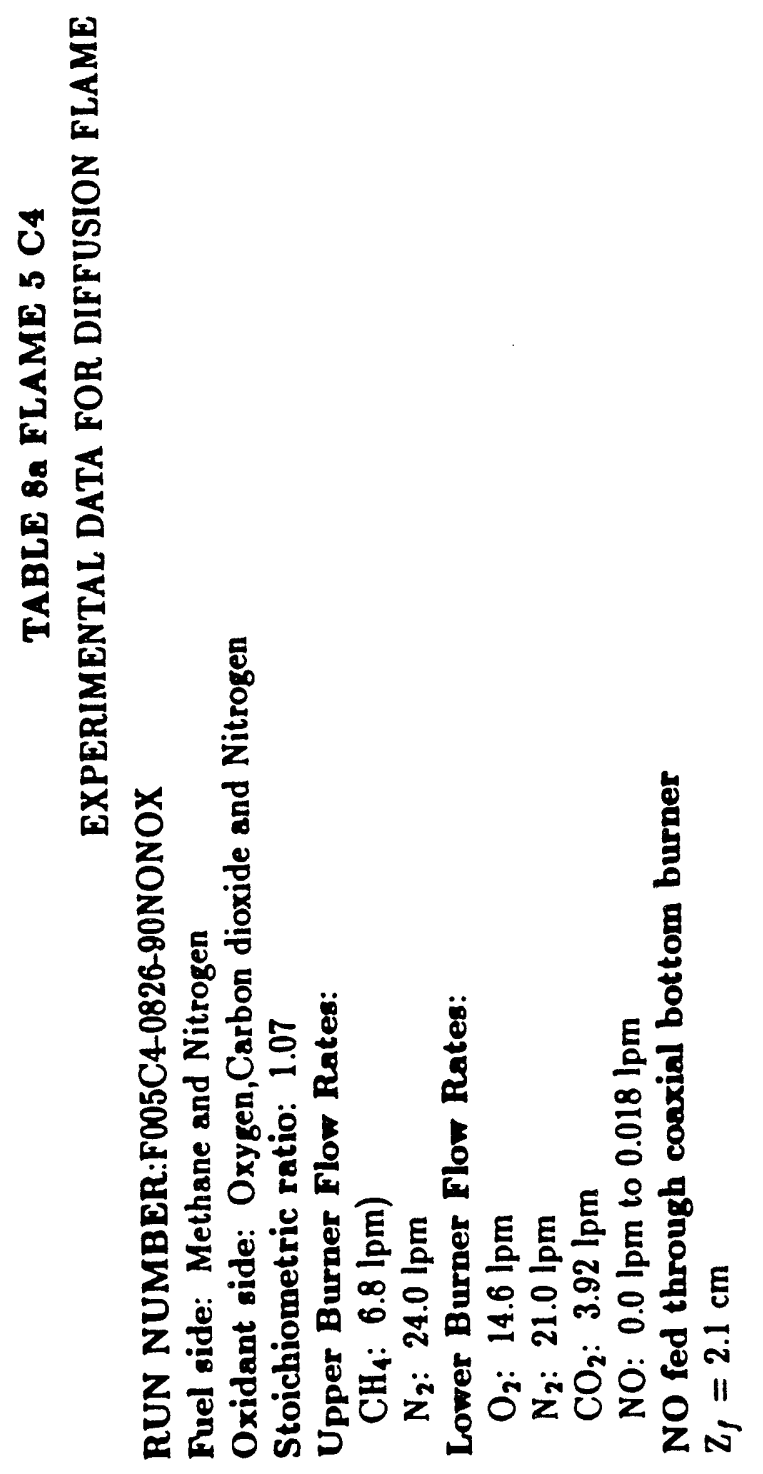

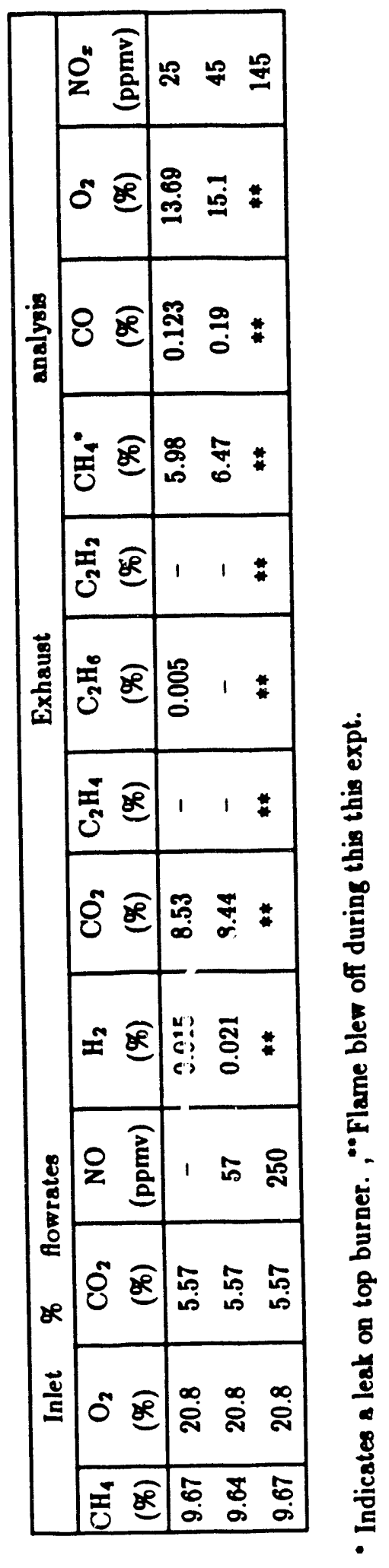




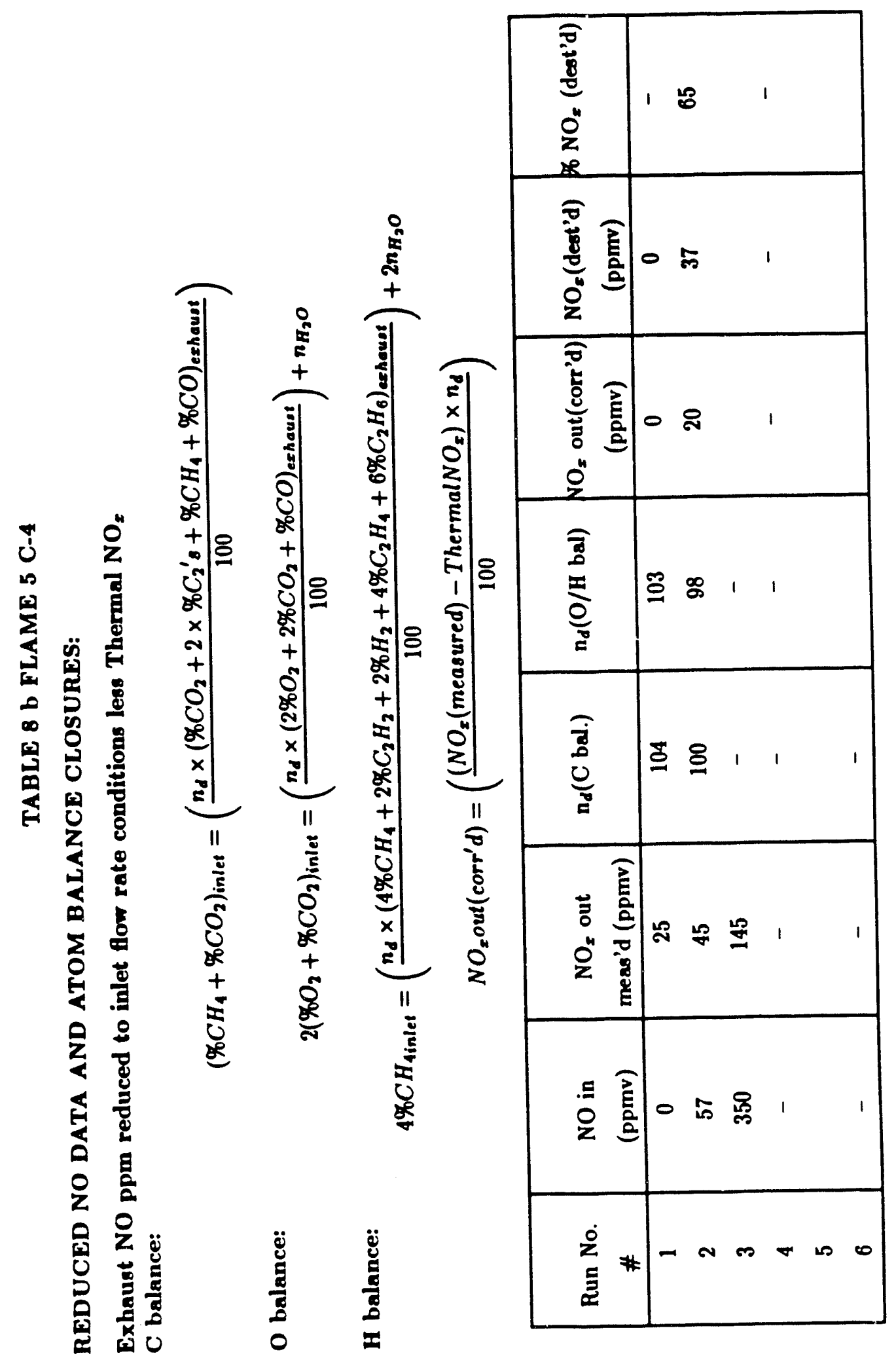




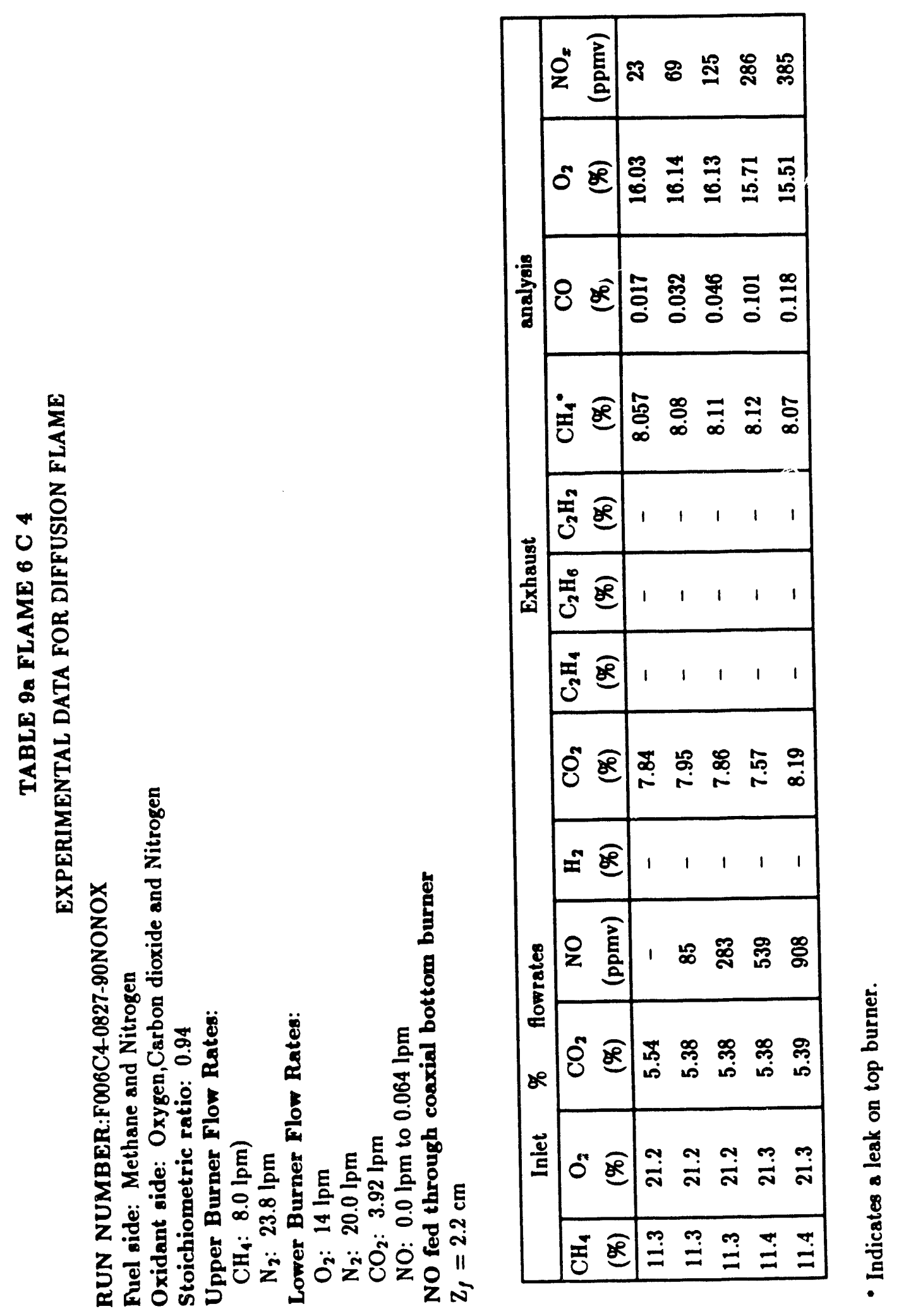




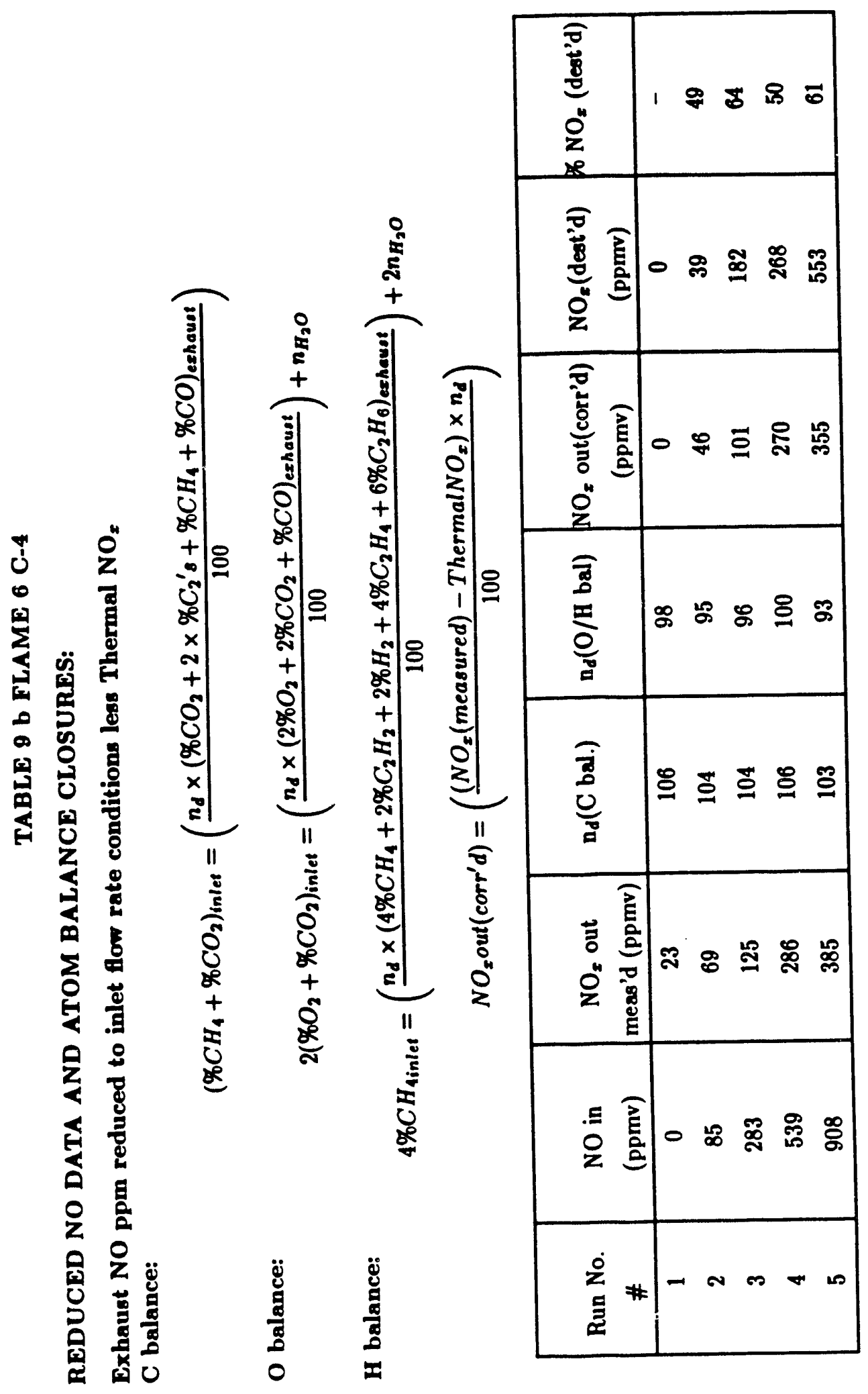




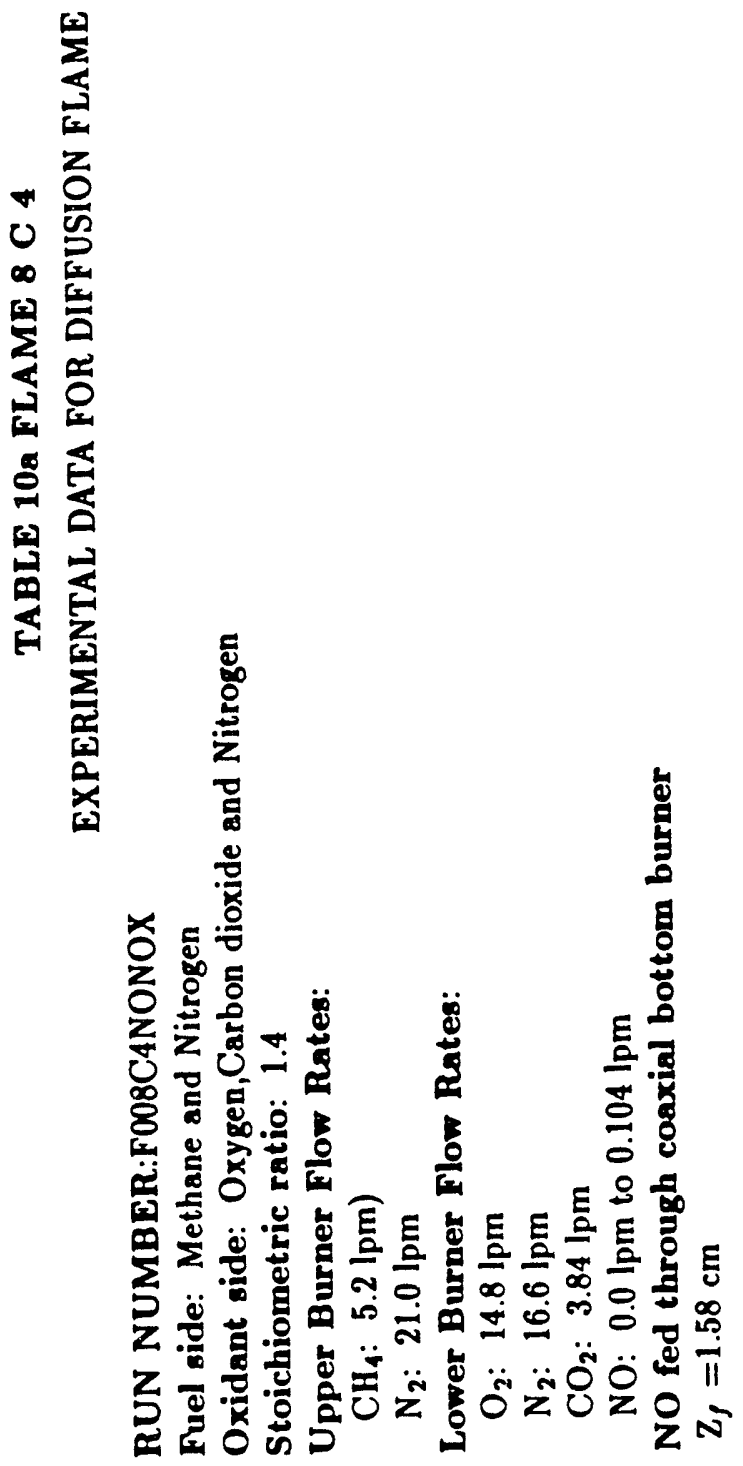

\begin{tabular}{|c|c|c|}
\hline & 党 & 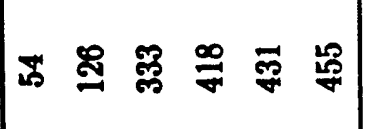 \\
\hline & 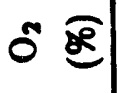 & 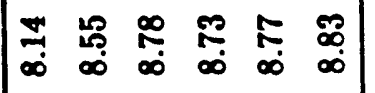 \\
\hline 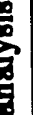 & $8 \overparen{8}$ & 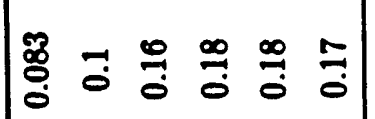 \\
\hline & $\overline{0}$ & 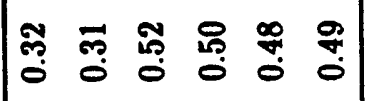 \\
\hline & ज્ञ & $\left|\begin{array}{llllll}1 & 1 & 1 & 1 & 1 & 1\end{array}\right|$ \\
\hline \multirow[t]{4}{*}{ 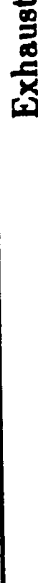 } & 䒿 & $\begin{array}{llllll}1 & 1 & 1 & 1 & 1 & 1\end{array}$ \\
\hline & ज्ञ & $\begin{array}{llllll}1 & 1 & 1 & 1 & 1 & 1\end{array}$ \\
\hline & 8 & 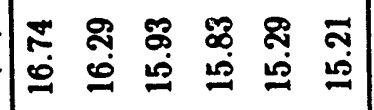 \\
\hline & $\approx \bar{g}$ & 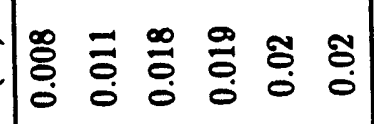 \\
\hline \multirow{2}{*}{ 总 } & 号 & 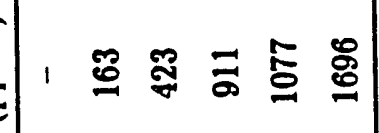 \\
\hline & 8 & 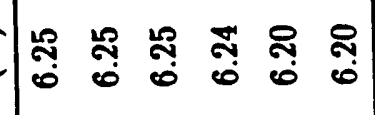 \\
\hline \multirow[t]{2}{*}{$\frac{\underline{\underline{U}}}{\underline{\underline{E}}}$} & 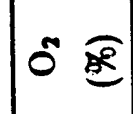 & 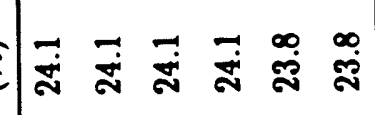 \\
\hline & 헝 & 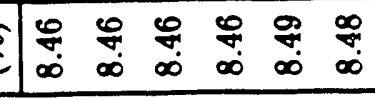 \\
\hline
\end{tabular}




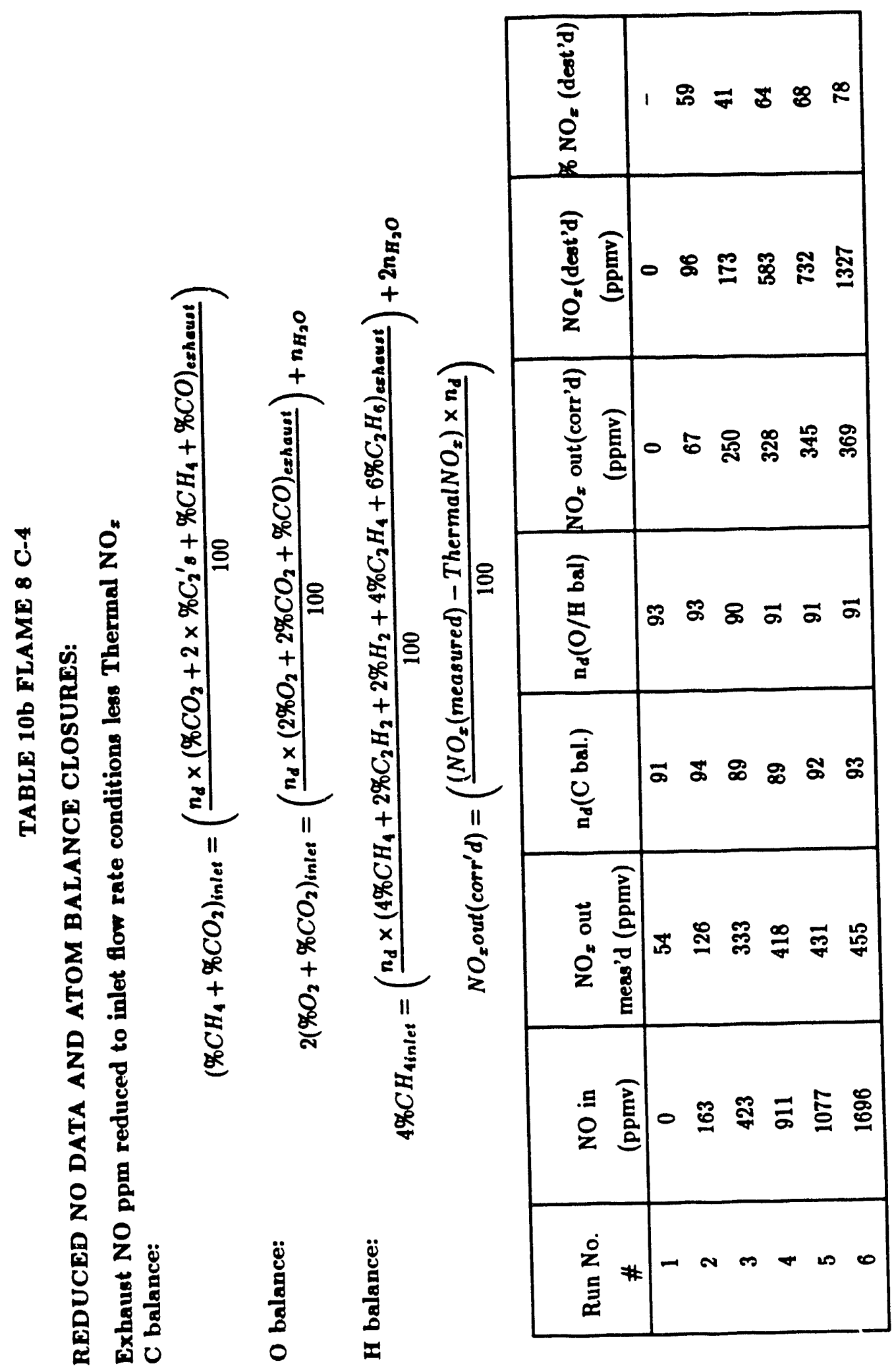




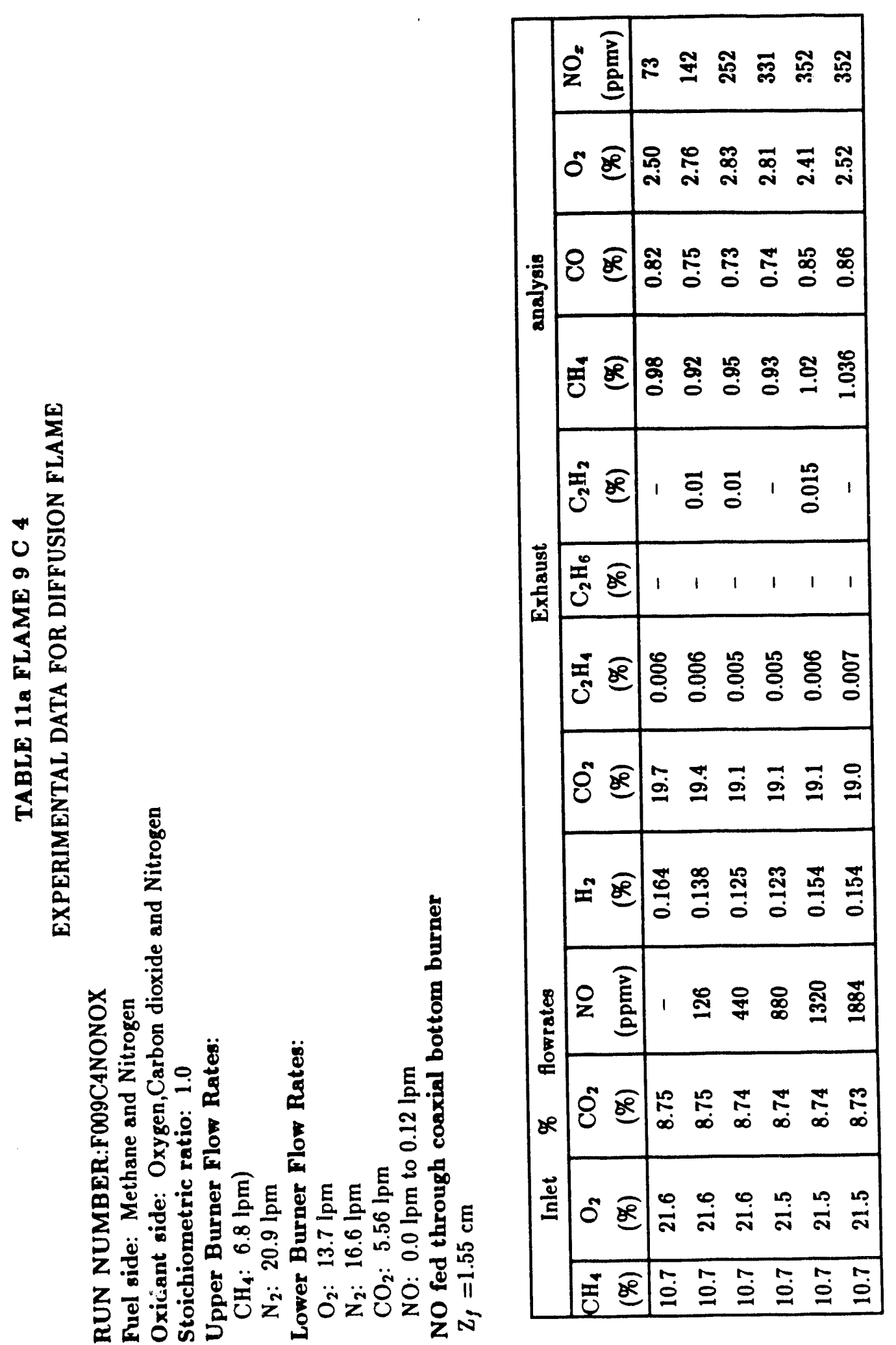




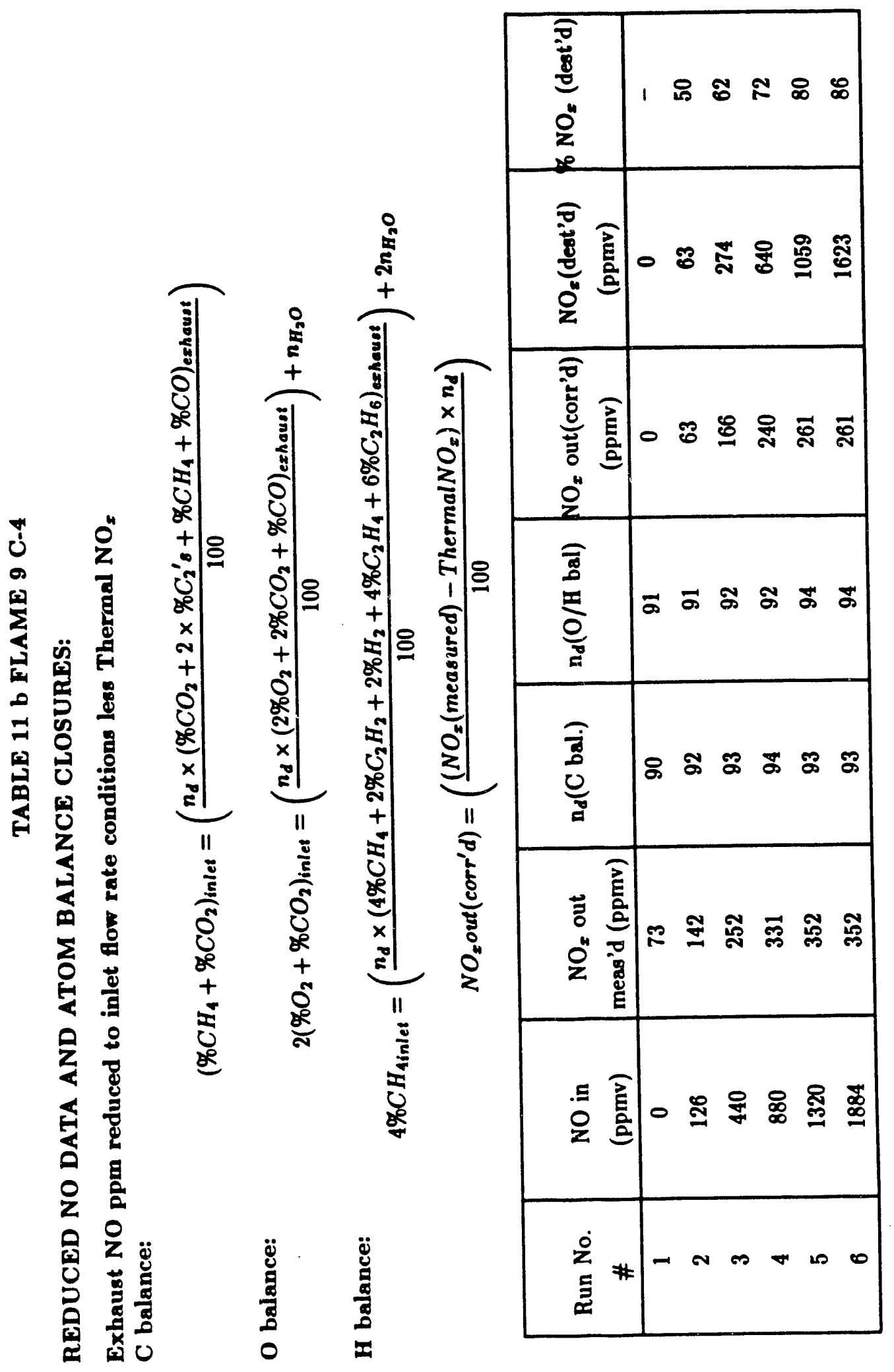




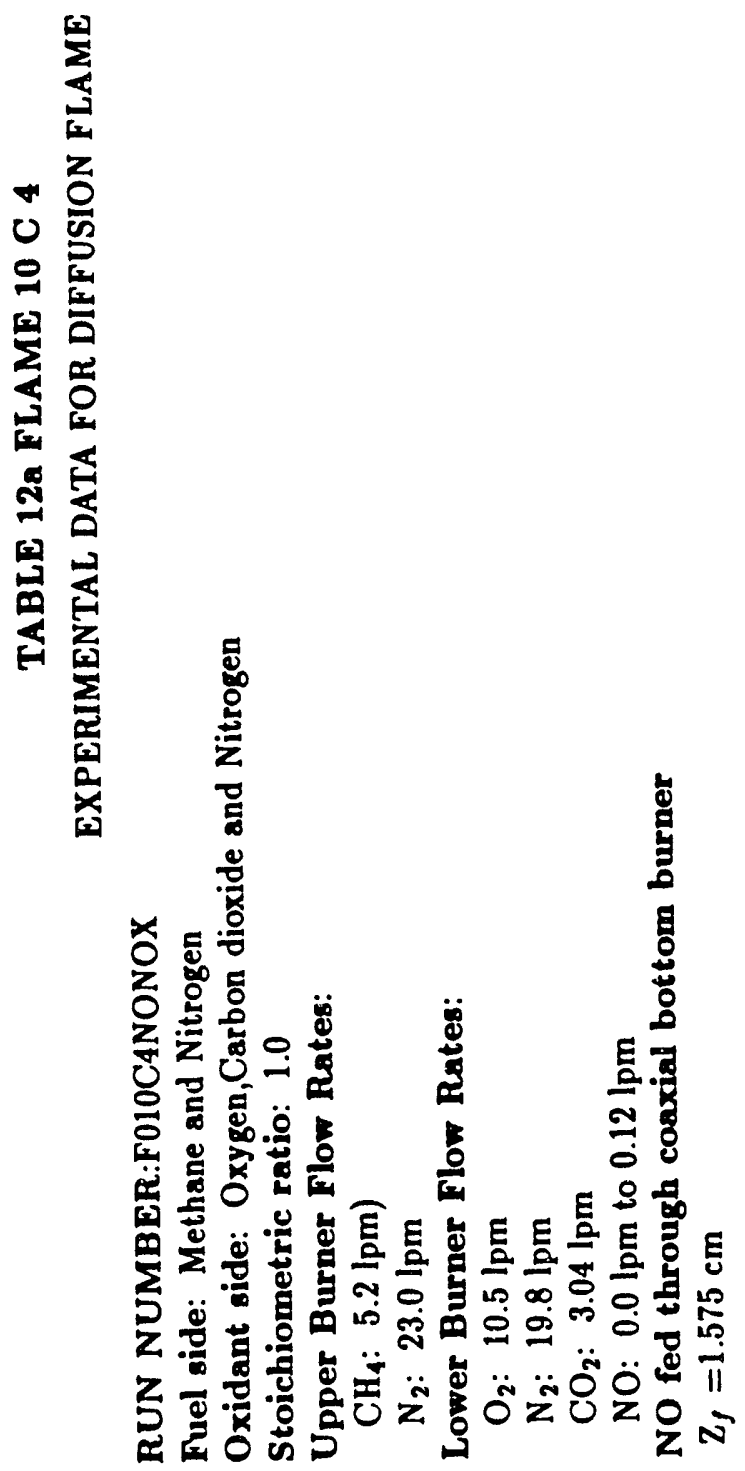

\begin{tabular}{|c|c|}
\hline 章 & 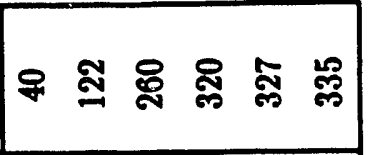 \\
\hline $0 \cong$ & กุ \\
\hline 8 & 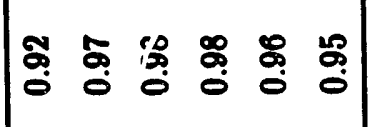 \\
\hline 画 & 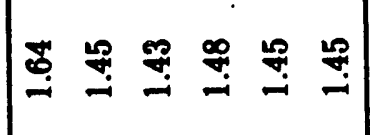 \\
\hline 표 & 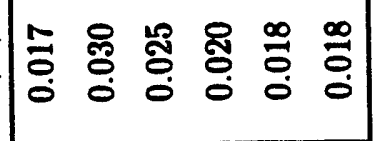 \\
\hline 跑 & $\begin{array}{llllll}1 & 1 & 1 & 1 & 1 & 1 \\
\end{array}$ \\
\hline 虍 & 居 \\
\hline 8 & 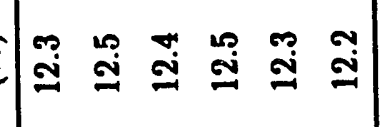 \\
\hline$\approx \Xi$ & 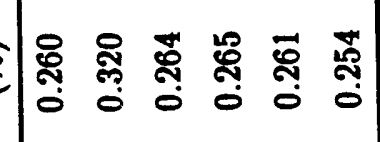 \\
\hline 8 & 10 \\
\hline 80 & 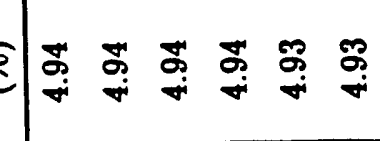 \\
\hline 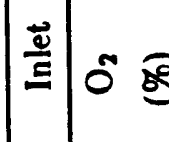 & 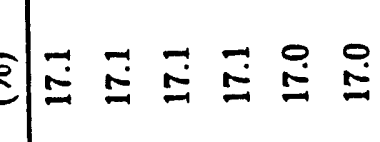 \\
\hline$\sqrt{\mathrm{F}^{\circ}}$ & 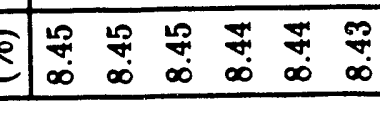 \\
\hline
\end{tabular}




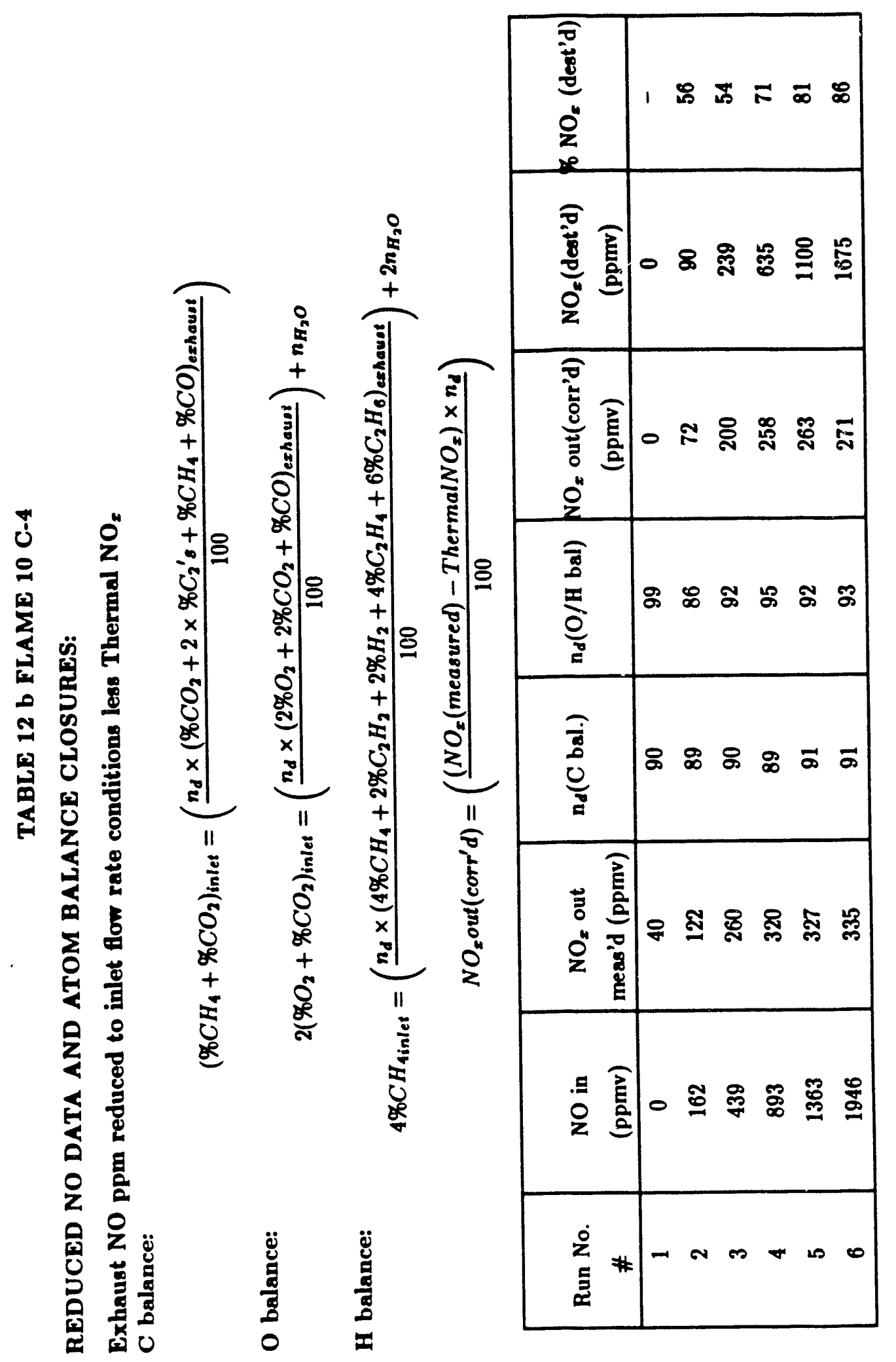




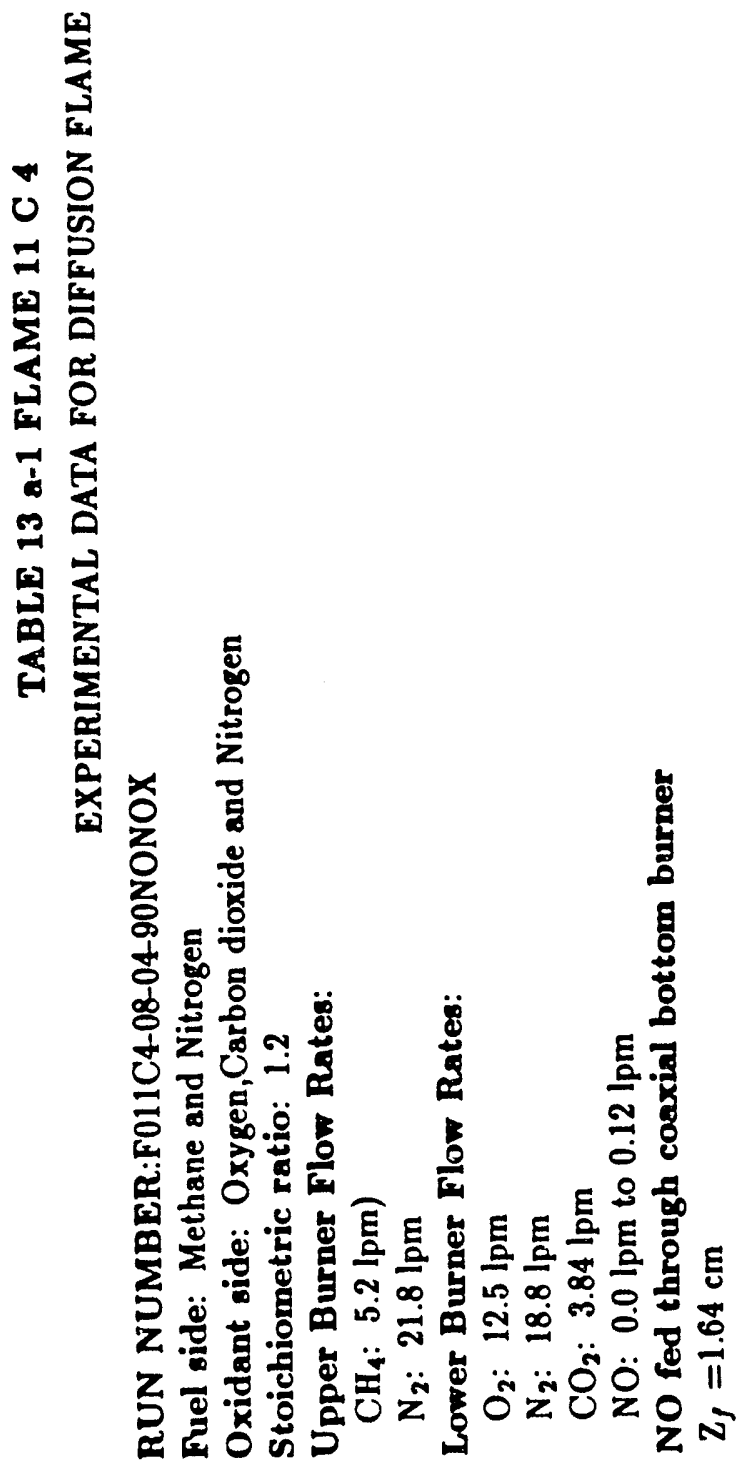

\begin{tabular}{|c|c|c|}
\hline & 艺 & 융 \& \\
\hline & $0 \longdiv { 8 }$ & 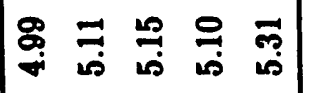 \\
\hline \multirow[t]{3}{*}{ 量 } & $8 \longdiv { 8 }$ & శ్రి \\
\hline & $\widetilde{\bar{z}}$ & 胥 \\
\hline & స્ & $\begin{array}{lllll}1 & 1 & 1 & 1 & 1\end{array}$ \\
\hline \multirow[t]{4}{*}{ 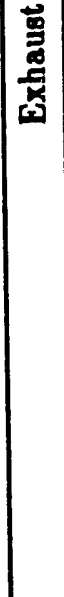 } & טָ̃ & $\begin{array}{lllll}1 & 1 & 1 & 1 & 1 \\
1 & 1 & & 1\end{array}$ \\
\hline & 运 & $\begin{array}{lllll}1 & 1 & 1 & 1 & 1\end{array}$ \\
\hline & 8 & 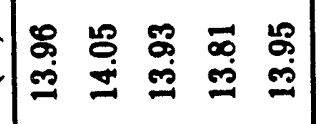 \\
\hline & $=\overparen{E}$ & 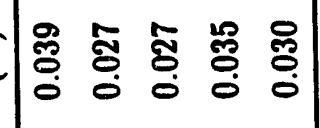 \\
\hline \multirow{2}{*}{ 造 } & 을 & , 谷尔点 \\
\hline & 8 & 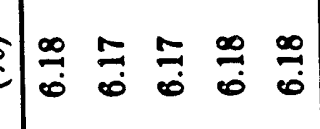 \\
\hline \multirow[t]{2}{*}{$\underline{\underline{\underline{v}}}$} & 08 & 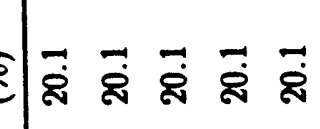 \\
\hline & 㝴 & 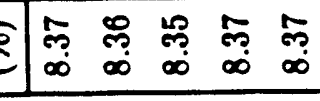 \\
\hline
\end{tabular}




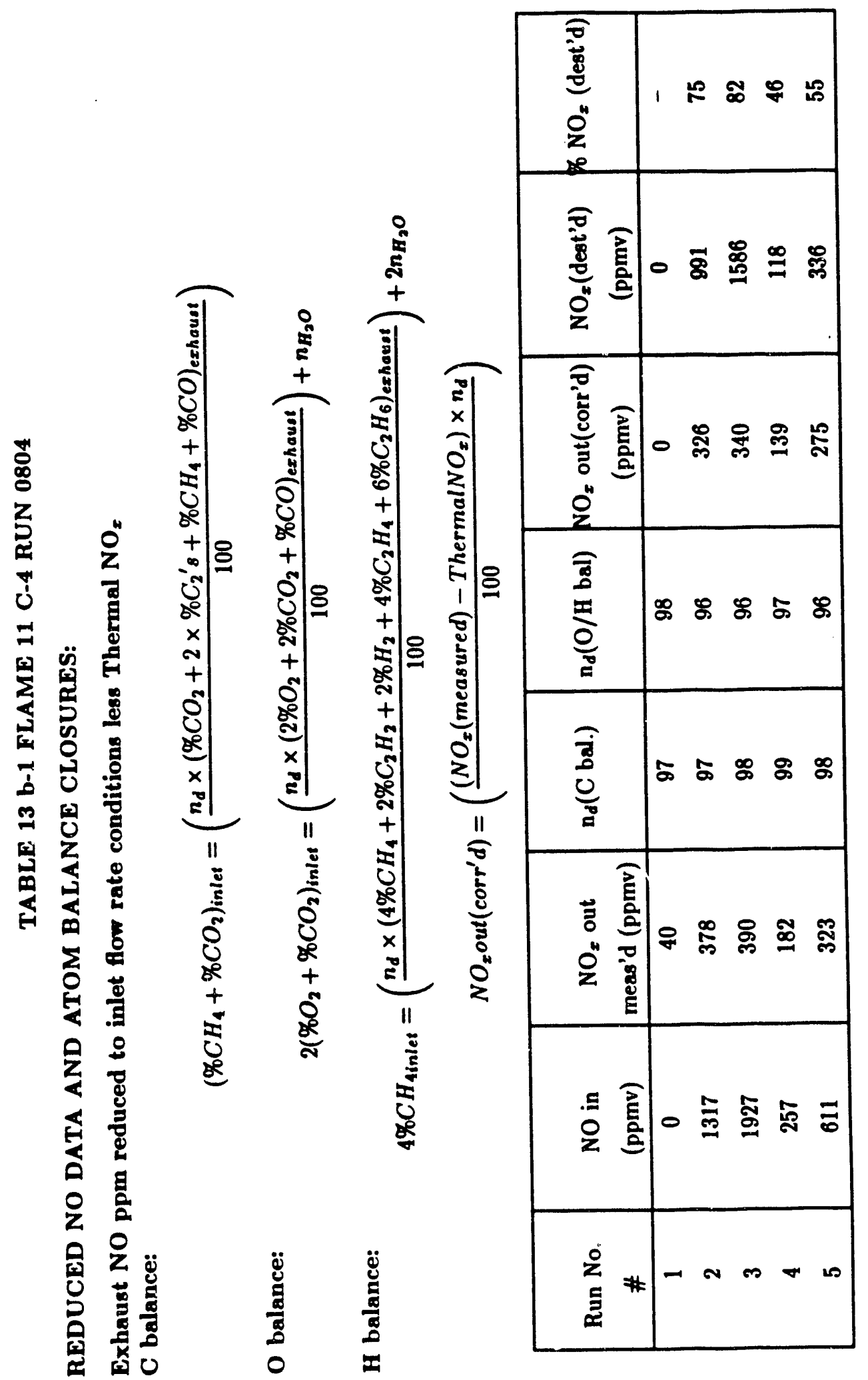




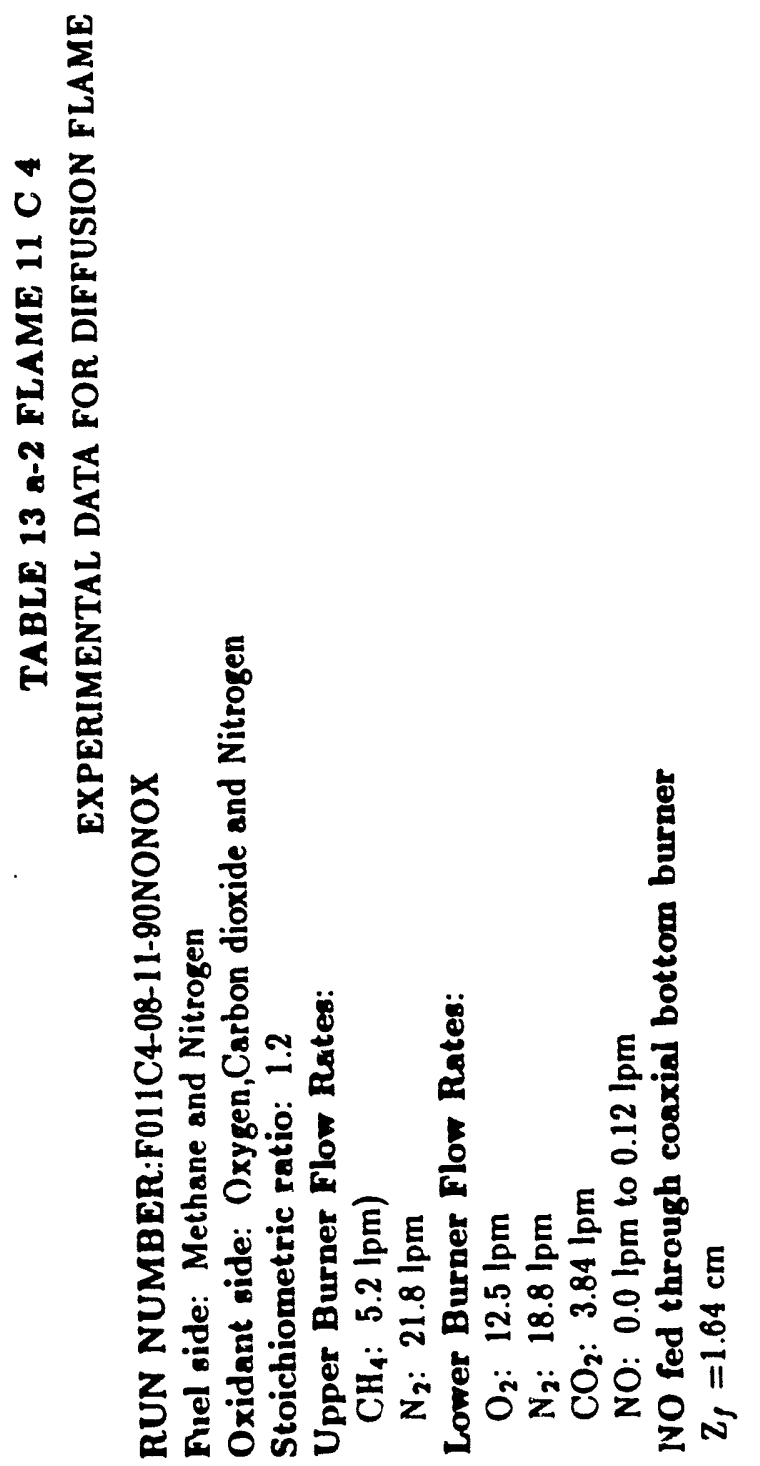

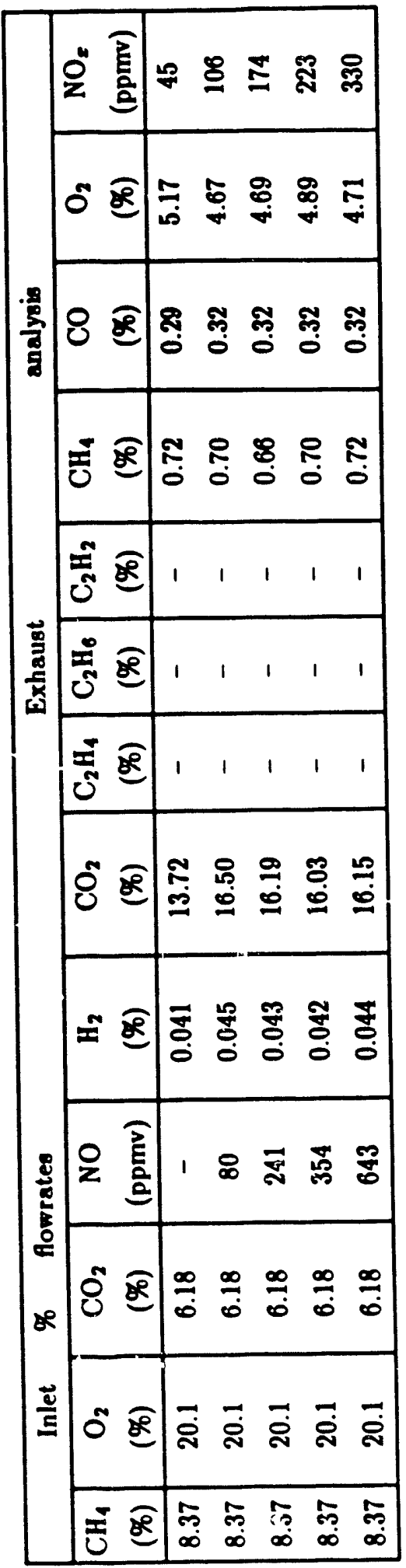




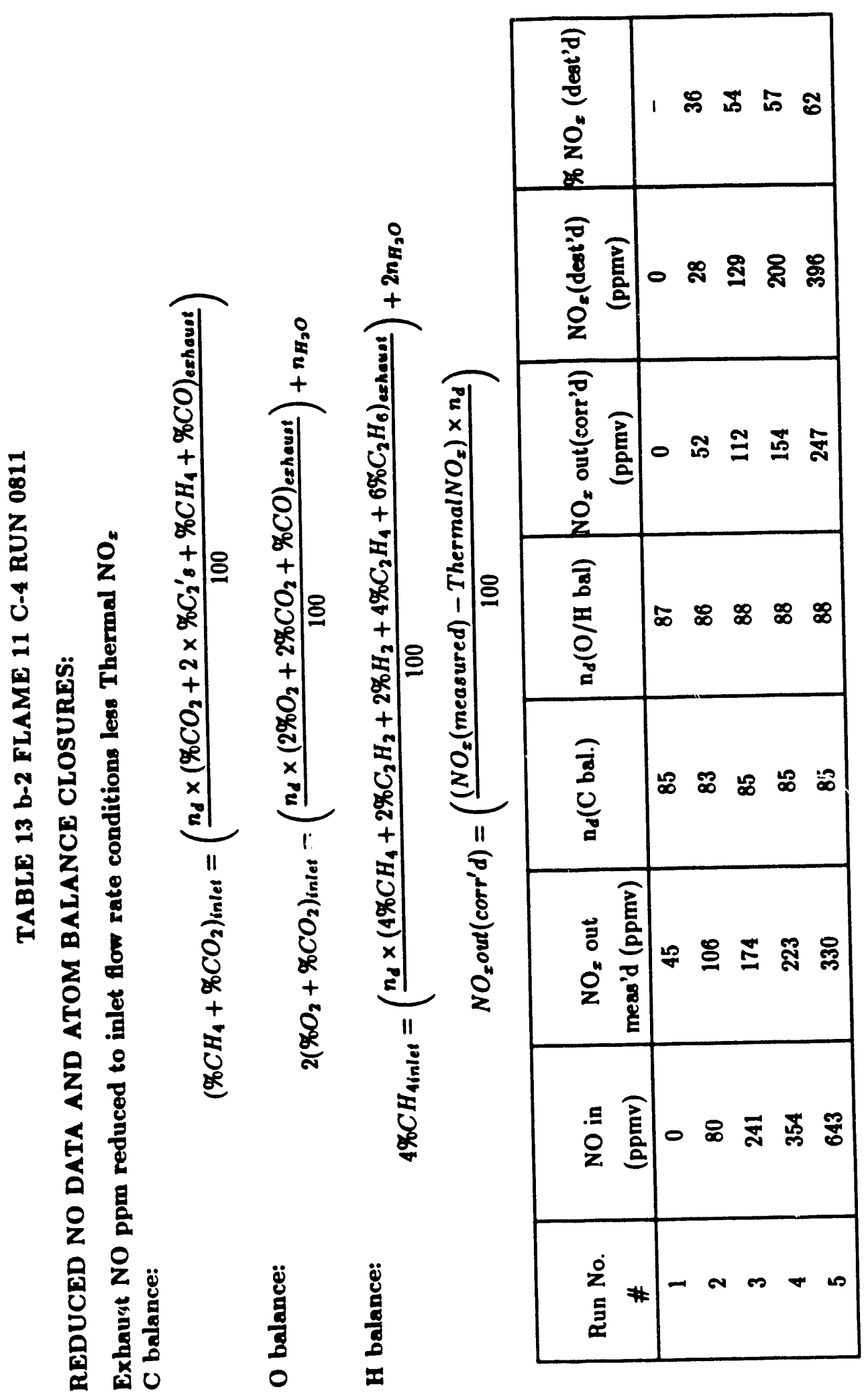




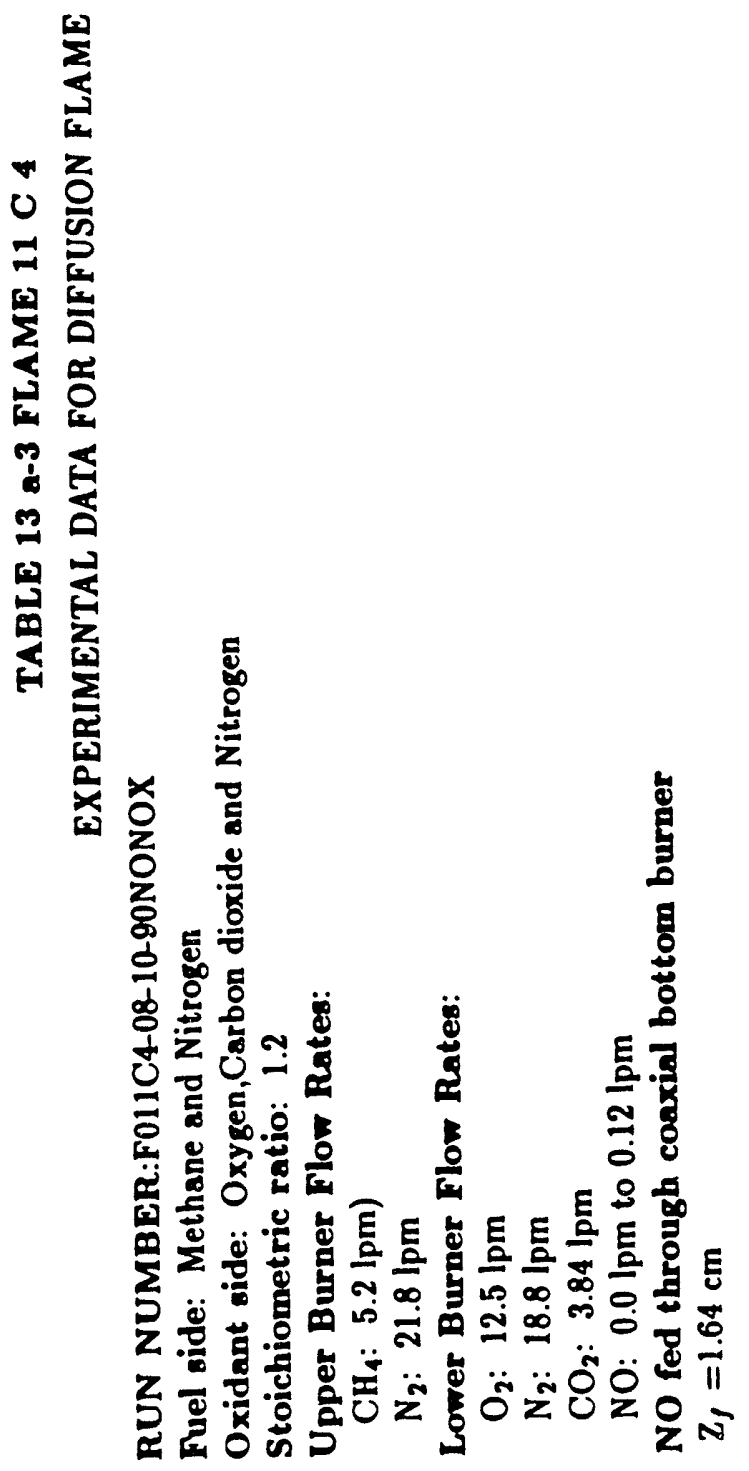

\begin{tabular}{|c|c|c|}
\hline & 艺 & $=\mathscr{m}$ \\
\hline & 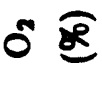 & 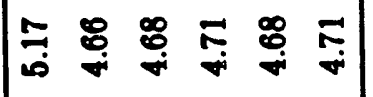 \\
\hline & $8 \sqrt{8}$ & 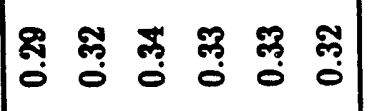 \\
\hline & $\overline{0} \bar{\theta}$ & 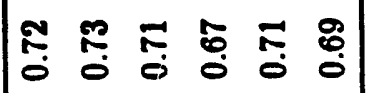 \\
\hline & :ָ & $\begin{array}{llllll}1 & 1 & 1 & 1 & 1 & 1\end{array}$ \\
\hline \multirow[t]{2}{*}{ 这 } & ثึ: & $\begin{array}{llllll}1 & 1 & 1 & 1 & 1 & 1 \\
\end{array}$ \\
\hline & 远 & $\begin{array}{llllll}1 & 1 & 1 & 1 & 1 & 1 \\
\end{array}$ \\
\hline & 8 & 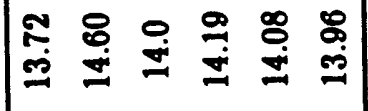 \\
\hline & $\approx \mathbb{E}$ & $\mid \begin{array}{lll}\overline{0} \\
0 \\
0\end{array}$ \\
\hline & 을 & 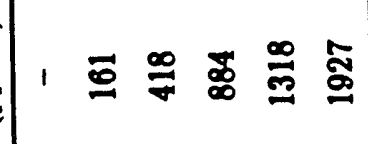 \\
\hline$\theta^{\circ}$ & 8 & $\frac{\infty}{0} \underset{0}{\infty} \frac{\infty}{0} \stackrel{7}{0}$ \\
\hline 4 & $0 \longdiv { \mathscr { E } }$ & 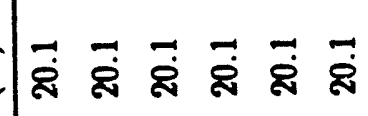 \\
\hline & $\overline{1}$ & 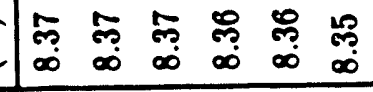 \\
\hline
\end{tabular}




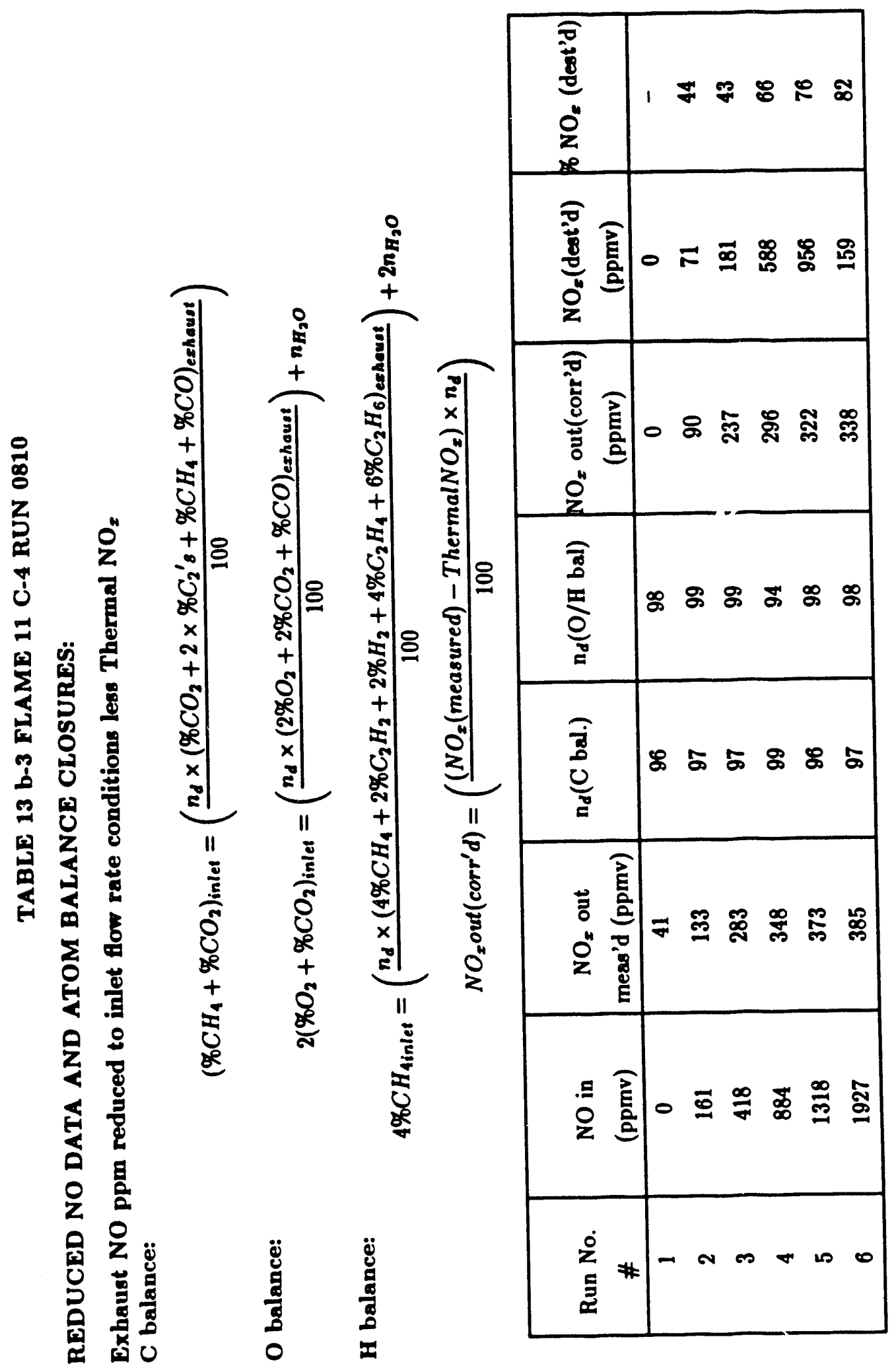




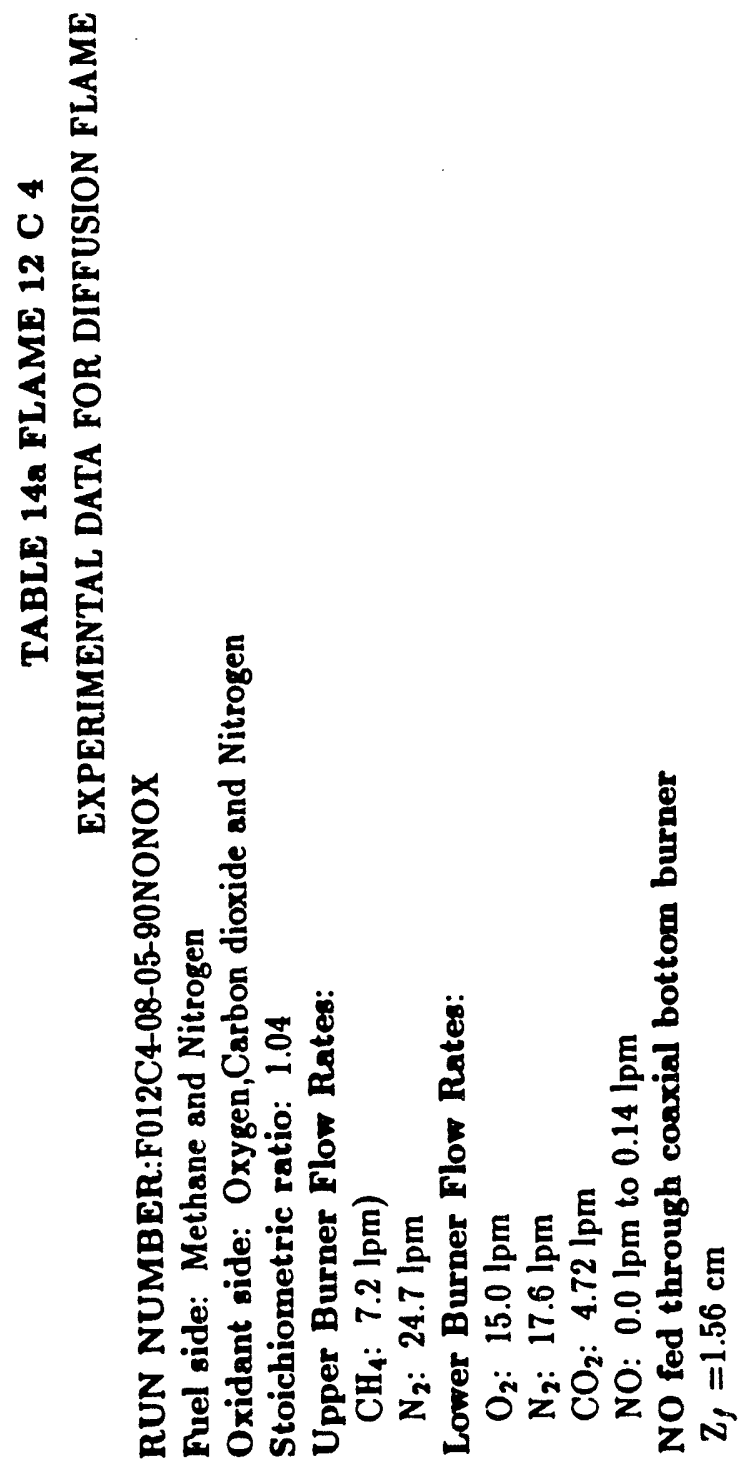

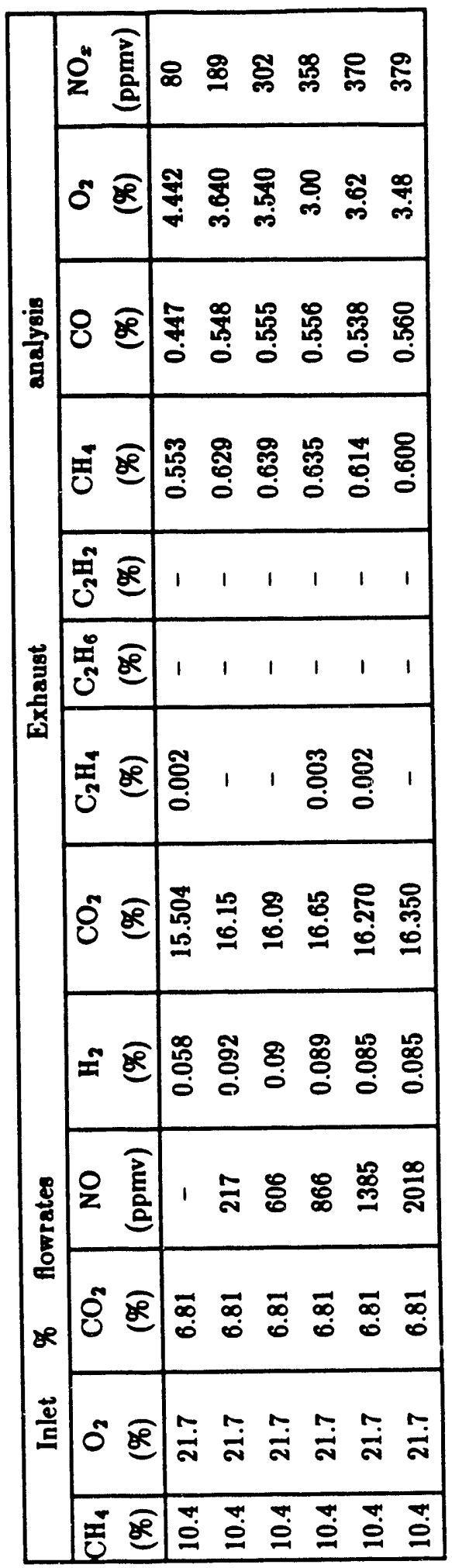




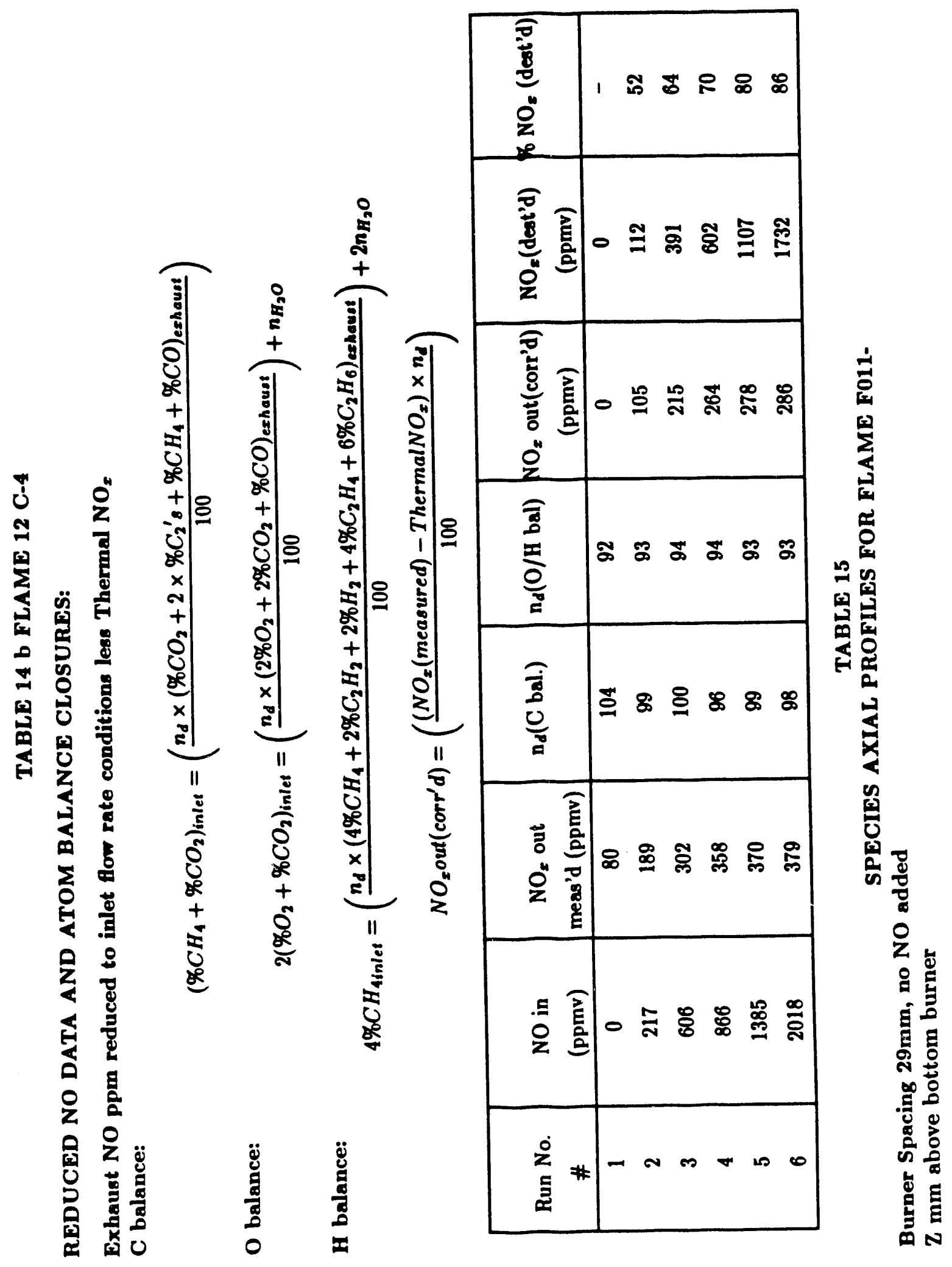




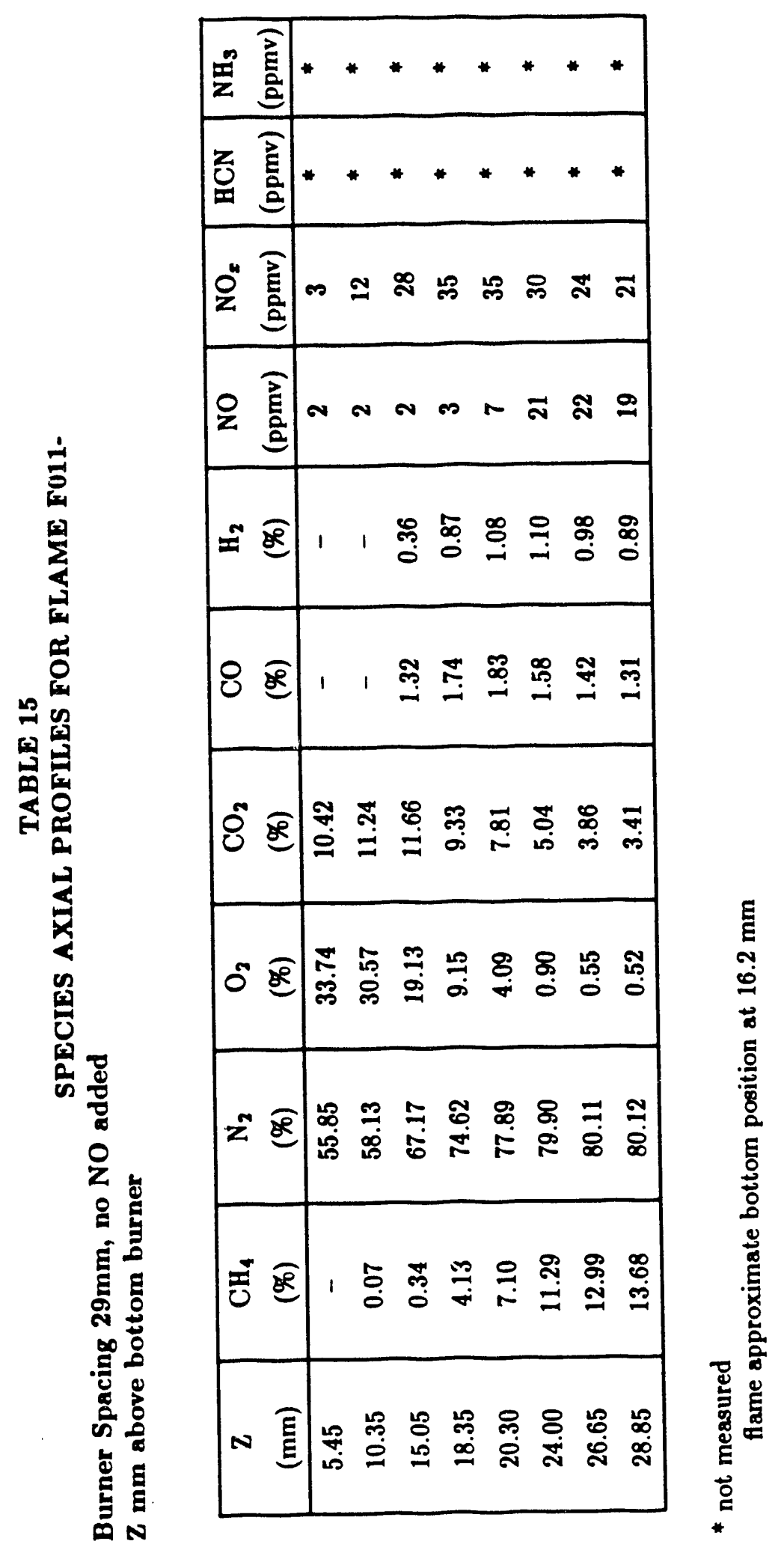




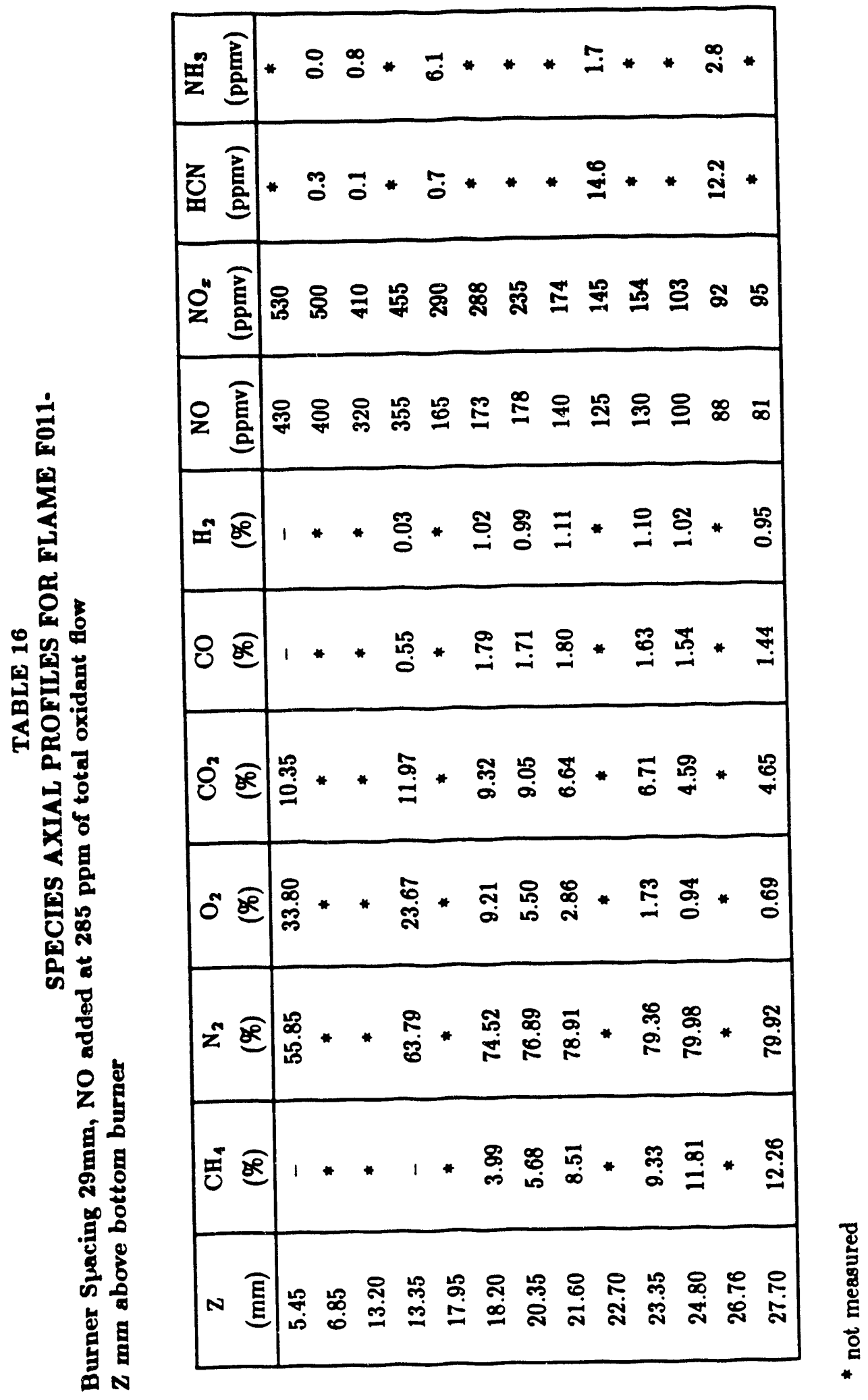


Table 17 REACTION MECHANISM FOR 'CH4/02/N2' DIFFUSION FLAME

FORWARD RATE CONSTANT: $\quad k f=A * T * * N * \operatorname{EXP}(-E / R / T)$ where $R[=] \mathrm{Kcal} / \mathrm{Mole} / \mathrm{K}$,

STOICHOMETRIC REACTION

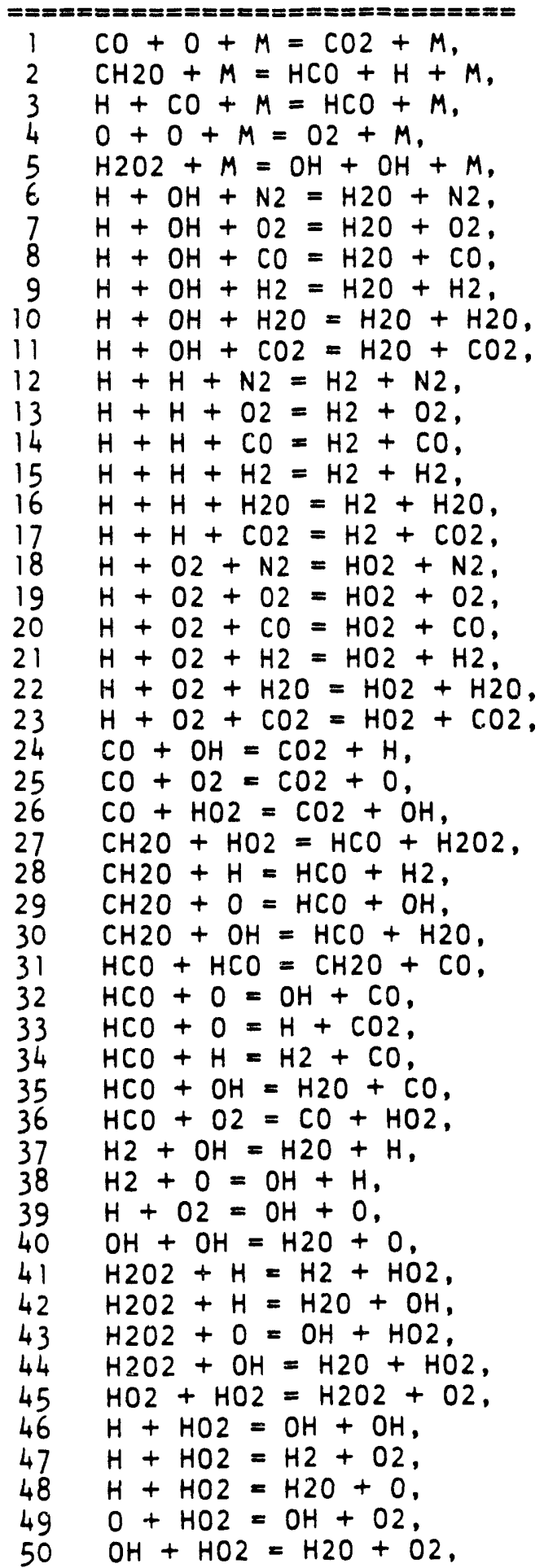

E [ = $\mathrm{Kcal} / \mathrm{Mole}$

\begin{tabular}{lrr}
$A$ & \multicolumn{1}{c}{$N$} & \multicolumn{1}{c}{$E$} \\
$===========$ & \multicolumn{1}{l}{$=======$} & \multicolumn{1}{l}{$========$} \\
$0.268300 E+23$ & -2.25000 & 6.16000 \\
$0.360000 E+18$ & 0.00000 & 86.96000 \\
$0.700000 E+15$ & 0.00000 & 1.69000 \\
$0.100000 E+19$ & -1.00000 & 0.00000 \\
$0.130000 E+18$ & 0.00000 & 45.50000 \\
$0.219000 E+23$ & -2.00000 & 0.00000 \\
$0.490000 E+22$ & -1.76000 & 0.00000 \\
$0.490000 E+22$ & -1.76000 & 0.00000 \\
$0.980000 E+22$ & -1.76000 & 0.00000 \\
$0.192000 E+24$ & -2.04000 & 0.00000 \\
$0.350000 E+24$ & -2.44000 & 0.00000 \\
$0.543200 E+19$ & -1.30000 & 0.00000 \\
$0.658000 E+19$ & -1.32000 & 0.00000 \\
$0.658000 E+19$ & -1.32000 & 0.00000 \\
$0.537000 E+17$ & -0.49300 & 0.00000 \\
$0.187000 E+20$ & -1.11000 & 0.00000 \\
$0.246000 E+22$ & -2.29000 & 0.00000 \\
$0.745000 E+19$ & -1.00000 & 0.00000 \\
$0.711000 E+20$ & -1.44000 & 0.00000 \\
$0.711000 E+20$ & -1.44000 & 0.00000 \\
$0.177000 E+19$ & -0.77000 & 0.00000 \\
$0.270000 E+20$ & -0.85000 & 0.00000 \\
$0.410000 E+18$ & -0.50000 & 0.00000 \\
$0.151000 E+08$ & 1.30000 & -0.76500 \\
$0.690000 E+08$ & 1.00000 & 34.81000 \\
$0.100000 E+12$ & 0.00000 & 10.00000 \\
$0.100000 E+13$ & 0.00000 & 8.00000 \\
$0.309000 E+11$ & 1.00000 & 3.31000 \\
$0.191300 E+14$ & 0.00000 & 3.10800 \\
$0.420000 E+11$ & 0.87200 & 0.00000 \\
$0.140000 E+13$ & 0.50000 & 0.00000 \\
$0.370000 E+13$ & 0.50000 & 0.00000 \\
$0.370000 E+13$ & 0.50000 & 0.00000 \\
$0.330000 E+15$ & 0.00000 & 0.00000 \\
$0.639000 E+13$ & 0.50000 & 0.00000 \\
$0.580000 E+14$ & -0.50000 & 0.00000 \\
$0.573400 E+07$ & 2.00000 & 2.86830 \\
$0.799700 E+06$ & 2.25000 & 6.67740 \\
$0.146627 E+18$ & -0.92986 & 17.30891 \\
$0.596000 E+09$ & 1.26000 & 0.00000 \\
$0.152000 E+13$ & 0.00000 & 3.71600 \\
$0.940000 E+13$ & 0.00000 & 3.49700 \\
$0.850000 E+06$ & 2.00000 & 2.62000 \\
$0.184800 E+07$ & 2.00000 & -1.08050 \\
$0.314000 E+11$ & 0.00000 & -2.26540 \\
$0.150000 E+14$ & 0.00000 & -0.55000 \\
$0.420000 E+13$ & 0.00000 & 0.00000 \\
$0.350000 E+13$ & 0.00000 & 0.50000 \\
$0.189000 E+14$ & 0.00000 & -0.39280 \\
$0.906000 E+13$ & 0.00000 & -0.95360
\end{tabular}


Table 17 (cont'd)

STOICHOMETRIC REACTION

\begin{tabular}{|c|c|}
\hline $\begin{array}{l}51 \\
52 \\
53 \\
54 \\
55 \\
56 \\
57 \\
58 \\
59 \\
60 \\
61 \\
62 \\
63 \\
64 \\
65 \\
66 \\
67 \\
68 \\
69 \\
70 \\
71 \\
72 \\
73 \\
74 \\
75 \\
76 \\
77 \\
78 \\
79 \\
80 \\
81 \\
82 \\
83 \\
84 \\
85 \\
86 \\
87 \\
88 \\
89 \\
90 \\
91 \\
92 \\
93 \\
94 \\
95 \\
96 \\
97\end{array}$ & 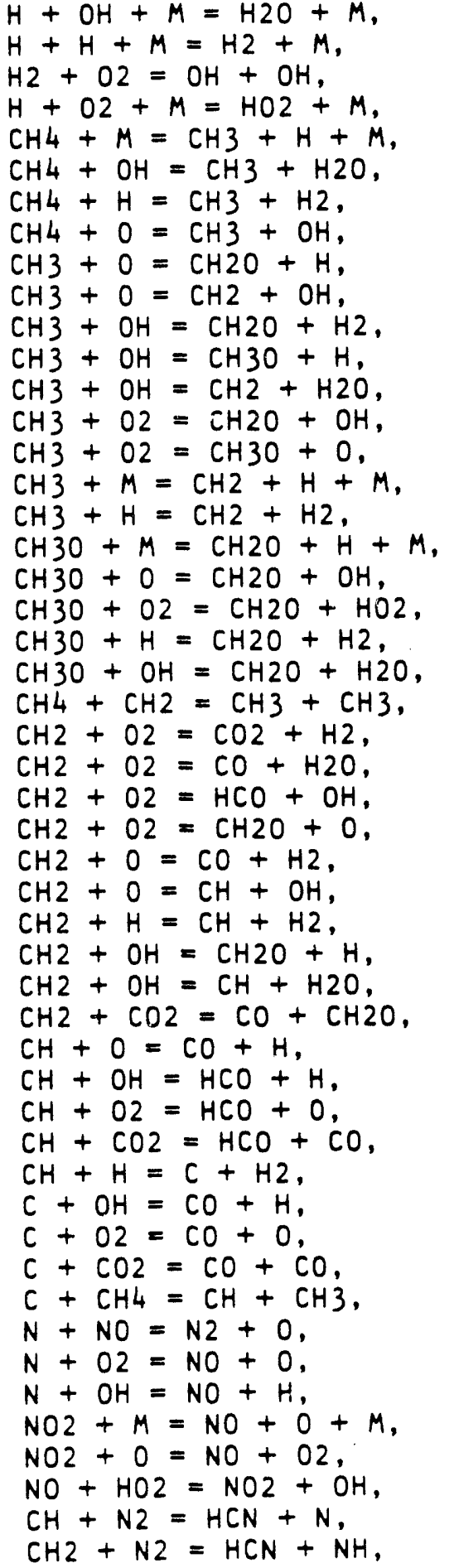 \\
\hline
\end{tabular}

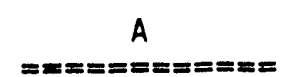

$0.750000 E+24$

$0.100000 E+19$

$0.170000 E+14$

$0.210000 E+19$

$0.100000 E+18$

$0.350000 E+04$

$0.220000 E+05$

$0.120000 E+08$

$0.680000 E+14$

$0.500000 E+14$

$0.100000 E+13$

$0.900000 E+15$

$0.150000 E+14$

$0.520000 E+14$

$0.700000 E+13$

$0.190000 \mathrm{E}+17$

$0.900000 E+14$

$0.100000 E+15$

$0.100000 E+14$

$0.630000 E+11$

$0.200000 E+14$

$0.100000 E+14$

$0.100000 E+14$

$0.690000 E+12$

$0.190000 E+11$

$0.430000 E+11$

$0.200000 E+14$

$0.500000 E+14$

$0.500000 E+14$

$0.730000 E+18$

$0.300000 E+14$

$0.450000 E+14$

$0.110000 E+12$

$0.570000 E+14$

$0.300000 E+14$

$0.330000 E+14$

$0.340000 E+13$

$0.150000 \mathrm{E}+15$

$0.500000 E+14$

$0.200000 E+14$

$0.600000 E+09$

$0.500000 E+14$

$0.330000 E+13$

$0.640000 E+10$

$0.380000 E+14$

$0.110000 E+17$

$0.100000 E+14$

$0.210000 E+13$

$0.190000 E+12$

$0.100000 E+14$

\begin{tabular}{cr}
$N$ & \multicolumn{1}{c}{$E$} \\
$=======$ & \multicolumn{1}{c}{$=======$} \\
-2.60000 & 0.00000 \\
-1.00000 & 0.00000 \\
0.00000 & 47.78000 \\
-1.00000 & 0.00000 \\
0.00000 & 88.00000 \\
3.08000 & 2.00000 \\
3.00000 & 8.75000 \\
2.08000 & 7.63000 \\
0.00000 & 0.00000 \\
0.00000 & 12.00000 \\
0.00000 & 0.00000 \\
0.00000 & 15.40000 \\
0.00000 & 5.00000 \\
0.00000 & 34.57000 \\
0.00000 & 25.65000 \\
0.00000 & 91.60000 \\
0.00000 & 15.10000 \\
0.00000 & 25.00000 \\
0.00000 & 0.00000 \\
0.00000 & 2.60000 \\
0.00000 & 0.00000 \\
0.00000 & 0.00000 \\
0.00000 & 9.50000 \\
0.00000 & 0.50000 \\
0.00000 & -1.00000 \\
0.00000 & -0.50000 \\
0.00000 & 9.00000 \\
0.00000 & 0.00000 \\
0.00000 & 12.00000 \\
-1.56000 & 0.00000 \\
0.00000 & 0.00000 \\
0.00000 & 3.00000 \\
0.00000 & 1.00000 \\
0.00000 & 0.00000 \\
0.00000 & 0.00000 \\
0.00000 & 0.00000 \\
0.00000 & 0.69000 \\
0.00000 & 0.00000 \\
0.00000 & 0.00000 \\
0.00000 & 0.00000 \\
0.00000 & 0.00000 \\
0.00000 & 24.00000 \\
0.30000 & 0.00000 \\
1.00000 & 6.28000 \\
0.00000 & 0.00000 \\
0.00000 & 66.00000 \\
0.00000 & 0.60000 \\
0.00000 & -0.48000 \\
0.00000 & 13.60000 \\
0.00000 & 74.00000 \\
& \\
&
\end{tabular}


Table 17 (cont'd)

STOICHOMETRIC REACTION

$101 \mathrm{CH}+\mathrm{N}=\mathrm{CN}+\mathrm{H}$,

$102 \mathrm{C}+\mathrm{NO}=\mathrm{CN}+0$,

$103 \mathrm{CH} 2+\mathrm{N}=\mathrm{HCN}+\mathrm{H}$,

$104 \mathrm{~N}+\mathrm{CH}_{4}=\mathrm{NH}+\mathrm{CH}$,

$105 \mathrm{CH}+\mathrm{NO}=\mathrm{HCN}+0$,

$106 \mathrm{~N}+\mathrm{CO} 2=\mathrm{NO}+\mathrm{CO}$.

$107 \mathrm{HCN}+\mathrm{OH}=\mathrm{CN}+\mathrm{H} 2 \mathrm{O}$.

$108 \mathrm{HCN}+\mathrm{O}=\mathrm{CN}+\mathrm{OH}$,

$109 \mathrm{CN}+\mathrm{H} 2=\mathrm{HCN}+\mathrm{H}$,

$110 \mathrm{HCN}+\mathrm{O}=\mathrm{NCO}+\mathrm{H}$,

$111 \mathrm{HCN}+\mathrm{O}=\mathrm{NH}+\mathrm{CO}$,

$112 \mathrm{CN}+\mathrm{O}=\mathrm{CO}+\mathrm{N}$,

$113 \mathrm{CN}+\mathrm{O2}=\mathrm{NCO}+\mathrm{O}$,

$114 \mathrm{CN}+\mathrm{OH}=\mathrm{NCO}+\mathrm{H}$,

$115 \mathrm{NCO}+\mathrm{H}=\mathrm{NH}+\mathrm{CO}$,

$116 \mathrm{NCO}+\mathrm{O}=\mathrm{NO}+\mathrm{CO}$,

$117 \mathrm{NCO}+\mathrm{N}=\mathrm{N} 2+\mathrm{CO}$,

$118 \mathrm{NCO}+\mathrm{M}=\mathrm{N}+\mathrm{CO}+\mathrm{M}$,

$119 \mathrm{NH}+\mathrm{O2}=\mathrm{NO}+\mathrm{OH}$,

$120 \mathrm{NH} 2+\mathrm{NO}=\mathrm{N} 2+\mathrm{H}_{2} \mathrm{O}$,

$121 \mathrm{NH}+\mathrm{OH}=\mathrm{N}+\mathrm{H} 2 \mathrm{O}$,

$122 \mathrm{NH}+\mathrm{N}=\mathrm{N} 2+\mathrm{H}$,

$123 \mathrm{NH}+\mathrm{H}=\mathrm{N}+\mathrm{H}_{2}$,

$124 \mathrm{NH} 2+\mathrm{O}=\mathrm{NH}+\mathrm{OH}$,

$125 \mathrm{NH2}+\mathrm{OH}=\mathrm{NH}+\mathrm{H} 2 \mathrm{O}$,

$126 \mathrm{NH} 2+\mathrm{H}=\mathrm{NH}+\mathrm{H}_{2}$,

$127 \mathrm{~N} 2 \mathrm{O}+\mathrm{M}=\mathrm{N} 2+\mathrm{O}+\mathrm{M}$,

$128 \mathrm{~N} 2 \mathrm{O}+\mathrm{O}=\mathrm{NO}+\mathrm{NO}$,

$129 \mathrm{~N} 2 \mathrm{O}+\mathrm{O}=\mathrm{N} 2+\mathrm{O} 2$,

$130 \mathrm{~N} 2 \mathrm{O}+\mathrm{H}=\mathrm{N} 2+\mathrm{OH}$,

$131 \mathrm{NCO}+\mathrm{NO}=\mathrm{N} 2 \mathrm{O}+\mathrm{CO}$,

$132 \mathrm{NCO}+\mathrm{H2}=\mathrm{HNCO}+\mathrm{H}$,

$133 \mathrm{HNCO}+\mathrm{H}=\mathrm{NH2}+\mathrm{CO}$,

$134 \mathrm{NH}+\mathrm{O} 2=\mathrm{HNO}+0$,

$135 \mathrm{NH}+\mathrm{NO}=\mathrm{N} 2 \mathrm{O}+\mathrm{H}$,

$136 \mathrm{NH}+\mathrm{OH}=\mathrm{HNO}+\mathrm{H}$,

$137 \mathrm{NH2}+\mathrm{O}=\mathrm{HNO}+\mathrm{H}$,

$138 \mathrm{NH2}+\mathrm{NO}=\mathrm{N} 2 \mathrm{H}+\mathrm{OH}$,

$139 \mathrm{~N} 2 \mathrm{H}+\mathrm{NO}=\mathrm{N} 2+\mathrm{HNO}$,

$140 \mathrm{HNO}+\mathrm{M}=\mathrm{H}+\mathrm{NO}+\mathrm{M}$,

$141 \mathrm{HNO}+\mathrm{OH}=\mathrm{NO}+\mathrm{H} 2 \mathrm{O}$.

$142 \mathrm{HNO}+\mathrm{H}=\mathrm{H2}+\mathrm{NO}$.

$143 \mathrm{NH} 3+\mathrm{M}=\mathrm{NH2}+\mathrm{H}+\mathrm{M}$,

$144 \mathrm{NH} 3+\mathrm{O}=\mathrm{NH} 2+\mathrm{OH}$,

$145 \mathrm{NH} 3+\mathrm{H}=\mathrm{NH} 2+\mathrm{H}_{2}$.

$146 \mathrm{NH} 3+\mathrm{OH}=\mathrm{NH2}+\mathrm{H}_{2} \mathrm{O}$,

$147 \mathrm{~N} 2 \mathrm{H}+\mathrm{M}=\mathrm{N} 2+\mathrm{H}+\mathrm{M}$,

$148 \mathrm{~N} 2 \mathrm{H}+\mathrm{H}=\mathrm{N} 2+\mathrm{H}_{2}$,

$149 \mathrm{NH}+\mathrm{NH} 2=\mathrm{N} 2 \mathrm{H} 2+\mathrm{H}$,

$150 \mathrm{~N} 2 \mathrm{H} 2+\mathrm{M}=\mathrm{N} 2 \mathrm{H}+\mathrm{H}+\mathrm{M}$,

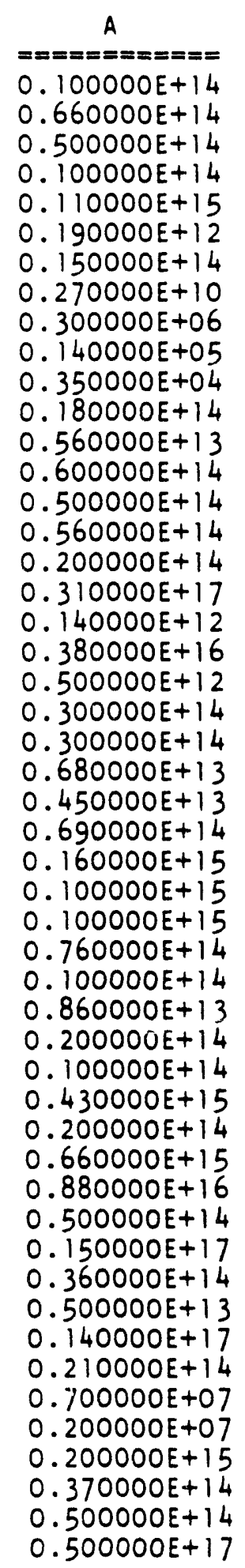

$N$
$=====0=$
0.00000
0.00000
0.00000
0.00000
0.00000
0.00000
0.00000
1.58000
2.45000
2.64000
2.64000
0.00000
0.00000
0.00000
0.00000
0.00000
0.00000
-0.50000
0.00000
-1.25000
0.50000
0.00000
0.00000
0.00000
0.00000
0.00000
0.00000
0.00000
0.00000
0.00000
0.00000
0.00000
0.00000
0.00000
-0.50000
0.00000
-0.50000
-1.25000
0.00000
0.00000
0.00000
0.00000
0.00000
0.00000
2.39000
2.04000
0.00000
0.00000
0.00000
0.00000

E

0.00000

0.00000

0.00000

24.00000

0.00000

3.40000

10.92900

26.60000

2.23700

4.98000

4.98000

0.00000

0.00000

0.00000

0.00000

0.00000

0.00000

48.00000

2.00000

0.00000

2.00000

0.00000

0.00000

0.00000

2.20000

3.65000

51.60000

28.20000

28.20000

15.20000

$-0.39000$

9.00000

3.00000

12.00000

0.00000

0.00000

0.00000

0.00000

0.00000

48.68000

0.00000

0.00000

90.60000

9.00000

10.17100

0.56600

20.00000

3.00000

0.00000

50.00000 
Table 17 (cont'd)

STOICHOMETRIC REACTION

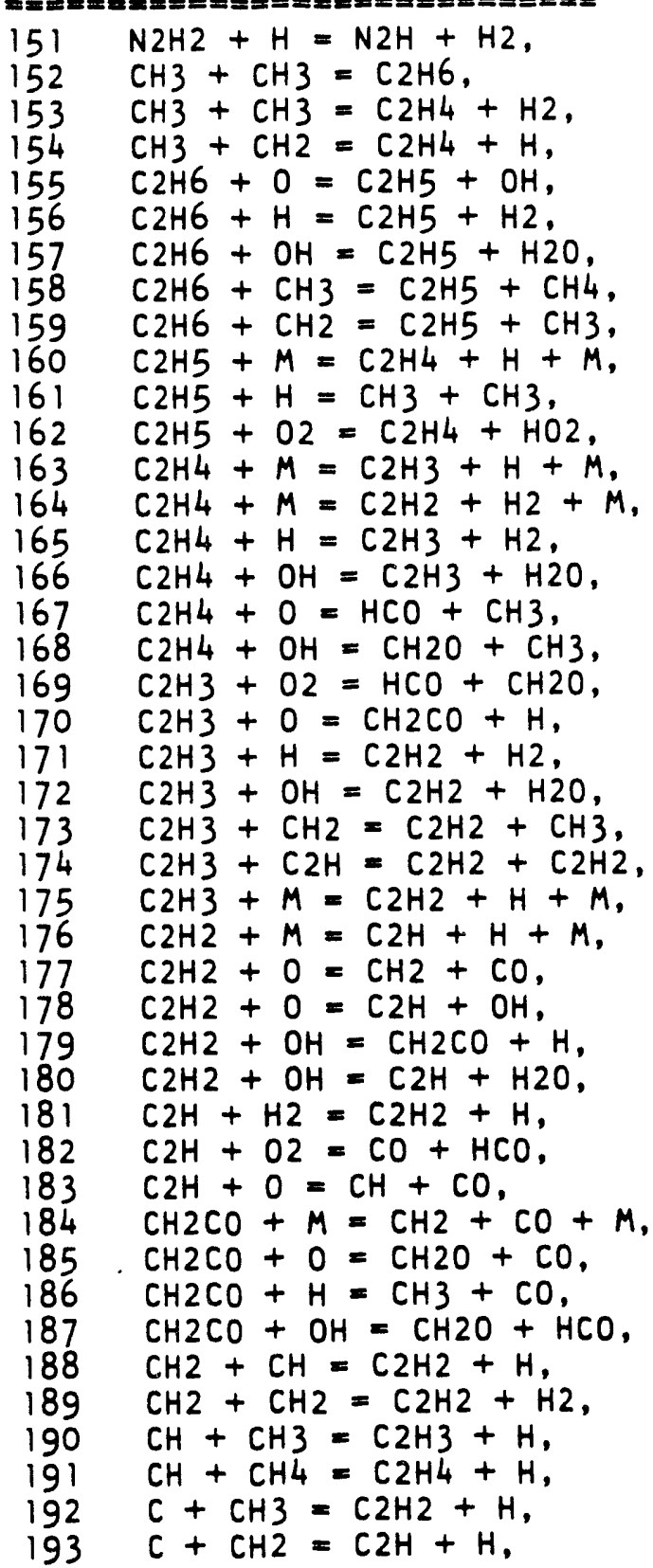

A

$m=x==m x=m=m=$

$0.500000 E+14$

$0.160000 E+14$

$0.210000 E+15$

$0.300000 E+14$

$0.250000 E+14$

$0.540000 E+03$

$0.870000 \mathrm{E}+10$

$0.550000 \mathrm{E}+00$

$0.220000 E+14$

$0.100000 E+18$

$0.400000 E+14$

$0.320000 E+13$

$0.260000 \mathrm{E}+18$

$0.260000 E+18$

$0.110000 E+15$

$0.480000 E+13$

$0.160000 E+10$

$0.200000 E+13$

$0.400000 E+13$

$0.330000 E+14$

$0.400000 E+14$

$0.500000 E+13$

$0.300000 E+14$

$0.300000 E+14$

$0.800000 E+15$

$0.420000 E+17$

$0.220000 E+11$

$0.320000 E+16$

$0.320000 \mathrm{E}+12$

$0.600000 E+13$

$0.410000 E+06$

$0.240000 E+13$

$0.500000 E+14$

$0.360000 E+16$

$0.200000 E+14$

$0.110000 E+14$

$0.280000 E+14$

$0.400000 E+14$

$0.320000 E+14$

$0.300000 E+14$

$0.600000 E+14$

$0.500000 E+14$

$0.500000 E+14$

\section{$N$}

$=== \pm=x=$

0.00000

0.00000

0.00000

0.00000

0.00000

3.50000

1.05000

4.00000

0.00000

0.00000

0.00000

0.00000

0.00000

0.00000

0.00000

0.00000

1.20000

0.00000

0.00000

0.00000

0.00000

0.00000

0.00000

0.00000

0.00000

0.00000

1.00000

$-0.60000$

0.00000

0.00000

2. 39000

0.00000

0.00000

0.00000

0.00000

0.00000

0.00000

0.00000

0.00000

0.00000

0.00000

0.00000

0.00000

\section{$E$}

$z=x=2 x=$

1.00000

$-0.30600$

19.20000

0.00000

6.36000

5. 20000

1.81000

8.28000

8.66000

31.00000

0.00000

5.02000

96.60000

79.35000

8.50000

1.23000

0.74600

0.96000

$-0.25000$

0.00000

0.00000

0.00000

0.00000

0.00000

31.50000

107.00000

2.58000

15.00000

0.20000

7.00000

0.86000

0.00000

0.00000

59.30000

0.00000

3.43000

0.00000

0.00000

0.00000

0.00000

0.00000

0.00000

0.00000 
"1

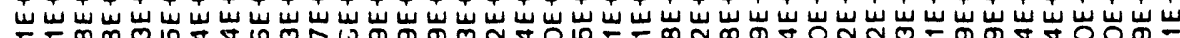

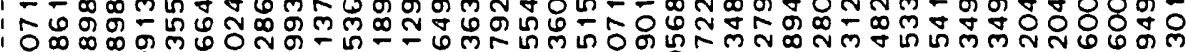

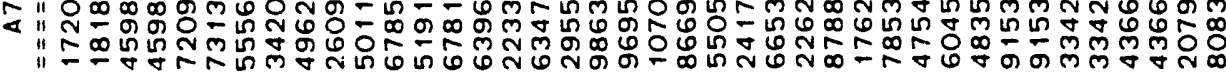
" 0000000000000000000000000000000000000000 ๓ं

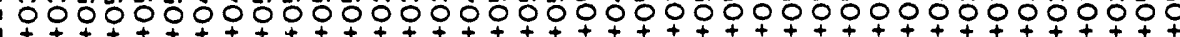

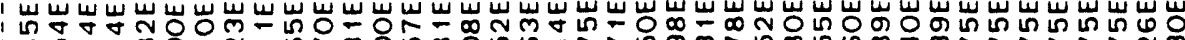

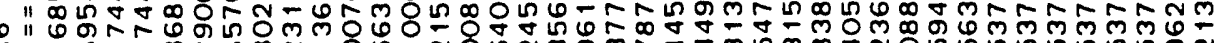
$4 " 1 .-6$ -

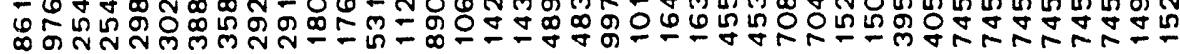

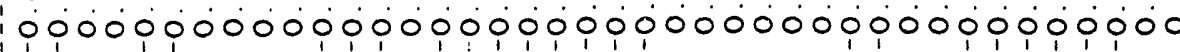
"I

1

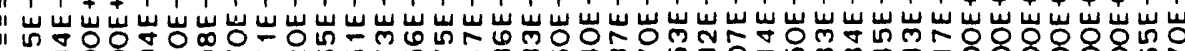
1"

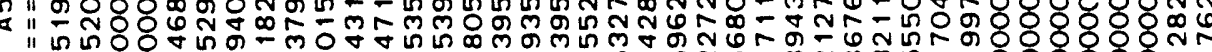

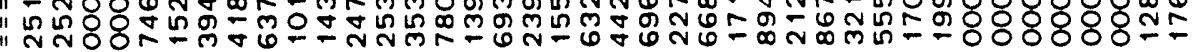

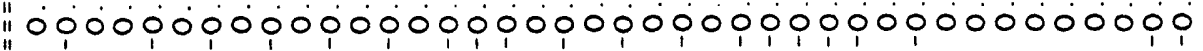
(1)

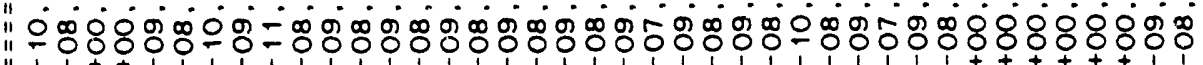
"1

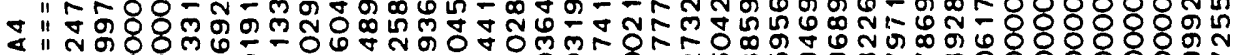

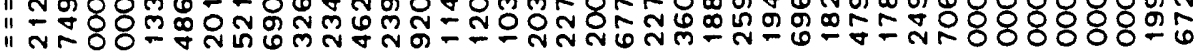
"100000010000010000000,0,100000,00000000000

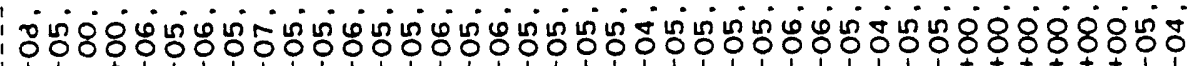

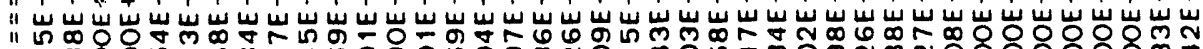
" r mon 9"1

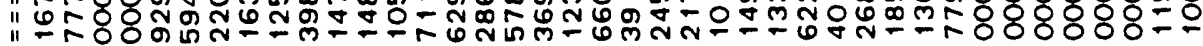

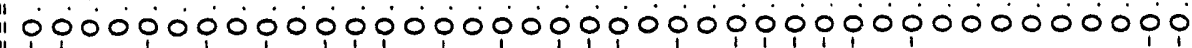
"I

"

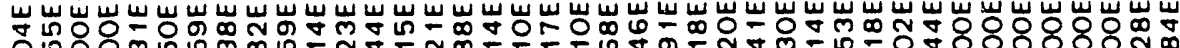

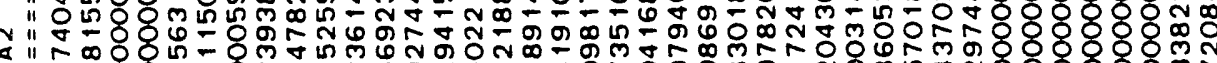

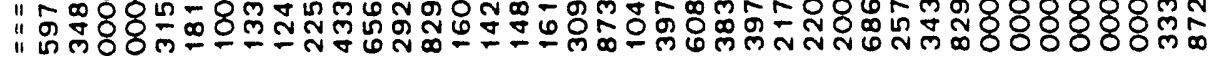
" $000000000,00000,00000,00000,0,10,00000000$ "I

1

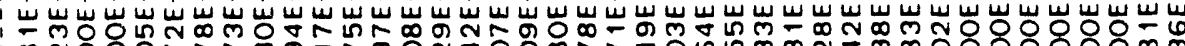

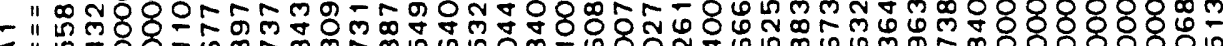

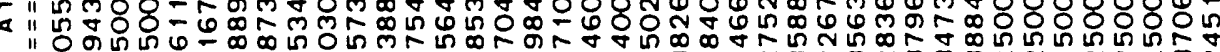
MNANA J 0000000000000000000000000000000000000000 c.

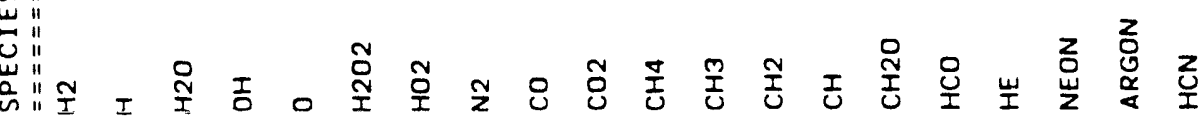




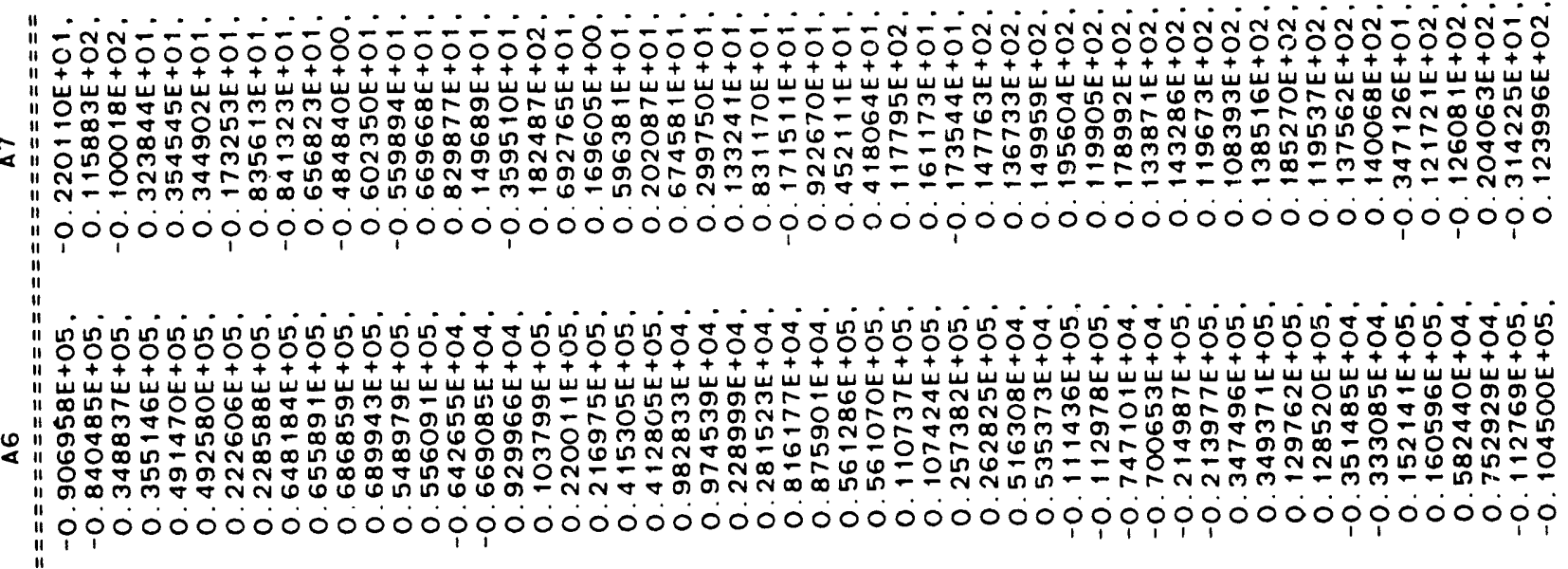
$\dot{n}$

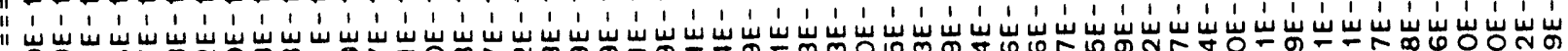

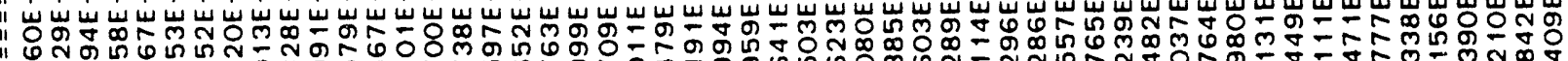

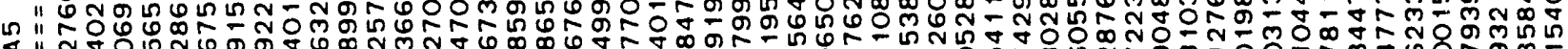

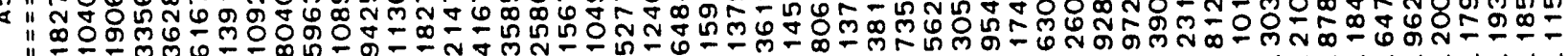

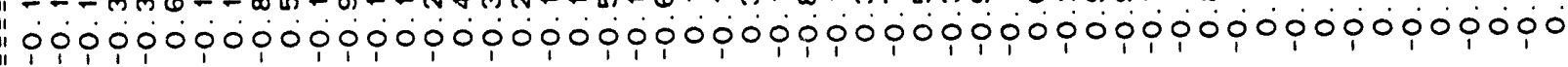
"I"

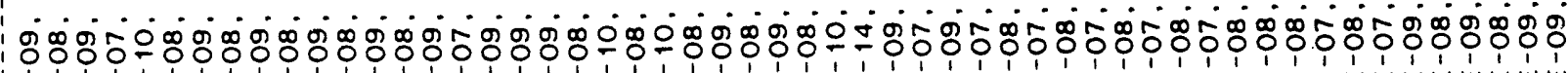

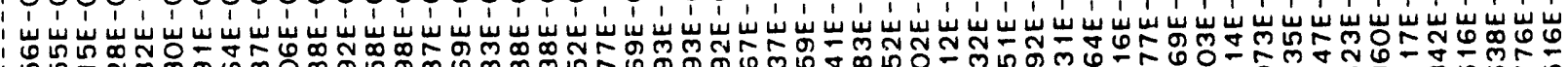
"1 × "

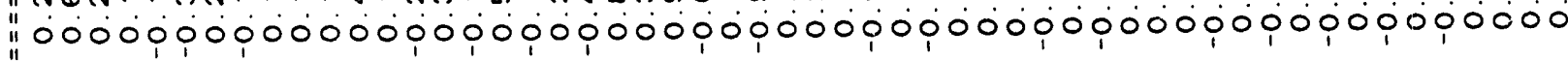

" "1 " ON M

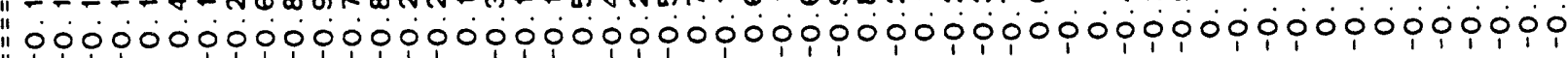

"I

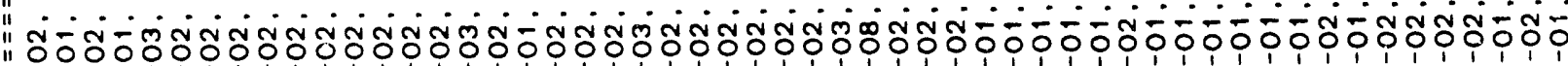

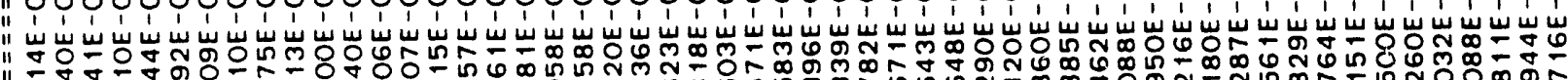
N 1 ○。 4 " 000000000000000000000000000000000000000000000000000000

".....................

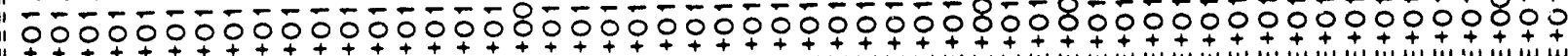

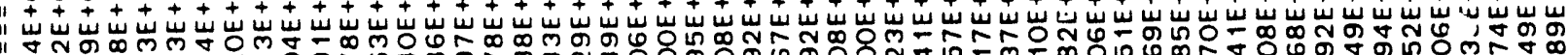

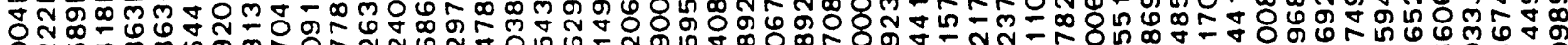

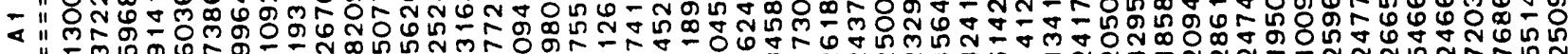
"1 " 000000000000000000000000000000000000000000000000000000

쓰메

ㄴ.

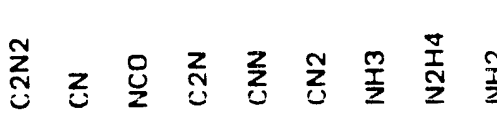

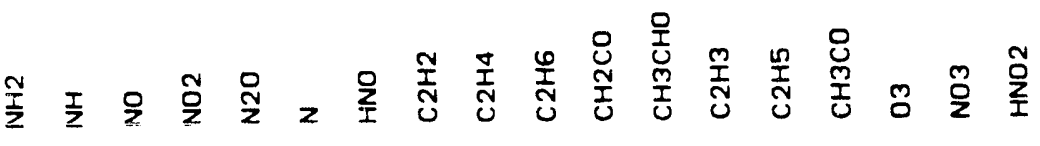




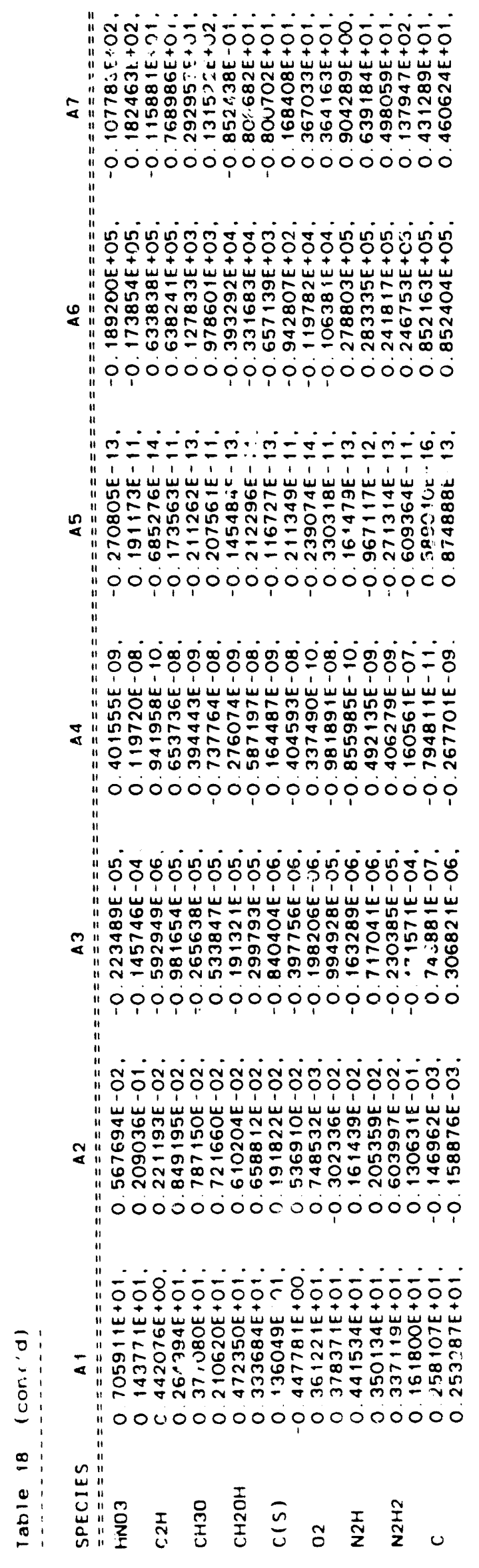


Table 19 Equilibrium Constants of Spe-ies

The data shown below $f$ it modified Arrhenius expression:
$\mathrm{KP}, \mathrm{i}=\mathrm{A} * \mathrm{~T} * \mathrm{H} * \mathrm{EXP}(-\mathrm{E} / \mathrm{R} / \mathrm{T})$
Where $\mathrm{R}=1.987 * \mathrm{~K} 1 \mathrm{O}^{\wedge}(-3), \mathrm{K}, \mathrm{Kcal} / \mathrm{Mole} / \mathrm{K}$,
$\mathrm{E}[=] \mathrm{Kcal} / \mathrm{Mole}$,

\begin{tabular}{|c|c|c|c|}
\hline SPECIES & A & $\mathbf{N}$ & $E$ \\
\hline 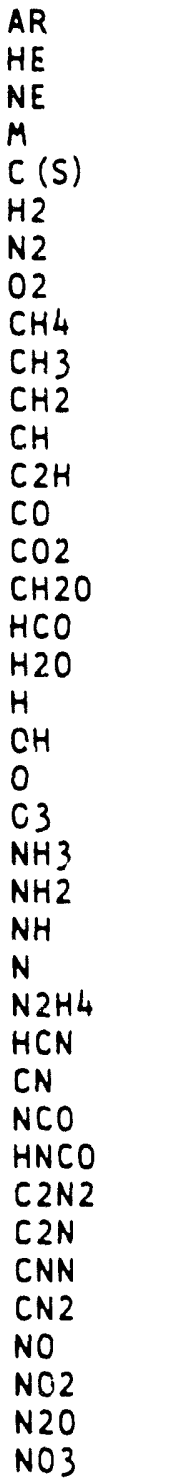 & $\begin{array}{l}0.10000000 E+01 \\
0.10000000 E+01 \\
0.10000000 E+01 \\
0.10000000 E+01 \\
0.10000000 E+01 \\
0.10000000 E+01 \\
0.10000000 E+01 \\
0.10000000 E+01 \\
0.91501490 E-01 \\
0.12659590 E+03 \\
0.10942560 E+06 \\
0.98995510 E+07 \\
0.15185170 E+10 \\
0.44973550 E+07 \\
0.70695720 E+01 \\
0.22087240 E+02 \\
0.60114120 E+05 \\
0.44514290 E+00 \\
0.57402340 E+01 \\
0.23855150 E+02 \\
0.76485410 E+02 \\
0.39985250 E-04 \\
0.22708190 E-03 \\
0.37929920 E+00 \\
0.11481070 E+02 \\
0.33892710 E+02 \\
0.27943690 E-12 \\
0.46461080 E+03 \\
0.54930820 E+07 \\
0.24366000 E+02 \\
0.20848 .550 E+00 \\
0.65778360 E+02 \\
0.51783650 E+07 \\
0.66433400 E+02 \\
0.11186410 E+02 \\
0.41119610 E+01 \\
0.42889430 E-03 \\
0.36310090 E-05 \\
0.46248130 E-10\end{array}$ & $\begin{array}{r}0.00000 \\
0.00000 \\
0.00000 \\
0.00000 \\
0.00000 \\
0.00000 \\
0.00000 \\
0.00000 \\
-1.30880 \\
-0.92997 \\
-0.69568 \\
-0.34124 \\
-0.72901 \\
-0.60557 \\
-0.22837 \\
-0.92851 \\
-0.71864 \\
-0.72481 \\
0.63712 \\
-0.17626 \\
0.43322 \\
0.24392 \\
-0.68432 \\
-0.48854 \\
-0.00468 \\
0.52741 \\
0.17238 \\
-0.28741 \\
-0.13393 \\
0.05174 \\
-0.35489 \\
0.14675 \\
0.03590 \\
0.03170 \\
0.21923 \\
0.01346 \\
0.01717 \\
0.47950 \\
0.74380\end{array}$ & $\begin{array}{r}0.00000 \\
0.00000 \\
0.00000 \\
0.00000 \\
0.00000 \\
0.00000 \\
0.00000 \\
0.00000 \\
-18.12005 \\
35.02684 \\
0.72 .75912 \\
142.42220 \\
146.56569 \\
-25.70979 \\
-93.85992 \\
-27.63321 \\
10.85438 \\
-57.58922 \\
51.78321 \\
9.65523 \\
59.43514 \\
33.80483 \\
-11.29351 \\
45.46653 \\
84.15144 \\
112.73841 \\
21.32647 \\
32.46957 \\
98.35054 \\
47.86087 \\
-14.22454 \\
74.12702 \\
133.53236 \\
139.85102 \\
113.16164 \\
21.57882 \\
7.68731 \\
19.06228 \\
16.11318\end{array}$ \\
\hline
\end{tabular}




\begin{tabular}{|c|c|c|c|}
\hline $\begin{array}{l}\text { SPEC I ES } \\
=x===x\end{array}$ & $\stackrel{\grave{A}}{===}=$ & $\underset{==0}{N}$ & $E$ \\
\hline $\begin{array}{l}\mathrm{HNO} 2 \\
\mathrm{HNO} 3 \\
\mathrm{CH} 3 \mathrm{O} \\
\mathrm{CH} 2 \mathrm{OH} \\
\mathrm{HO} 2 \\
\mathrm{H} 2 \mathrm{O} 2 \\
\mathrm{HNO} \\
\mathrm{C} 2 \mathrm{H} 2 \\
\mathrm{C} 2 \mathrm{H} 4 \\
\mathrm{C} 2 \mathrm{H} 6 \\
\mathrm{CH} 2 \mathrm{CO} \\
\mathrm{CH} 3 \mathrm{CHO} \\
\mathrm{C} 2 \mathrm{H} 3 \\
\mathrm{C} 2 \mathrm{H} 5 \\
\mathrm{CH} 3 \mathrm{CO} \\
\mathrm{C} \\
\mathrm{N} 2 \mathrm{H} \\
\mathrm{N} 2 \mathrm{H} 2\end{array}$ & $\begin{array}{l}0.33504530 E-06 \\
0.15611360 E-12 \\
0.13286590 E-01 \\
0.23163320 E+00 \\
0.12430530 E-01 \\
0.51218650 E-05 \\
0.17053500 E-01 \\
0.10482000 E+06 \\
0.15422000 E+01 \\
0.13695890 E-05 \\
0.11476650 E+03 \\
0.50588560 E-03 \\
0.73203610 E+05 \\
0.56073050 E-01 \\
0.90340430 E+01 \\
0.17233620 E+09 \\
0.20986270 E-01 \\
0.66937420 E-05\end{array}$ & $\begin{array}{l}0.60229 \\
0.59833 \\
-0.91604 \\
-1.02170 \\
-0.14977 \\
-0.15591 \\
-0.23728 \\
-0.65848 \\
-1.24340 \\
-1.49970 \\
-0.79547 \\
-1.11440 \\
-1.29840 \\
-1.48610 \\
-1.23120 \\
-0.00015 \\
-0.07174 \\
-0.24923\end{array}$ & $\begin{array}{r}-18.66886 \\
-33.22463 \\
3.50447 \\
-3.98950 \\
2.26538 \\
-32.74775 \\
23.56979 \\
54.65442 \\
12.23952 \\
-21.00259 \\
-11.08547 \\
-40.29437 \\
71.79826 \\
27.52591 \\
-4.13276 \\
171.29887 \\
58.31050 \\
50.28600\end{array}$ \\
\hline
\end{tabular}


Table 20 Transport Parameters

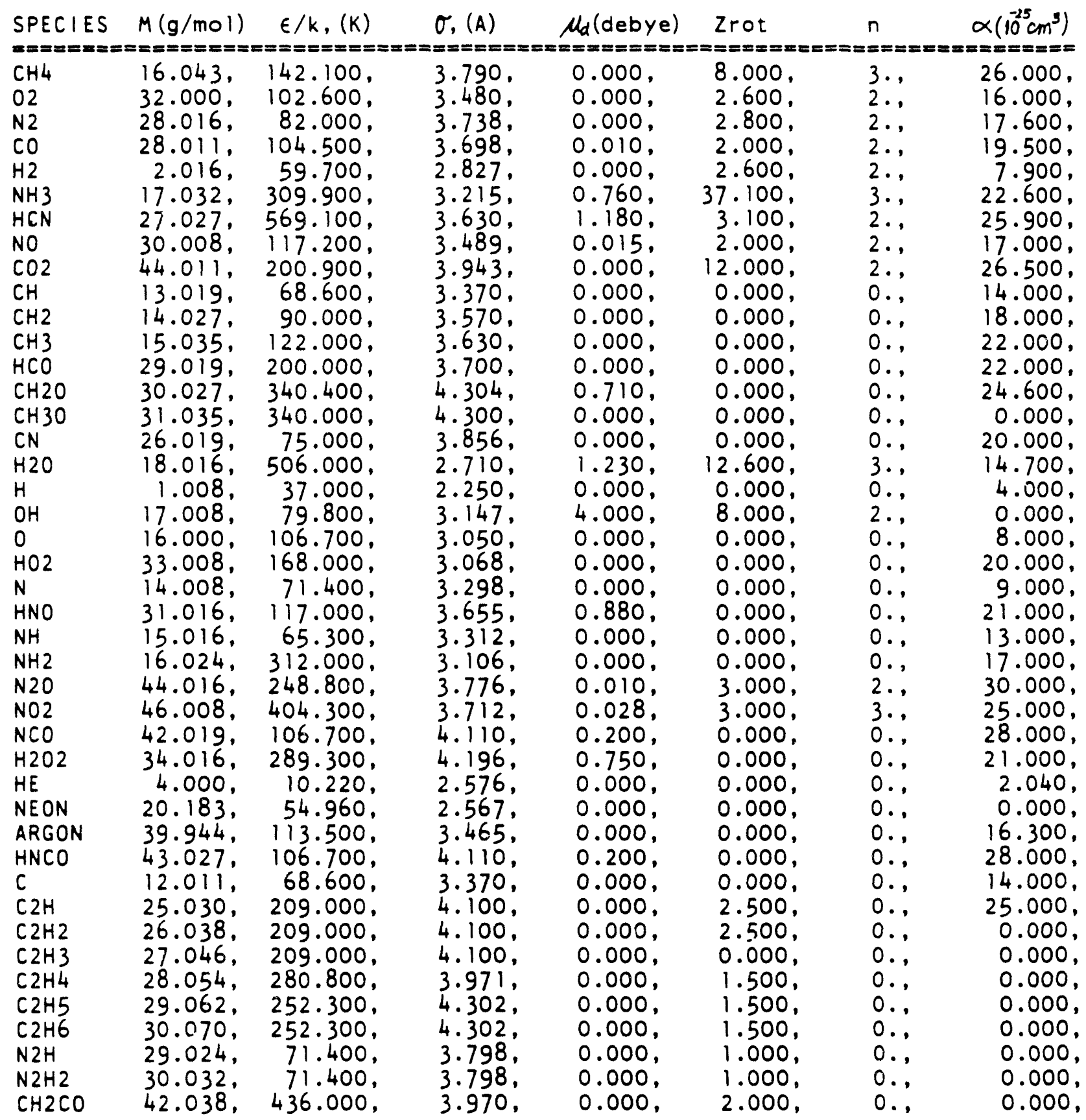



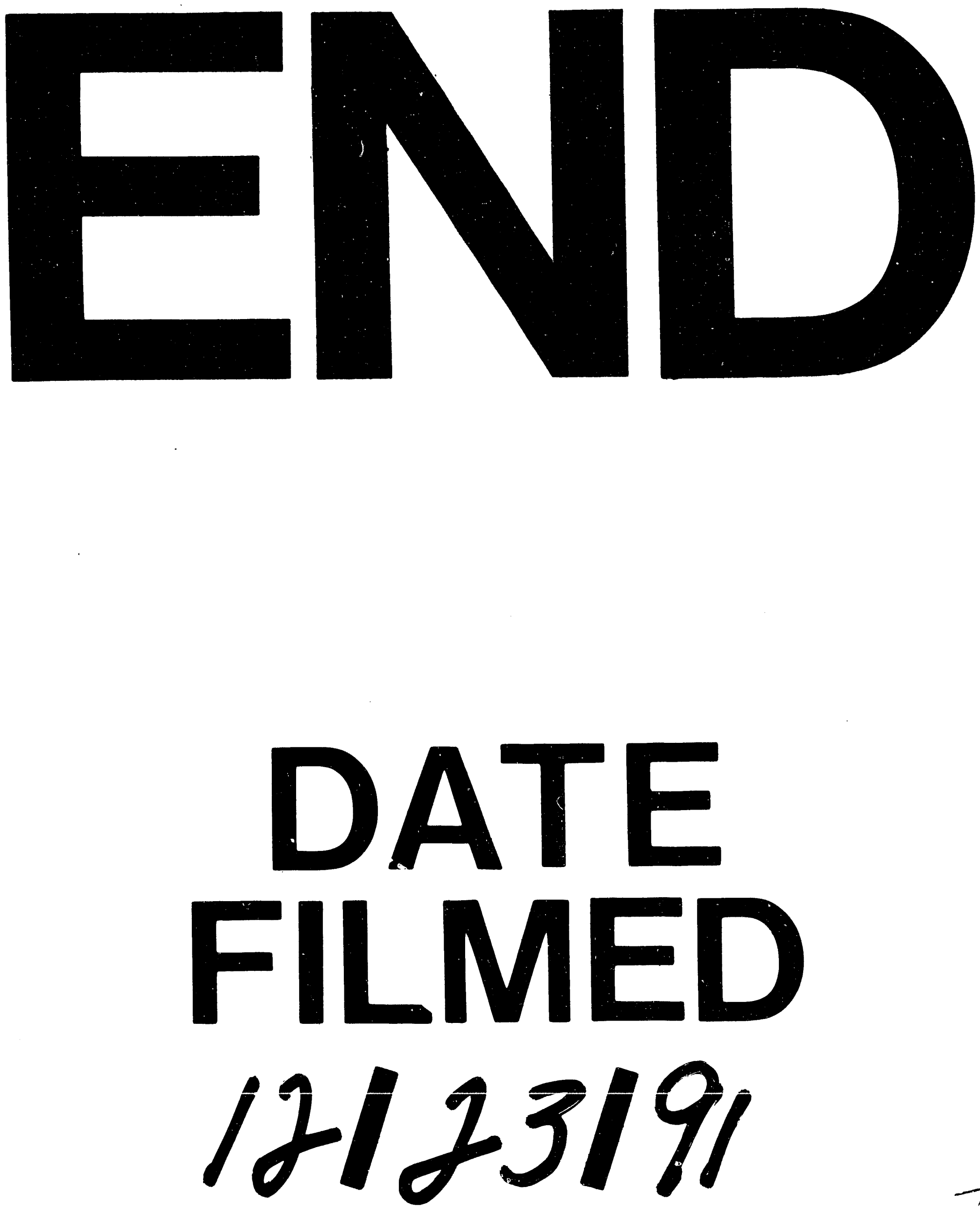
